\title{
Building Industry Reporting and Design for Sustainability (BIRDS) New Residential Database Technical Manual
}

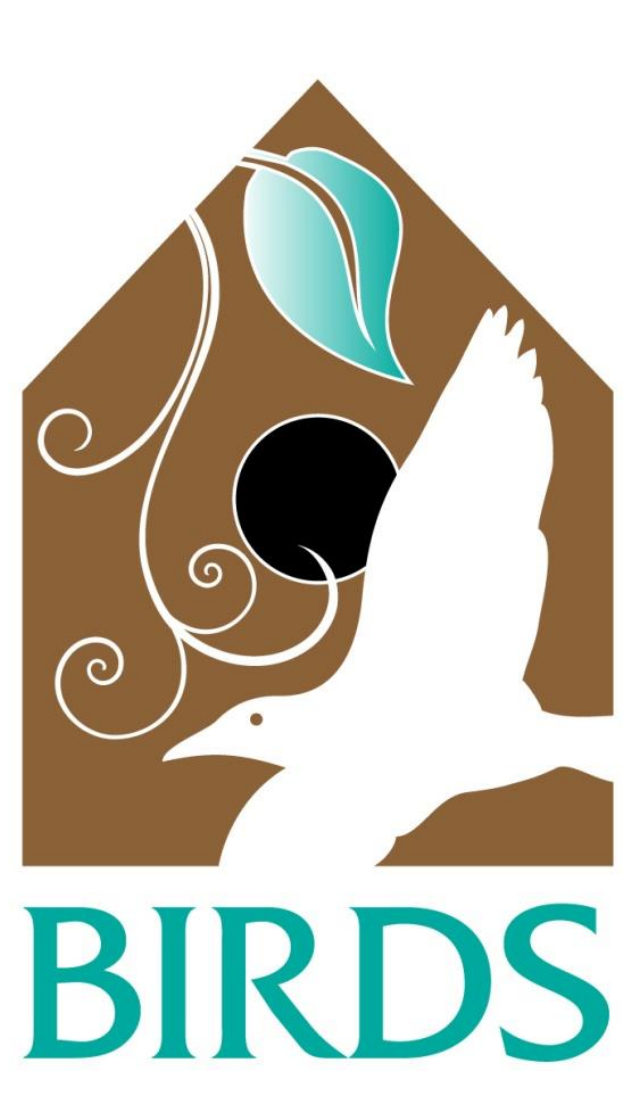

\author{
Joshua Kneifel \\ Priya Lavappa \\ Anne Landfield Greig \\ Sangwon Suh
}

This publication is available free of charge from:

http://dx.doi.org/10.6028/NIST.TN.1878 

NIST Technical Note 1878

\title{
Building Industry Reporting and Design for Sustainability (BIRDS) New Residential Database Technical Manual
}

\author{
Joshua Kneifel \\ Priya Lavappa \\ Applied Economics Office \\ Engineering Laboratory \\ Anne Landfield Greig \\ Four Elements Consulting, LLC
}

Sangwon Suh

Industrial Ecology Research Services, LLC

This publication is available free of charge from: http://dx.doi.org/10.6028/NIST.TN.1878

April 2015

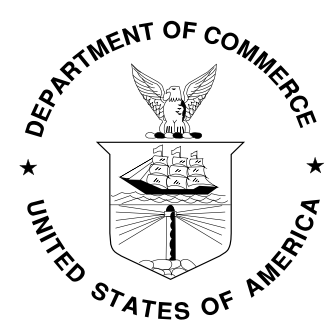

U.S. Department of Commerce Penny Pritzker, Secretary

National Institute of Standards and Technology Willie May, Acting Under Secretary of Commerce for Standards and Technology and Acting Director 
Certain commercial entities, equipment, or materials may be identified in this document in order to describe an experimental procedure or concept adequately. Such identification is not intended to imply recommendation or endorsement by the National Institute of Standards and Technology, nor is it intended to imply that the entities, materials, or equipment are necessarily the best available for the purpose.

National Institute of Standards and Technology Technical Note 1878

Natl. Inst. Stand. Technol. Tech. Note 1878, 120 pages (April 2015) http://dx.doi.org/10.6028/NIST.TN.1878

CODEN: NTNOEF 


\begin{abstract}
Building stakeholders need practical metrics, data, and tools to support decisions related to sustainable building designs, technologies, standards, and codes. The Engineering Laboratory of the National Institute of Standards and Technology (NIST) has addressed this high priority national need by extending its metrics and tools for sustainable building products, known as Building for Environmental and Economic Sustainability (BEES), to whole buildings. Whole building sustainability metrics have been developed based on innovative extensions to life-cycle assessment (LCA) and life-cycle costing (LCC) approaches involving whole building energy simulations. The measurement system evaluates the sustainability of both the materials and the energy used by a building over time. It assesses the "carbon footprint" of buildings as well as 11 other environmental performance metrics, and integrates economic performance metrics to yield science-based measures of the business case for investment choices in high-performance green buildings.

Building Industry Reporting and Design for Sustainability (BIRDS) applies the new sustainability measurement system to an extensive whole building performance database NIST has compiled for this purpose. The BIRDS new residential building database includes energy, environmental, and cost measurements for 9120 new residential buildings, covering 10 single-family dwellings ( 5 one-story and 5 two-story of a various of conditioned floor area) in 228 cities across all U.S. states for study period lengths ranging from 1 year to 40 years. The sustainability performance of buildings designed to meet current state energy codes can be compared to their performance when meeting four alternative building energy standard editions to determine the impact of energy efficiency on sustainability performance. The impact of the building location and the investor's time horizon on sustainability performance (economic and environmental) can also be measured.
\end{abstract}

\title{
Keywords
}

Building economics; economic analysis; life-cycle costing; life-cycle assessment; energy efficiency; residential buildings 


\section{Preface}

This documentation was developed by the Applied Economics Office in the Engineering Laboratory (EL) at the National Institute of Standards and Technology (NIST). The document explains how the BIRDS new residential database was developed, including the assumptions and data sources for the energy, environmental, and cost estimate calculations. The intended audience is BIRDS v2.0 users, researchers and decision makers in the residential building sector, and others interested in building sustainability.

\section{Disclaimers}

The policy of the National Institute of Standards and Technology is to use metric units in all of its published materials. Because this report is intended for the U.S. construction industry that uses U.S. customary units, it is more practical and less confusing to include U.S. customary units as well as metric units. Measurement values in this report are therefore stated in metric units first, followed by the corresponding values in U.S. customary units within parentheses. 


\section{Acknowledgements}

The authors wish to thank all those who contributed ideas and suggestions for this report. They include Dr. Eric O'Rear and Dr. Robert Chapman of EL's Applied Economics Office, Stuart Dols of EL's Energy and Environment Division, and Dr. Nicos S. Martys of EL's Materials and Structural Systems Division. A special thanks to the Industrial Ecology Research Services team of Shivira Tomar, Christine Chen, and Matthew Leighton for their superb technical support in developing whole building life-cycle assessments for BIRDS. Thanks goes to our industry contacts that were instrumental in advising on the assumptions used to develop the product-level life-cycle impact assessments: Daniel Lea of the Cellulose Insulation Manufacturers Association, Dr.

Richard S. Duncan of the Spray Polyurethane Foam Alliance (SPFA), Anders Schmidt of dk-Teknik Energy \& Environment, and members of the Extruded Polystyrene Foam Association (XPSA). Thanks to Mr. Brian Presser and Mr. Samuel Sharpe for assisting in developing the energy simulations and generating the new residential sustainability database. Thanks to Mr. Tarang Hirani for assisting in the development of BIRDS v2.0 web interface. Finally, the many Beta testers of BIRDS v2.0 deserve special thanks for contributing suggestions leading to substantial improvements in the tool.

\section{Author Information}

Joshua Kneifel

Economist

National Institute of Standards and Technology

Engineering Laboratory

100 Bureau Drive, Mailstop 8603

Gaithersburg, MD 208998603

Tel.: 301-975-6857

Email: joshua.kneifel@nist.gov

Priya Lavappa

Computer Specialist

National Institute of Standards and Technology

Engineering Laboratory

100 Bureau Drive, Mailstop 8603

Gaithersburg, MD 208998603

Tel.: 301-975-4522

Email: priya.lavappa@nist.gov 
Anne Landfield Greig

Principal

Four Elements Consulting, LLC

Seattle, WA

Tel: 206-935-4600

Sangwon Suh

Director and Founder

Industrial Ecology Research Services (IERS), LLC

5951 Encina Rd, Suite 206

Goleta, CA 93117

Tel: 805-324-4674

Email: suh@iersweb.com 


\section{Contents}

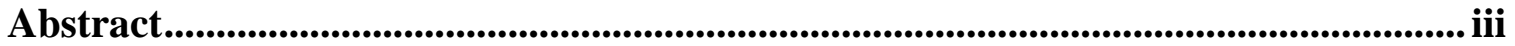

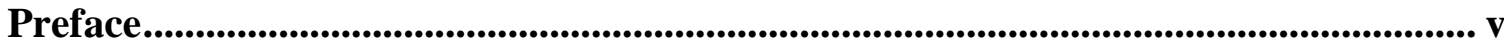

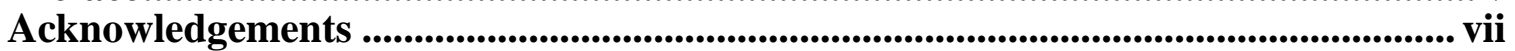

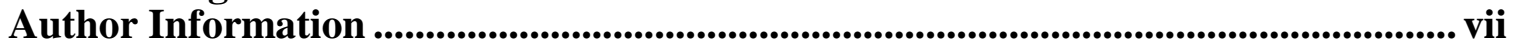

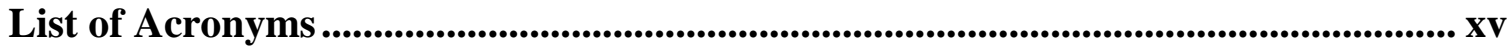

1 Introduction ........................................................................................................... 1

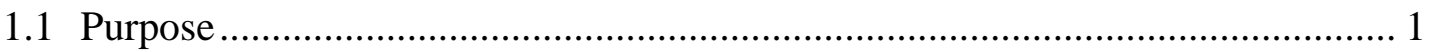

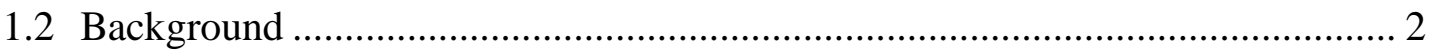

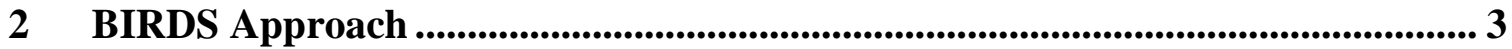

2.1 Rethink Sustainability Measurement .......................................................... 3

2.2 Establish Consistency.................................................................................. 5

3 Energy Performance Measurement .......................................................................... 7

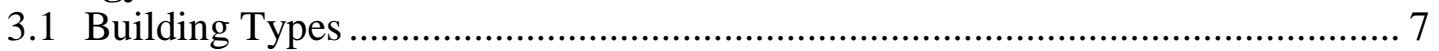

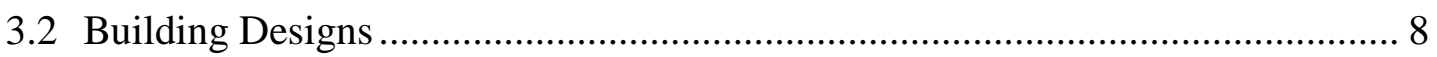

3.3 Energy Simulation Design ......................................................................... 12

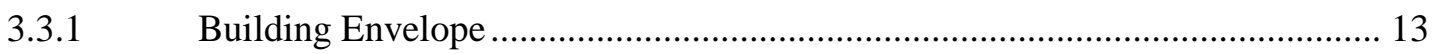

3.3.2 Heating, Ventilation, and Air Conditioning Equipment.................................. 20

3.3.3 Outdoor Air Ventilation and Infiltration ....................................................... 20

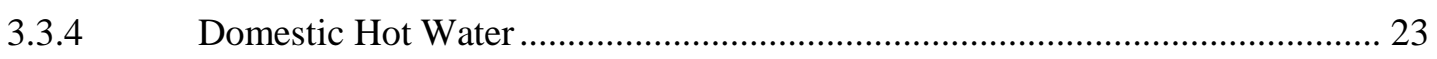

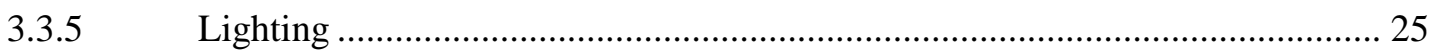

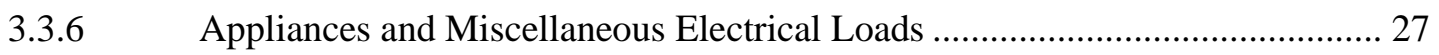

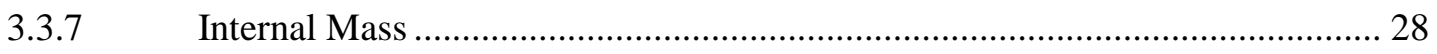

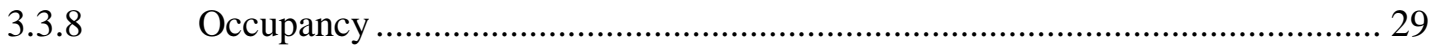

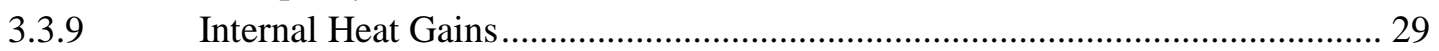

4 Environmental Performance Measurement ........................................................... 31

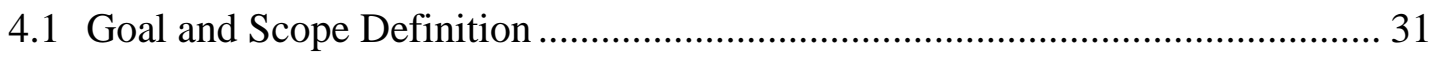

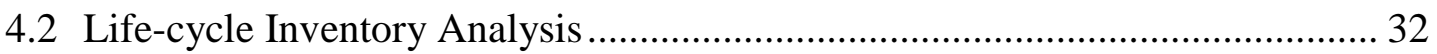

4.3 Life-cycle Impact Assessment ..................................................................... 36

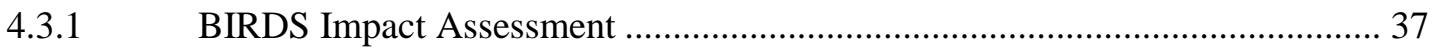

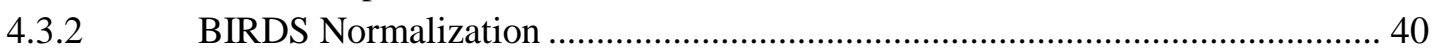

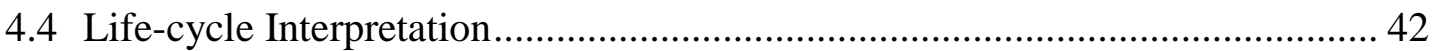

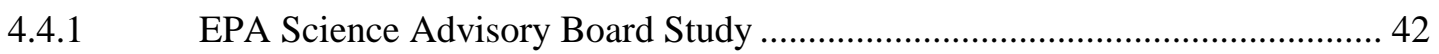

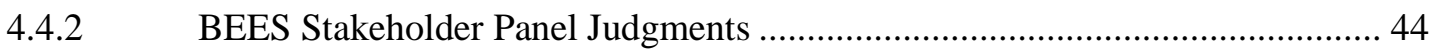

4.5 BIRDS Residential Energy Technologies ....................................................... 48

4.5.1 General Information Regarding the Energy Technology LCIs ......................... 48

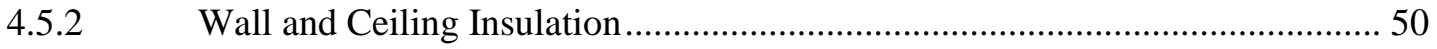

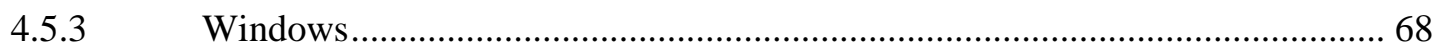

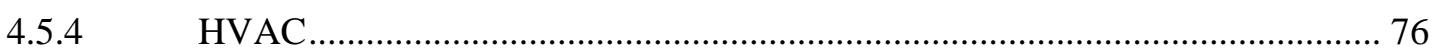

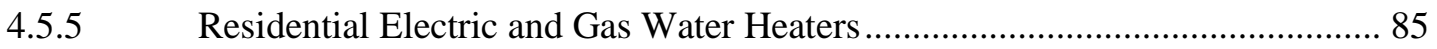

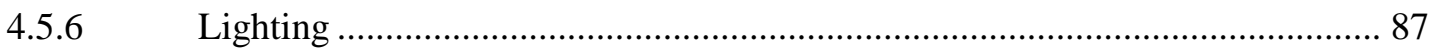

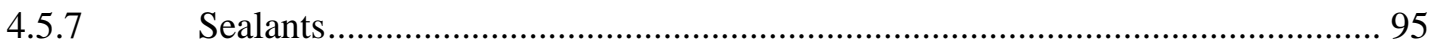

5 Economic Performance Measurement ......................................................................... 99

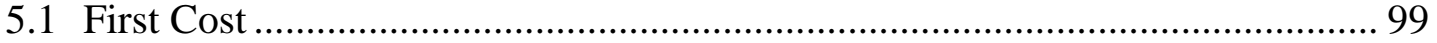




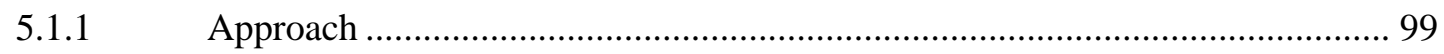

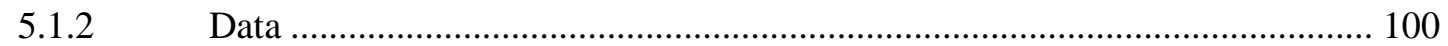

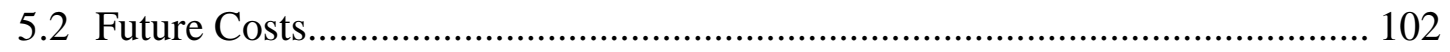

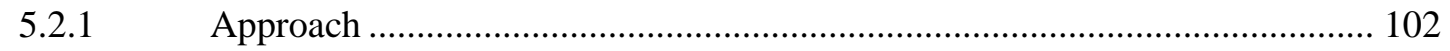

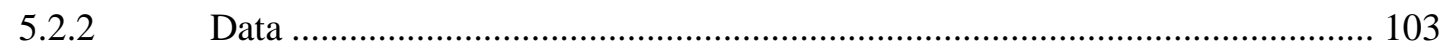

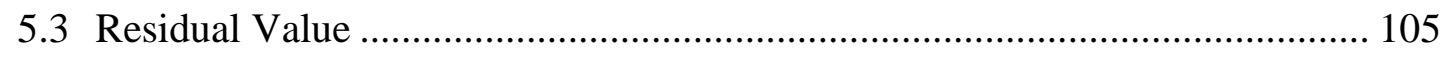

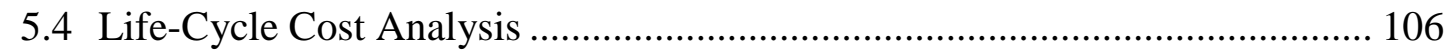

6 Limitations and Future Research......................................................................... 107

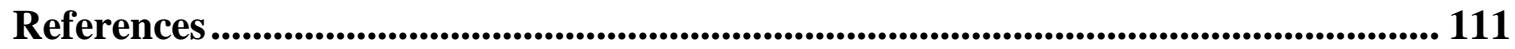

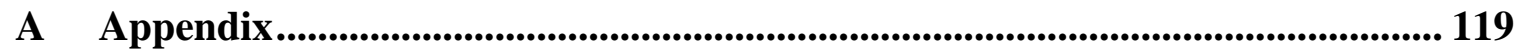




\section{List of Figures}

Figure 2-1 BIRDS Sustainability Framework ...................................................... 5

Figure 3-1 State Residential Energy Codes ….................................................... 10

Figure 3-2 Locations and Climate Zones ................................................................. 11

Figure 3-3 Building Material Layers for Exterior Wall ................................................ 14

Figure 3-4 Building Material Layers for Ceiling ........................................................ 15

Figure 3-5 Building Material Layers for Roof ........................................................ 15

Figure 3-6 Building Material Layers for Slab-on-Grade Foundation ............................ 16

Figure 3-7 Domestic Hot Water Load Profiles as a Proportion of Peak Flow Rate, By

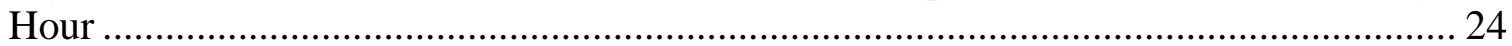

Figure 3-8 Electrical Equipment Load Profiles as a Proportion of Peak Wattage, By Hour

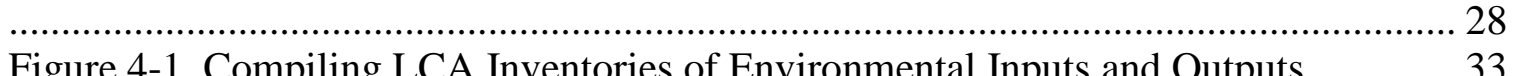

Figure 4-2 Illustration of Supply Chain Contributions to U.S. Construction Industry .... 35

Figure 4-3 BEES Stakeholder Panel Importance Weights Synthesized across Voting

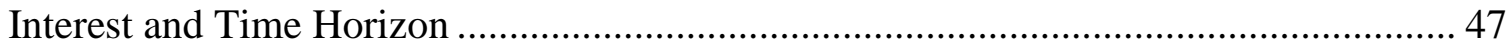

Figure 4-4 BEES Stakeholder Panel Importance Weights by Stakeholder Voting Interest

Figure 4-5 BEES Stakeholder Panel Importance Weights by Time Horizon

Figure 4-6 Insulation System Boundaries - Fiberglass Blanket Example...................... 51

Figure 4-7 Windows System Boundaries ............................................................... 70

Figure 4-8 HVAC System Boundaries - Electric Furnace Example ............................. 77

Figure 4-9 Lighting System Boundaries - CFL Example ....................................... 88

Figure 4-10 Sealants System Boundaries - Exterior Sealant Example ......................... 95

Figure 5-1 Baseline Construction Costs .................................................................. 100

Figure 5-2 Baseline Maintenance and Repair Costs by Year ..................................... 104

Figure A-1 Conditioned Floor Area of New 1-Story Single-Family Housing .............. 119

Figure A-2 Conditioned Floor Area of New 2-Story Single-Family Housing .............. 120 


\section{List of Tables}

Table 3-1 Building Prototype Characteristics ................................................................ 8

Table 3-2 Energy Code by State ……………………................................................ 9

Table 3-3 2003 IECC Climate Zones....................................................................... 12

Table 3-4 Material Parameter Calculation Approach ………………………………..... 13

Table 3-5 2003 IECC Energy Code Requirements for Exterior Envelope ....................... 17

Table 3-6 2006, 2009, 2012 IECC Energy Code Requirements for Windows................. 18

Table 3-7 2006, 2009, 2012 IECC Energy Code Requirements for Exterior Envelope.. 19

Table 3-8 2006, 2009, 2012 IECC Energy Code Requirements for Foundation.............. 19

Table 3-9 IECC Energy Code Requirements for Infiltration............................................ 20

Table 3-10 62.2-2010 Minimum Air Exchange Rate Requirements ............................... 22

Table 3-11 Hot Water Consumption.............................................................................. 23

Table 3-12 Domestic Hot Water Daily Internal Heat Gains ............................................ 25

Table 3-13 Annual Lighting Electricity Consumption ……………………………….... 26

Table 3-14 Lighting Load Profile as Proportion of Peak Wattage in Use, By Hour ....... 26

Table 3-15 Appliance and MEL Electricity Consumption ............................................ 27

Table 3-16 Occupancy Load Profile as a Proportion of Maximum Occupancy, and Total

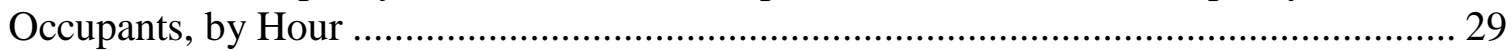

Table 3-17 Daily Heat Gain Comparison-Reference ....................................................... 30

Table 4-1 Construction Industry Outputs Mapped to BIRDS Building Types................. 35

Table 4-2 BIRDS Life-cycle Impact Assessment Calculations by Building Component 40

Table 4-3 BIRDS Normalization References ............................................................... 41

Table 4-4 Pairwise Comparison Values for Deriving Impact Category Importance

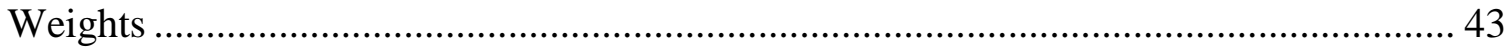

Table 4-5 Relative Importance Weights based on Science Advisory Board Study......... 44

Table 4-6 Relative Importance Weights based on BEES Stakeholder Panel Judgments 46

Table 4-7 Specified Insulation Types and R-Values ……………………..................... 50

Table 4-8 Fiberglass Blanket Mass by Application ........................................................ 52

Table 4-9 Fiberglass Insulation Constituents................................................................ 53

Table 4-10 Energy Requirements for Fiberglass Insulation Manufacturing ………........ 53

Table 4-11 Blown Cellulose Insulation by Application ................................................ 54

Table 4-12 Cellulose Insulation Constituents ................................................................ 55

Table 4-13 B-Side Formulation - Material Constituent Percentages ............................... 57

Table 4-14 SPF Insulation Reference Unit Parameters for Original and BIRDS LCAs . 58

Table 4-15 Material Constituents for Open-Cell and Closed-Cell SPF Insulation.......... 59

Table 4-16 Mineral Wool Blanket Mass by Application................................................. 61

Table 4-17 Mineral Wool Insulation Constituents........................................................... 62

Table 4-18 Energy Requirements for Mineral Wool Insulation Manufacturing ............. 62

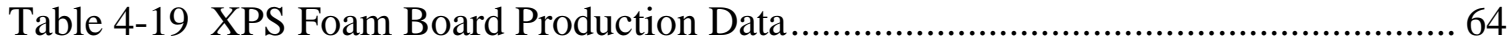

Table 4-20 Raw Material Inputs to Produce Polyiso Foam................................................ 66

Table 4-21 Energy Inputs and Process Outputs for 1 Board-Foot Polyiso Foam............. 67

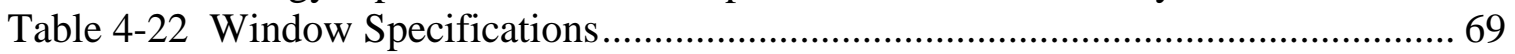

Table 4-23 Dimensions and Main Parts of the Wood Clad Casement Window.............. 71

Table 4-24 Dimensions and Main Parts of the Aluminum Casement Window............... 71

Table 4-25 Dimensions and Main Parts of the Vinyl Casement Window ....................... 71 
Table 4-26 Dimensions and Main Parts of the Wood Clad Double Hung Window ........ 72

Table 4-27 Dimensions and Main Parts of the Aluminum Double Hung Window ......... 73

Table 4-28 Dimensions and Main Parts of the Vinyl Double Hung Window ................. 73

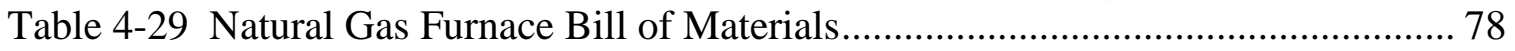

Table 4-30 Electric Furnace Bill of Materials .............................................................. 79

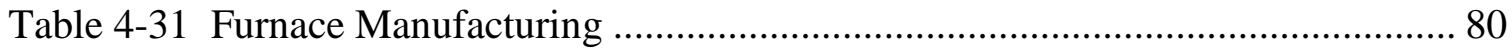

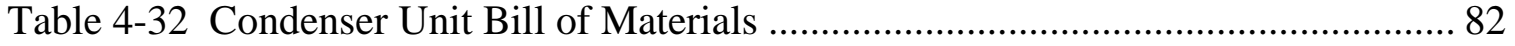

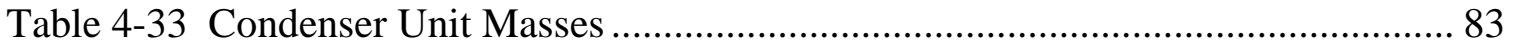

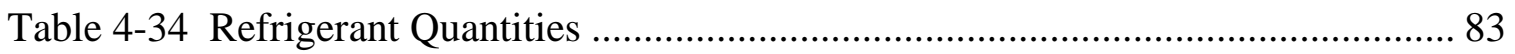

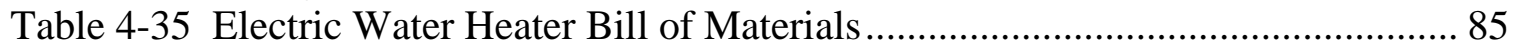

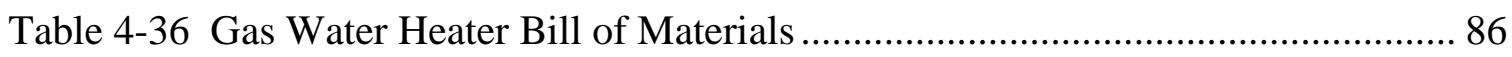

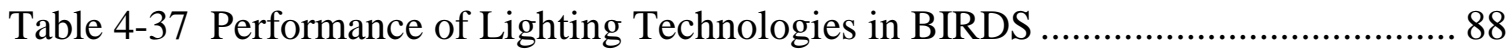

Table 4-38 Incandescent Light Bulb Bill of Materials ................................................. 89

Table 4-39 CFL Bill of Materials ............................................................................ 91

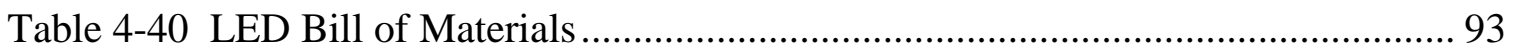

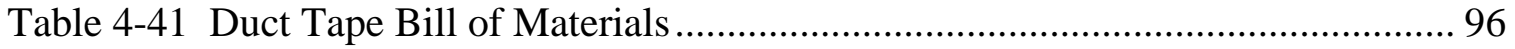

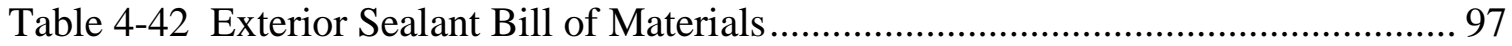

Table 5-1 Energy Efficiency Component Requirements for Alternative Building Designs

Table 5-2 2009 SPV Discount Factors for Future Non-Fuel Costs, 3 \% Real Discount

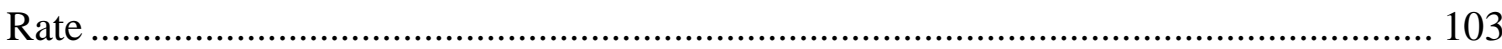




\section{List of Acronyms}

\section{Acronym Definition}

ABS acrylontrile-butadiene-styrene

$\mathrm{ACH}$ air changes per hour

AEO Applied Economics Office

AFUE annual fuel utilization efficiency

AHP Analytical Hierarchy Process

AHRI Air Conditioning, Heating, and Refrigeration Institute

AHS American Housing Survey

ASHRAE American Society of Heating, Refrigerating and Air-Conditioning Engineers

BA Building America

BEA Bureau of Economic Analysis

BEES Building for Environmental and Economic Sustainability

BIRDS Building Industry Reporting and Design for Sustainability

C\&D construction and demolition

CDD Cooling Degree Day

CFA conditioned floor area

CFC-11 Trichlorofluoromethane

CFL compact fluorescent lamp

CFM cubic feet per minute

$\mathrm{CO} 2$ carbon dioxide

$\mathrm{CO} 2 \mathrm{e} \quad$ carbon dioxide equivalent

COP Coefficient of Performance

E+ EnergyPlus

EERE Office of Energy Efficiency \& Renewable Energy

eGDP environmental gross domestic product

EIA Energy Information Administration

EL Engineering Laboratory

ELA effective leakage area

EPA Environmental Protection Agency

EPD Environmental Product Declaration

EPDM ethylene propylene diene monomer

EPS expanded polystyrene 


\begin{tabular}{ll} 
Acronym & Definition \\
GDP & gross domestic product \\
GWB & Gypsum Wall Board \\
HBCD & hexabromocyclododecane \\
HCFC & hydrochlorofluorocarbon \\
HDD & Heating Degree Day \\
HDPE & high density polyethylene \\
HFC & Pentafluoropropane \\
HVAC & Heating, Ventilation, and Air Conditioning \\
IECC & International Energy Conservation Code \\
IGU & insulated glass unit \\
I-O & input-output \\
IPCC & Intergovernmental Panel on Climate Change \\
ISO & International Organization for Standardization \\
LBL & Lawrence Berkeley Laboratory \\
LCA & life-cycle assessment \\
LCC & life-cycle cost \\
LCI & Life Cycle Inventory \\
LCIA & life-cycle impact assessment \\
LED & light-emitting diode \\
Low-E & low-emissivity \\
M\&R & maintenance and replacement \\
MBH & Million Btu per Hour \\
MDI & methylene diphenyl diisocyanate \\
MRR & maintenance, repair, and replacement \\
MSDS & Material safety data sheet \\
NAHB & National Association of Home Builders \\
NBR & number of bedrooms \\
NIST & National Institute of Standards and Technology \\
NS & Net Savings \\
PBDE & polybrominated diphenyl ethers \\
Product Category Rules \\
\hline HCR
\end{tabular}




\section{Acronym Definition}

PCR Product Category Rules

PIB polyisobutylene

PIMA Polyisocyanurate Insulation Manufacturers Association

PM10 particulate matter less than 10 micrometers in diameter

pMDI polymeric methylene diphenyl diisocyanate

PNS Net LCC savings as a percentage of base case LCC

PP propylene

PUR Polyurethane

PV present value

PVC Polyvinyl chloride

SAB Science Advisory Board

SEER Seasonal Energy Efficiency Ratio

SHGC Solar Heat Gain Coefficient

SOC Survey of Construction

SPF spray polyurethane foam

SPV single present value

TCPP Tris(2-chloroisopropyl)phosphate

TRACI Tool for the Reduction and Assessment of Chemical and other environmental Impar

UPV Uniform Present Value Discount Factor

UPV* Modified Uniform Present Value Discount Factor

VOC volatile organic compound

VT Visual Transmittance

XPS Extruded Polystyrene

XPSA Extruded Polystyrene Foam Association 


\section{Introduction}

\subsection{Purpose}

Building stakeholders need practical metrics, data, and tools to support decisions related to sustainable building designs, technologies, standards, and codes. The Engineering Laboratory (EL) of the National Institute of Standards and Technology (NIST) has addressed this high priority national need by extending its metrics and tools for sustainable building products, known as Building for Environmental and Economic Sustainability (BEES), to whole buildings. Whole building sustainability metrics have been developed based on innovative extensions to life-cycle assessment (LCA) and life-cycle costing (LCC) approaches involving whole building energy simulations. The measurement system evaluates the sustainability of both the materials and the energy used by a building over time. It assesses the "carbon footprint" of buildings as well as 11 other environmental performance metrics, and integrates economic performance metrics to yield science-based measures of the business case for investment choices in high-performance green buildings.

The approach developed for BEES has now been applied at the whole building level to address building sustainability measurement in a holistic, integrated manner that considers complex interactions among building materials, energy technologies, and systems across dimensions of performance, scale, and time. Building Industry Reporting and Design for Sustainability (BIRDS) applies the new sustainability measurement system to an extensive whole building performance database NIST has compiled for this purpose. The energy, environment, and cost data in BIRDS measure building operating energy use through detailed energy simulations, building materials use through innovative life-cycle material inventories, and building costs over time.

BIRDS v1.0 included energy, environmental, and cost measurements for 12540 new commercial and non low-rise residential buildings, covering 11 building prototypes in 228 cities across all U.S. states for 9 study period lengths. See Lippiatt et al. (2013) for additional details. Similarly, the new residential building database incorporated into BIRDS v2.0 includes energy, environmental, and cost measurements for 9120 new residential buildings, covering 10 single family dwellings ( 5 one-story and 5 two-story of various conditioned floor area) in 228 cities across all U.S. states for study period length ranging from 1 year to 40 years. The sustainability performance of buildings designed to meet current state energy codes can be compared to their performance when meeting up to three user-selected alternative building energy standard editions to determine the impact of energy efficiency on sustainability performance. The impact of the building location and the investor's time horizon on sustainability performance (economic and environmental) can also be evaluated. ${ }^{1}$

\footnotetext{
${ }^{1}$ A forthcoming user guide will include a detailed tutorial of how to use the BIRDS new residential database web interface to makes these different types of comparisons.
} 


\subsection{Background}

A wave of interest in sustainability gathered momentum in 1992 with the Rio Earth Summit, during which the international community agreed upon a definition of sustainability in the Bruntland report: "meeting the needs of the present generation without compromising the ability of future generations to meet their own needs" (Brundtland 1987). In the context of sustainable development, needs can be thought to include the often-conflicting goals of environmental quality, economic well-being, and social justice. While the intent of the 1992 summit was to initiate environmental and social progress, it seemed to have instead brought about greater debate over the inherent conflict between sustainability and economic development.

This conflict is particularly apparent within the construction industry. Frequently, well-intentioned green development plans are not executed for economic reasons, and economic development plans fail to materialize over concerns for the environment and public health. Thus, an integrated approach to sustainable construction —one that simultaneously considers both environmental and economic performance- - lies at the heart of reconciling this conflict. For this reason, the BIRDS approach considers both the environmental and economic dimensions of sustainability. BIRDS, however, does not consider the social dimension of sustainability due to the current lack of applicable rigorous measurement methods. 


\section{BIRDS Approach}

\subsection{Rethink Sustainability Measurement}

One standardized and preferred approach for scientifically measuring the environmental performance of industrial products and systems is life-cycle assessment (LCA). LCA is a "cradle-to-grave" systems approach for measuring environmental performance. The approach is based on two principles. First, the belief that all stages in the life of a product generate environmental impacts and must be analyzed, including raw materials acquisition, product manufacture, transportation, installation, operation and maintenance, and ultimately recycling and waste management. An analysis that excludes any of these stages is limited because it ignores the full range of upstream and downstream impacts of stage-specific processes. LCA broadens the environmental discussion by accounting for shifts of environmental problems from one life-cycle stage to another. The second principle is that multiple environmental impacts must be considered over these life-cycle stages in order to implement a trade-off analysis that achieves a genuine reduction in overall environmental impact, rather than a simple shift of impact. By considering a range of environmental impacts, LCA accounts for problem-shifting from one environmental medium (land, air, water) to another.

The LCA method is typically applied to products, or simple product assemblies, in a "bottom up" manner. The environmental inputs and outputs to all the production processes throughout a product's life-cycle are compiled. These product life-cycle "inventories" quantify hundreds, even thousands, of environmental inputs and outputs. This is a data-intensive, time-consuming, and expensive process that must be repeated for every product.

The bottom-up approach becomes unwieldy and cost prohibitive for complex systems, such as buildings, that involve potentially hundreds of products. Furthermore, a building's sustainability is not limited to the collective sustainability of its products. The manner in which designers integrate these products and systems at the whole building level has a large influence on another major dimension of its sustainability performance, operating energy use.

The many dimensions of a building's environmental performance are ultimately balanced against its economic performance. Even the most environmentally conscious policymaker, building designer, or potential homeowner will ultimately weigh environmental benefits against economic costs. A 2006 poll by the American Institute of Architects showed that $90 \%$ of U.S. consumers would be willing to pay more to reduce their home's environmental impact, yet they would pay only $\$ 4000$ to $\$ 5000$, or about $2 \%$, more. ${ }^{2}$ More recent studies have shown an increase in this willingness to pay for more sustainable home designs. Kok and Kahn (2012) show that green labeled homes in California realize a sales price that is $\$ 34800$ or $9 \%(+/-4 \%)$ higher than a non-labeled home. Aroul and Hansz (2012) estimate a more modest increase of $2.1 \%$ to $2.4 \%$ in home transaction prices for green-rated homes for two Texas cities, Frisco and McKinney. There

\footnotetext{
${ }^{2}$ January 2006 survey cited in Green Buildings in the Washington Post (Cohen 2006).
} 
appears to be significant variation across locations in the value placed on green-rated homes, which may be driven by consumer preferences or knowledge. To satisfy stakeholders, the green building community needs to promote and design buildings with an attractive balance of environmental and economic performance.

These considerations require a different way of thinking about sustainability performance for buildings. In the BIRDS model, a unifying LCA framework developed for the U.S. economy is applied to the U.S. construction sector and its constituent building types. Through this "topdown" LCA approach, a series of baseline sustainability measurements are made for prototypical buildings, yielding a common yardstick for measuring sustainability with roots in wellestablished national environmental and economic statistics. Using detailed "bottom-up" data compiled through traditional LCA approaches, the baseline measurements for prototypical buildings are then "hybridized" to reflect a range of improvements in building energy efficiency, enabling assessment of their energy, environmental, and economic benefits and costs. The idea is to provide a cohesive database and measurement system based on sound science that can be used to prioritize green building issues and to track progress over time as design and policy solutions are implemented. "Bottom-up" and "top-down" data sources and approaches will be discussed in further detail in Chapter 4.

The BIRDS hybrid LCA approach combines the advantages of both bottom-up and top-down approaches - namely the use of higher-resolution, bottom-up data and the use of regularly-updated, top-down statistical data without truncation (Suh et al. 2004; Suh and Huppes 2005). The hybrid approach generally reduces the uncertainty of existing pure bottom up or pure top down systems: it helps reduce truncation error in the former and increases the resolution of the latter (Suh et al. 2004). The hybrid approach will be discussed in further detail in Chapter 4.

Operating energy use - a key input to whole building LCAs - is assessed in BIRDS using the bottom-up approach. Energy use is highly dependent upon a building's function, size, location, and the efficiency of its energy technologies. Energy efficiency requirements in current energy codes for residential buildings vary across states, and many states have not yet adopted the newest energy code editions. As of November 2014, state energy code adoptions range across all editions of the International Energy Conservation Code (IECC) for Residential Buildings (2003 IECC, 2006 IECC, 2009 IECC, and 2012 IECC). ${ }^{3}$ Some states do not have a code requirement for energy efficiency, leaving it up to the locality or jurisdiction to set its own requirement. To address these issues, operating energy use in BIRDS is tailored to residential building types, locations, and energy codes. The BIRDS database includes operating energy use predicted through energy simulation of 4 alternative building designs for 10 building types in 228 U.S. locations, with each design complying with some version of the IECC energy code.

${ }^{3}$ ICC $(2003,2006,2009,2012)$ 
Like operating energy use, a building's economic performance is dependent upon a building's design and location. Construction material and labor costs vary by location, as do maintenance, repair, and replacement costs over time. Energy technologies for compliance with a given IECC code edition vary across U.S. climate zones, as do their costs. Finally, a building's operating energy costs vary according to the quantity and price of energy use, which depend upon the building's location and fluctuate over time. All these variables are accounted for in the BIRDS database, as shown in Figure 2-1.

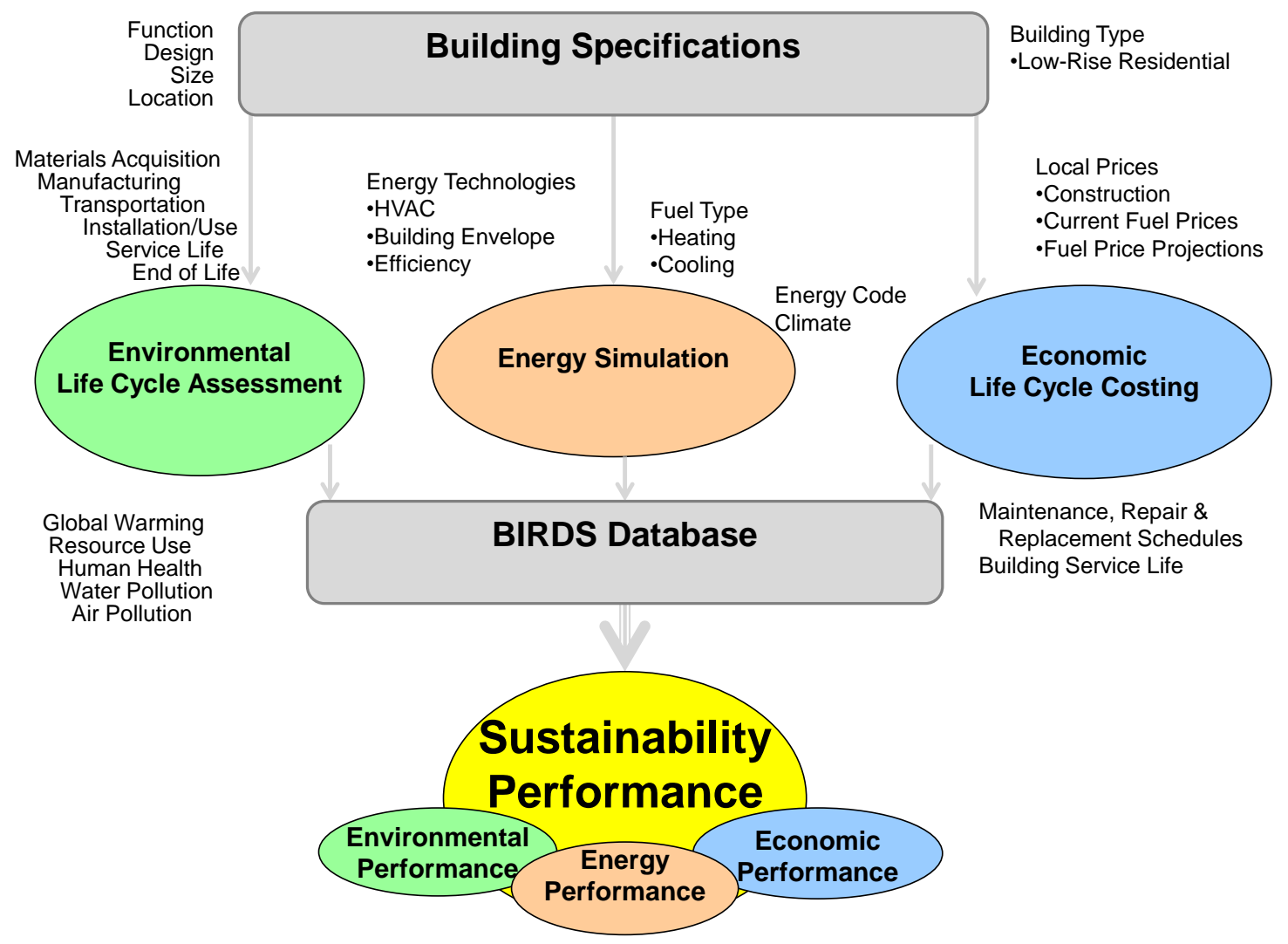

Figure 2-1 BIRDS Sustainability Framework

\subsection{Establish Consistency}

This new way of measuring building sustainability performance requires that special attention be paid to establishing consistency among its many dimensions. While BIRDS develops separate performance metrics for building energy, environmental, and economic performance, they are all developed using the same parameters and assumptions. For each of the 9120 buildings included in the BIRDS new residential database, consistent design specifications are used to estimate its operating energy use, environmental life-cycle impacts, and life-cycle costs. The building energy simulation, for example, specifies the same building envelope and HVAC technologies as do the bottom-up energy technology LCAs and cost estimates. 
One of the most important dimensions requiring BIRDS modeling consistency is the study period. The study period is the number of years of building operation over which energy, environmental, and economic performance are assessed. In economic terms, the study period represents the investor's time horizon. Over what period of time are the environmental and economic costs and benefits related to the capital investment decision of interest to the investor or policymaker? Since different stakeholders have different time perspectives, there is no one correct study period for developing a business case for sustainability. For this reason, 40 different study period lengths are offered in BIRDS, ranging from 1 year to 40 years.

Forty study period lengths are chosen to represent the wide cross section of potential investment time horizons. A 1-year study period is representative of a developer that intends to sell a property soon after it is constructed. A 5-year to 15-year study period best represents the typical length of time a homeowner is in a given house. The 20 -year to 40 -year study periods better represent homeowners that intend to be a permanent resident of a particular house. BIRDS sets the maximum study period at 40 years for consistency with requirements for federal building life-cycle cost analysis (Energy Independence and Security Act of 2007). Beyond 40 years, technological obsolescence becomes an issue, data become too uncertain, and the farther in the future, the less important the costs.

Once the BIRDS user sets the length of the study period, the energy, environmental, and economic data are all normalized to that period of time. This involves adjustments to a building's operating, maintenance, repair, and replacement data as well as to its remaining value at the end of the study period. This assures consistency and comparability among the three metrics, and is one of the strengths of the BIRDS approach.

The next 3 chapters go into more detail regarding the modeling of the energy, environmental, and economic performance measures within the BIRDS new residential building database. 


\section{Energy Performance Measurement}

The operating energy component (i.e. energy consumed during use of the building by occupants) of the BIRDS new residential database was built following the framework developed in Kneifel (2010) and further expanded in Kneifel (2011a) and Kneifel (2011b). The BIRDS new residential database includes the results of 9120 whole building energy simulations covering 4 energy efficiency designs for 10 single-family dwellings, 228 cities across the United States, and 40 study period lengths.

\subsection{Building Types}

The building characteristics in Table 3-1 describe the 10 building types included in the BIRDS new residential database, which include 5 one-story and 5 two-story single-family detached dwellings of varying conditioned floor area to represent the distribution of new home construction in the United States.

The prototype buildings range in size from $111.9 \mathrm{~m}^{2}\left(1205 \mathrm{ft}^{2}\right)$ to $420.2 \mathrm{~m}^{2}\left(4523 \mathrm{ft}^{2}\right)$. The house dimension ratios are rectangular and the same at approximately 2.56:1 and 1.60:1 for the 1-story and 2-story prototypes, respectively. These alternative building sizes are based on the U.S. Census' Survey of Construction (SOC) database (U.S. Census Bureau 2012). Figure A-1 and Figure A-2 show the percentile breakdown of the size of new single-family detached houses for one-story and two-story houses, respectively, both in frequency (left y-axis) and cumulative distribution (right y-axis). ${ }^{4}$ The building sizes selected for the residential prototype sizes attempt to represent the $10^{\text {th }}, 30^{\text {th }}, 50^{\text {th }}, 70^{\text {th }}$, and $90^{\text {th }}$ percentiles for each distribution.

All building prototypes are assumed to have wood-framing, 3 bedrooms, $2.4 \mathrm{~m}(8 \mathrm{ft})$ high ceilings, a roof slope of 4:12 (height:length) with $0.3 \mathrm{~m}(1 \mathrm{ft})$ overhangs on the north and south sides of the building, and no garage. The fraction of wall area covered by fenestration ranges from $13 \%$ to $24 \%$.

\footnotetext{
${ }^{4}$ Homes with less than $700 \mathrm{ft}^{2}$ are assumed to have $700 \mathrm{ft}^{2}$.
} 


\section{Table 3-1 Building Prototype Characteristics}

\begin{tabular}{|c|c|c|c|}
\hline Floors & $\begin{array}{l}\text { Conditioned Floor Area } \\
\qquad \mathbf{m}^{2}\left(\mathbf{f t}^{2}\right)\end{array}$ & $\begin{array}{l}\text { Dimensions } \\
\text { m (ft) }\end{array}$ & Fenestration \\
\hline 1 & 111.9 (1205) & $\begin{array}{c}6.61 \times 16.89 \\
(21.67 \times 55.42)\end{array}$ & $15 \%$ \\
\hline 1 & $148.6(1600)$ & $\begin{array}{l}7.62 \times 19.51 \\
(25.0 \times 64.0)\end{array}$ & $17 \%$ \\
\hline 1 & $176.6(1901)$ & $\begin{array}{c}8.31 \times 21.26 \\
(27.25 \times 69.75)\end{array}$ & $18 \%$ \\
\hline 1 & 215.8 (2323) & $\begin{array}{l}9.17 \times 23.53 \\
(30.1 \times 77.21)\end{array}$ & $20 \%$ \\
\hline 1 & $292.8(3152)$ & $\begin{array}{c}10.67 \times 27.43 \\
(35.0 \times 90.0)\end{array}$ & $24 \%$ \\
\hline 2 & $148.8(1602)$ & $\begin{array}{c}6.8 \times 10.9 \\
(22.37 \times 35.8)\end{array}$ & $13 \%$ \\
\hline 2 & 204.9 (2205) & $\begin{array}{l}8.00 \times 12.80 \\
(26.25 \times 42.0)\end{array}$ & $15 \%$ \\
\hline 2 & 251.2 (2704) & $\begin{array}{l}8.86 \times 14.17 \\
(29.07 \times 46.5)\end{array}$ & $17 \%$ \\
\hline 2 & 311.0 (3348) & $\begin{array}{c}9.85 \times 15.78 \\
(32.33 \times 51.78)\end{array}$ & $19 \%$ \\
\hline 2 & 420.2 (4523) & $\begin{array}{c}11.49 \times 18.29 \\
(37.7 \times 60.0)\end{array}$ & $22 \%$ \\
\hline
\end{tabular}

\subsection{Building Designs}

Current state energy codes are based on different editions of the International Energy Conservation Code (IECC), which have requirements that vary based on a building's characteristics and the climate zone of the location. For the BIRDS new residential database, the $I E C C$-equivalent design is used to meet current state energy codes and to define the alternative building designs. Table 3-2 shows that residential building energy codes as of November 2014 vary by state. It is important to consider that local jurisdictions have adopted energy standard editions that are more stringent than the state energy codes. ${ }^{5}$

\footnotetext{
${ }^{5}$ Local and jurisdictional requirements can be obtained from the Database of State Incentives for Renewables and Efficiency (DSIRE) (DSIRE 2014).
} 
Table 3-2 Energy Code by State

\begin{tabular}{|c|c|c|c|c|c|}
\hline Location & Energy Code & Location & Energy Code & Location & Energy Code \\
\hline AK & None & LA & 2006 & $\mathrm{OH}$ & 2009 \\
\hline $\mathrm{AL}$ & 2009 & MA & 2012 & OK & 2006 \\
\hline AR & 2003 & MD & 2012 & OR & 2009 \\
\hline $\mathrm{AZ}$ & None & $\mathrm{ME}$ & None & PA & 2009 \\
\hline $\mathrm{CA}$ & 2012 & MI & 2009 & RI & 2012 \\
\hline $\mathrm{CO}$ & 2003 & $\mathrm{MN}$ & 2006 & SC & 2009 \\
\hline $\mathrm{CT}$ & 2009 & MO & None & SD & None \\
\hline $\mathrm{DE}$ & 2012 & MS & None & $\mathrm{TN}$ & 2006 \\
\hline FL & 2009 & MT & 2009 & $\mathrm{TX}$ & 2009 \\
\hline GA & 2009 & $\mathrm{NC}$ & 2009 & UT & 2009 \\
\hline $\mathrm{HI}$ & 2006 & ND & 2009 & VA & 2012 \\
\hline IA & 2012 & $\mathrm{NE}$ & 2009 & VT & 2009 \\
\hline ID & 2009 & $\mathrm{NH}$ & 2009 & WA & 2012 \\
\hline IL & 2012 & $\mathrm{NJ}$ & 2009 & WI & 2006 \\
\hline IN & 2009 & NM & 2009 & WV & 2009 \\
\hline $\mathrm{KS}$ & None & NV & 2009 & WY & None \\
\hline KY & 2009 & NY & 2009 & & \\
\hline
\end{tabular}

State energy codes vary from no state code to 2003 IECC to 2012 IECC with some regional trends shown in Figure 3-1. The states in the central U.S. tend to wait longer to adopt newer IECC editions. However, there are many cases in which energy codes of neighboring states vary drastically. For example, Missouri has no state energy code while of the 8 surrounding states, 1 has no state energy code, 1 has adopted 2003 IECC, 2 have adopted 2006 IECC, 2 have adopted 2009 IECC, and 2 have adopted 2012 IECC. 


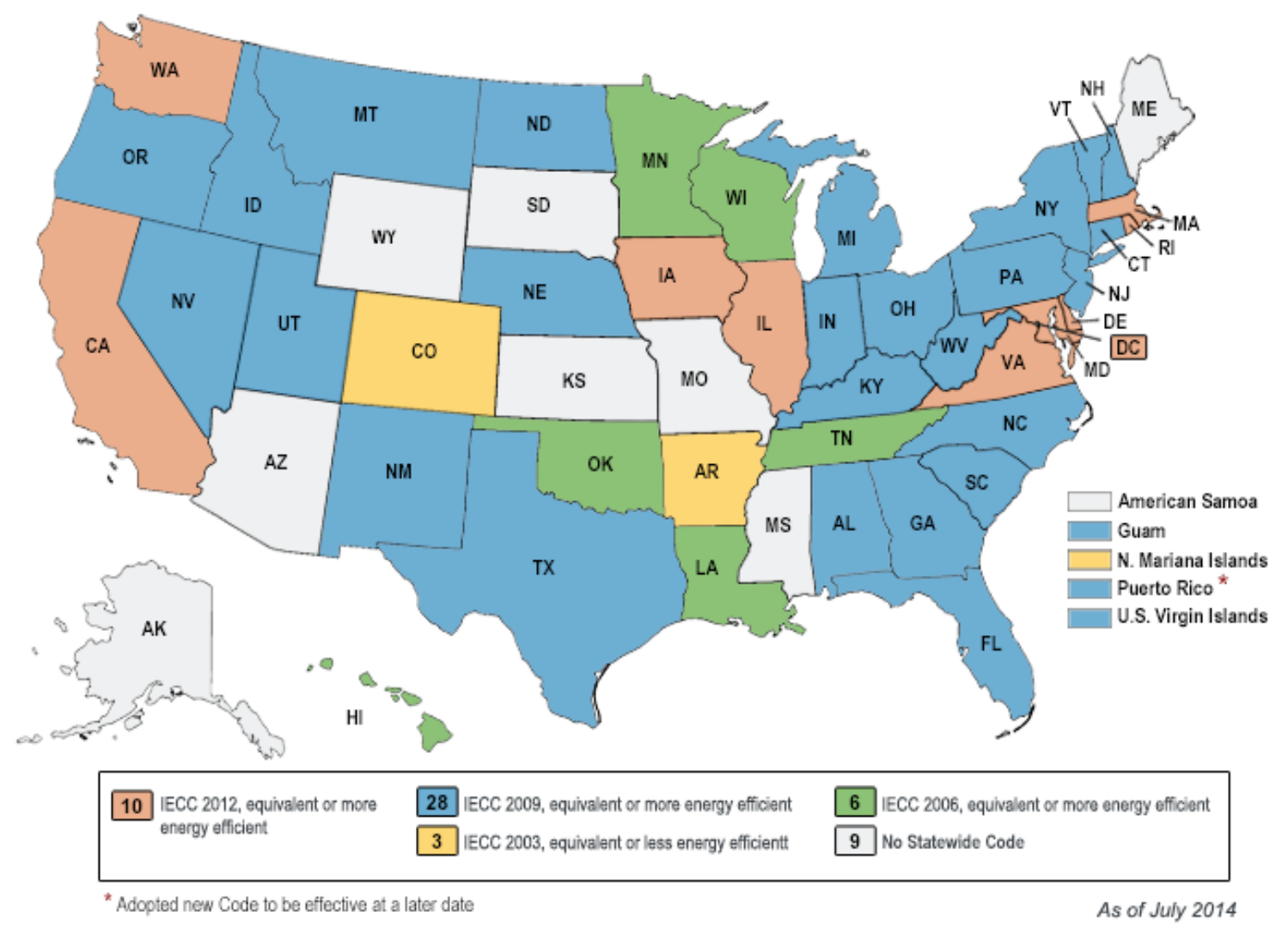

Figure 3-1 State Residential Energy $\operatorname{Codes}^{6}$

The prototype buildings are designed to meet the requirements for each of the editions of IECC (2003, 2006, 2009, and 2012) in the 228 cities, which are shown in Figure 3-2 along with current climate zones used in defining IECC building requirements. These cities are selected for three reasons. First, the cities are spread out to represent the entire United States, and represent as many climate zones in each state as possible. Second, the locations cover all the major population centers in the country. Third, multiple locations for a climate zone within a state are included to allow building costs to vary for each building design.

\footnotetext{
${ }^{6}$ Figure was obtained from the DOE Building Technologies Program in November 2014 (DOE 2014).
} 


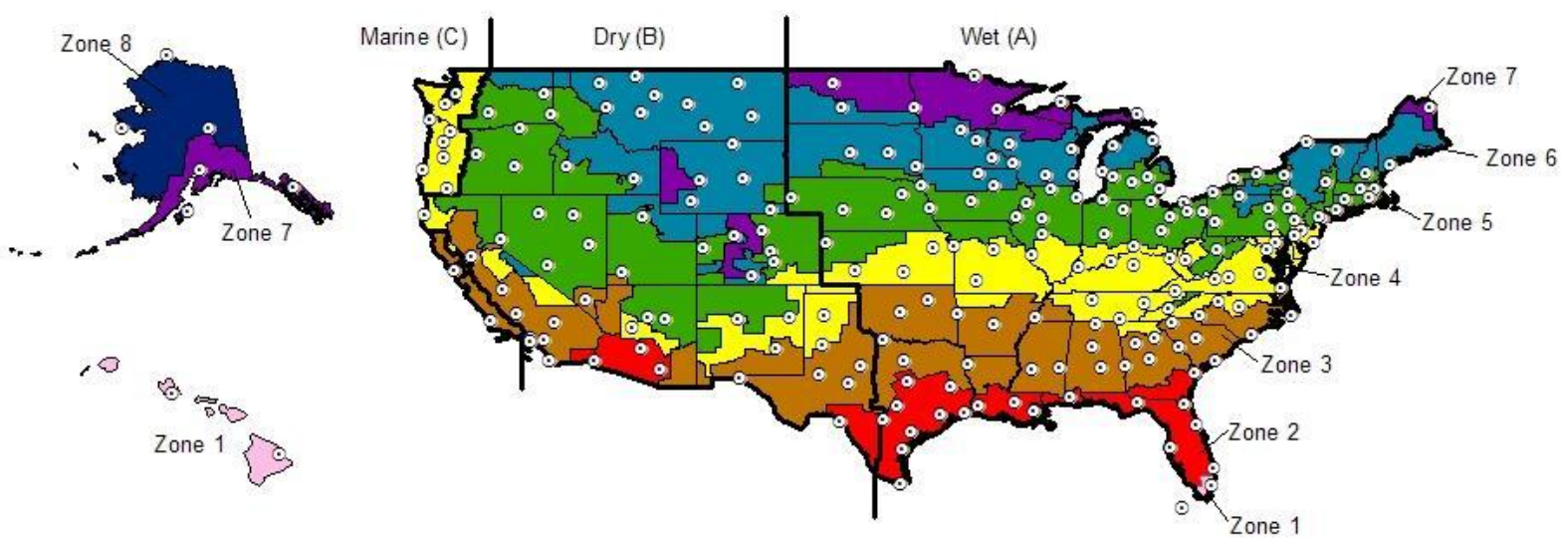

Figure 3-2 Locations and Climate Zones

The climate zones implemented in the IECC were consolidated from the 17 climate zones shown in Table 3-3 for 2003 IECC into 8 climate zones in 2006 IECC. The consolidation is more complex than simply grouping the older climate zones together. The zones in Table 3-3 are based solely on a city's heating degree days at a base of $18^{\circ} \mathrm{C}\left(65^{\circ} \mathrm{F}\right)$ (HDD65) while the zones in Figure 3-2 are based on the combination of a county's heating degree days and cooling degree days at a base of $10^{\circ} \mathrm{C}\left(50^{\circ} \mathrm{F}\right)(\mathrm{CDD} 50)$. The change in the approach results in some cities located in the same climate zone in 2003 IECC being located in a different climate zone in 2006 $I E C C$. The new climate zones are further separated into subzones, "wet," "dry," and "marine," as shown in Figure 3-2, for a total of 16 subzones. 
Table 3-3 2003 IECC Climate Zones

\begin{tabular}{|c|c|}
\hline & Climate Zone \\
\hline Zone & HDD \\
\hline 1 & 0 to 499 \\
\hline 2 & 500 to 999 \\
\hline 3 & 1000 to 1499 \\
\hline 4 & 1500 to 1999 \\
\hline 5 & 2000 to 2499 \\
\hline 6 & 2500 to 2999 \\
\hline 7 & 3000 to 3499 \\
\hline 8 & 3500 to 3999 \\
\hline 9 & 4000 to 4499 \\
\hline 10 & 4500 to 4999 \\
\hline 11 & 5000 to 5499 \\
\hline 12 & 5500 to 5999 \\
\hline 13 & 6000 to 6499 \\
\hline 14 & 6500 to 6999 \\
\hline 15 & 7000 to 8499 \\
\hline 16 & 8500 to 8999 \\
\hline 17 & 9000 to 12999 \\
\hline CDD50 $=$ Annual Cooling Degree Days base $10^{\circ} \mathrm{C}\left(50^{\circ} \mathrm{F}\right)$ \\
\hline HDD65 $=$ Annual Heating Degree Days base $18^{\circ} \mathrm{C}\left(65^{\circ} \mathrm{F}\right)$ \\
\hline \multicolumn{2}{|c|}{} \\
\hline
\end{tabular}

\subsection{Energy Simulation Design}

The prototype residential building designs in this report are based on a number of sources, including Kneifel (2012) and Hendron and Engebrecht (2010). Additional resources are RS Means cost databases, U.S. Census and Energy Information Administration (EIA) housing stock data, and a collection of ASHRAE standards and IECC codes. The prototype buildings are designed in the E+ Version 7.1 simulation software. ${ }^{7}$

Ten prototypical residential building designs are documented in detail in this section: 5 one-story and 5 two-story single-family detached homes. The framework for these designs is IECC for Residential Buildings (ICC 2003, 2006, 2009, 2012). IECC code defines the thermostat control, window specifications, exterior envelope R-values, minimum lighting efficiency, maximum infiltration rates, minimum mechanical ventilation, internal and structural mass, and heating, ventilating, and air-conditioning (HVAC) system requirements.

\footnotetext{
${ }^{7}$ Department of Energy (2012b)
} 
Although IECC defines the general construction requirements, the code does not address the building's plug loads, occupancy, or geometry. Also lacking are a number of small but important details and assumptions required to effectively simulate the energy use of a residential building.

One source of this additional information is the Building America House Simulation Protocols (Hendron and Engebrecht 2010), which is used for the annual loads, load profiles, and internal heat gains for lighting, occupancy, and domestic hot water.

Prototypical building sizes and geometries are selected based on three sources. The U.S. Census Bureau Survey of Construction (SOC) is used to determine the square footage for one-story and two-story residential detached buildings (SOC 2010). RSMeans Square Foot Costs (2011) are used to determine appropriate prototype building geometries.

Other codes and standards are needed to establish additional specifications: ASHRAE 90.2-2007 (ASHRAE 2007), ASHRAE 62.2-2010 (ASHRAE 2010), and the ASHRAE Fundamentals Handbook (ASHRAE 2009). Their use will be defined in detail where appropriate in the remainder of the document.

\subsubsection{Building Envelope}

Some building envelope assumptions are constant regardless of the building location's climate while other assumptions are specific to the climate zones shown in Figure 3-2. The following two subsections will define each set of assumptions separately.

\subsubsection{Non-Climate Zone-Specific Assumptions}

The EnergyPlus parameters for the materials used in the exterior envelope (excluding the roof) are estimated using an average transmittance with the surface-weighted path fractions. In other words, using a simple weighted average of parameter values based on the percentage of framing in the surface. The roof controls for varying materials by splitting the roof into two separate surfaces. The framing percentage for each surface type is shown in Table 3-4.

\section{Table 3-4 Material Parameter Calculation Approach}

\begin{tabular}{ccc}
\hline Construction & Pct. Frame & Approach \\
\hline Exterior Wall & $23 \%$ & surface-weighted path fractions \\
Ceiling & $11 \%$ & surface-weighted path fractions \\
Roof & $11 \%$ & split into separate surfaces \\
\hline
\end{tabular}


The exterior wall is assumed to be $3.8 \mathrm{~cm}$ x $8.9 \mathrm{~cm}(1.5 \mathrm{in} \times 3.5$ in) wood-framed $41 \mathrm{~cm}$ (16 in) on center (OC) with $9 \mathrm{~cm}$ (3.42 in) of fiberglass batt cavity insulation having a thermal resistance of $0.67 \mathrm{~m}^{2} \cdot \mathrm{K} / \mathrm{W}\left(\mathrm{R} 3.8 \mathrm{ft}^{2} \cdot{ }^{.0} \mathrm{~F} \cdot \mathrm{h} / \mathrm{Btu}\right)$ per $2.5 \mathrm{~cm}(1 \mathrm{in})$. The material layers for the exterior wall are defined in Figure 3-3. The construction is made of 5 or 6 layers depending on IECC requirements: wood siding, a felt air barrier, rigid insulation (if required), plywood sheathing, 3.8 $\mathrm{cm} \times 8.9 \mathrm{~cm}$ (1.5 in $\times 3.5 \mathrm{in})$ framing with batt insulation in wall cavity, and gypsum wall board (GWB).

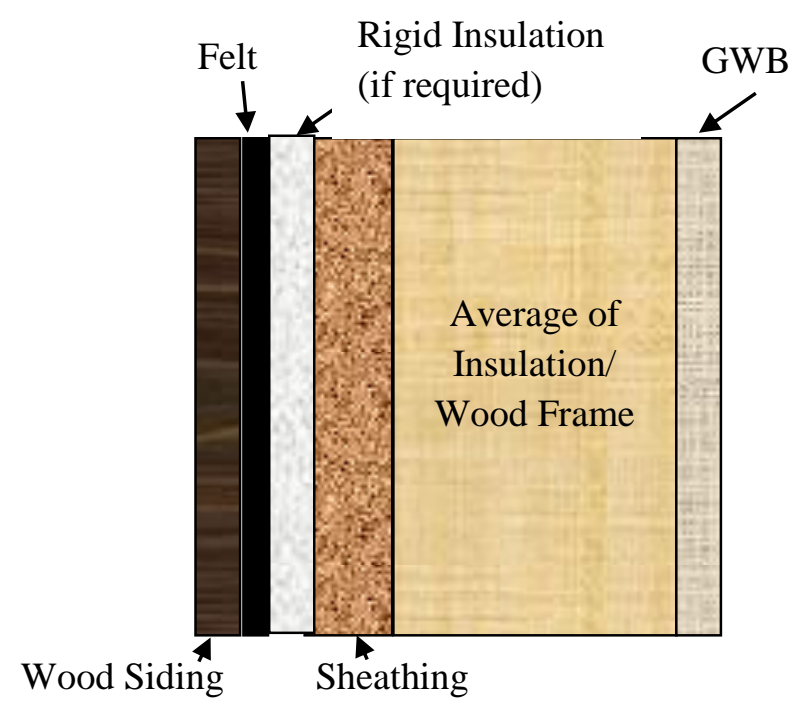

\section{Figure 3-3 Building Material Layers for Exterior Wall}

The average conductance ( $\mathrm{U}$-factor) of the framing/insulation combination material is calculated by the Two-Dimensional U-Factor Calculation equation from 2009 ASHRAE Fundamentals Handbook (ASHRAE 2009). For this material, $23 \%$ of the wall area is framing with the remaining $77 \%$ being the wall cavity that is filled with cavity insulation.

For the 2-story prototypes, the interior floor/ceiling (first level ceiling/second level floor) construction is assumed to be $3.8 \mathrm{~cm} \times 19.1 \mathrm{~cm}(1.5 \mathrm{in} \times 7.5 \mathrm{in})$ floor joists with $1.6 \mathrm{~cm}(5 / 8 \mathrm{in})$ plywood subflooring and $100 \%$ carpet finish. The framing accounts for $13 \%$ of the floor. No insulation is required for interior surfaces because there is no thermal benefit from restricting thermal transfer within the same zone.

The top floor ceiling is assumed to be $1.3 \mathrm{~cm}(0.5 \mathrm{in}) \mathrm{GWB}$ with $3.8 \mathrm{~cm} \times 14.0 \mathrm{~cm}(1.5 \mathrm{in} \times 5.5$ in) ceiling joists. There is blown-in cellulose insulation in the open cavity plus any additional blown-in insulation as required by 2009 IECC. The amount of blown-in insulation varies by climate zone, and will be described in Section 3.3.1.2. The average material U-factor is calculated in the same manner as the exterior wall for the wood frame/cavity layer. Framing accounts for $11 \%$ of the ceiling surface. The material layers for the ceiling are defined in Figure 3-4. 


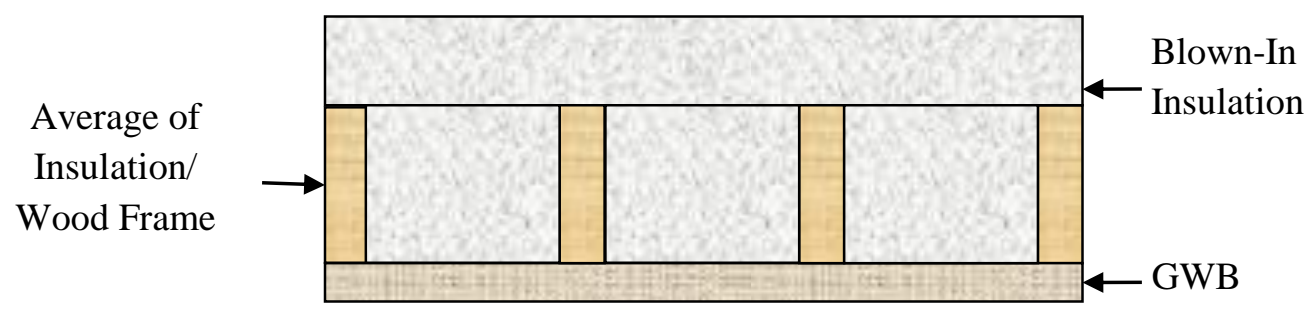

Figure 3-4 Building Material Layers for Ceiling

The roof construction is assumed to be $3.8 \mathrm{~cm} \times 14.0 \mathrm{~cm}$ (1.5 in x $5.5 \mathrm{in})$ rafters with $1.3 \mathrm{~cm}(0.5$ in) plywood sheathing, felt paper, and asphalt shingles. There is no insulation in the rafters, which makes it unnecessary to calculate an average U-factor. Instead the roof is split into two surfaces for energy simulation, one with framing ( $23 \%$ of roof area) and one without framing ( $77 \%$ of roof area). The material layers for the roof with framing are defined in Figure 3-5.

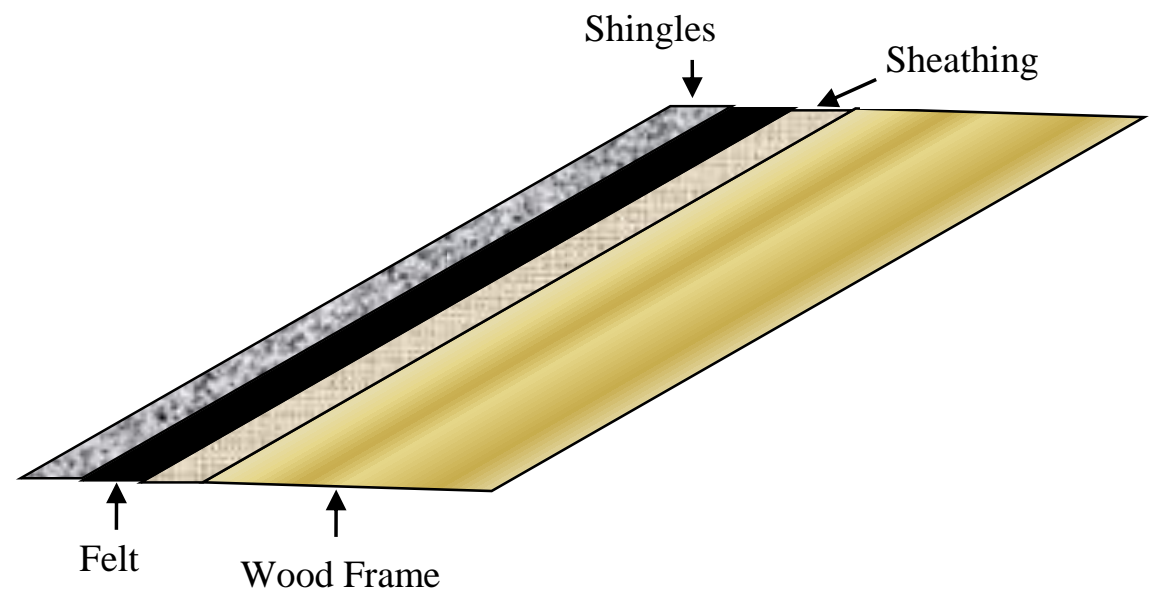

Figure 3-5 Building Material Layers for Roof

The foundation is a $10 \mathrm{~cm}(4 \mathrm{in})$ concrete slab. The floor finish is assumed to be $40 \%$ carpet, $40 \%$ hardwood, $15 \%$ vinyl tile, and $5 \%$ ceramic tile (based on RSMeans Square Foot Costs (2011)). Some climate zones require rigid insulation to be placed on the slab edge, which will be described in Section 3.3.1.2. The material layers for the slab are defined in Figure 3-6. The EnergyPlus Slab preprocessor is used to simulate the heat transfer between the ground and the slab, which recommends simulating horizontal insulation under the slab instead of vertical insulation on the edge of the slab for "slab-on-grade" foundations because the energy transfer that occurs on the vertical edges of the slab are significantly smaller than the energy transfer from the surface area contacting the ground. The Slab preprocessor assumes that the bottom of the slab is flush with the grade. 


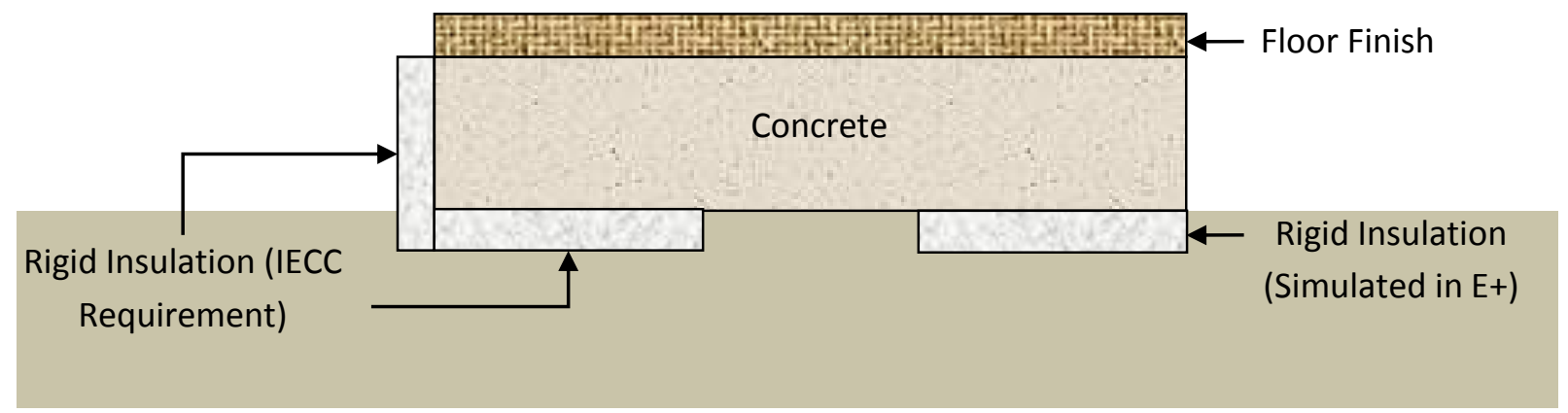

Figure 3-6 Building Material Layers for Slab-on-Grade Foundation

Window glazing area is assumed to be between $13 \%$ and $24 \%$ of conditioned floor area and is

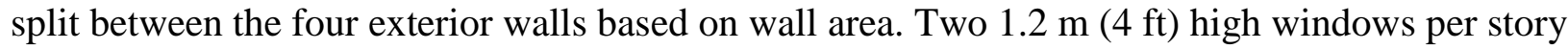
on each side of the house ( 8 in total) are assumed to be located equal distance from the wall edge. The width of the windows is based on the fraction of total wall area represented by each side. There are assumed to be two $0.9 \mathrm{~m} \times 2.0 \mathrm{~m}$ ( $3 \mathrm{ft} \times 6 \mathrm{ft} 8 \mathrm{in}) \times 4.4 \mathrm{~cm}$ (1.75 in) solid pine wood doors, located in the center of the wall on the north and south walls. Windows are defined in EnergyPlus using the "Simple Glazing System," which requires only 3 parameters: U-factor $\left(\mathrm{W} /\left(\mathrm{m}^{2} \cdot \mathrm{K}\right)\right.$ or Btu/ $\left.\mathrm{ft}^{2} \cdot{ }^{0} \mathrm{~F} \cdot \mathrm{h}\right)$, solar heat gain coefficient (SHGC), and visible transmittance (VT). These parameters vary by climate zone, and will be described in Section 3.3.1.2.

\subsubsection{Climate Zone-Specific Assumptions}

The exterior envelope performance requirements of IECC vary depending on the climate zone and edition of the code. The climate zones were redefined between 2003 IECC and 2006 IECC, which makes direct comparisons of building requirements difficult. The 2003 IECC requirements (shown in Table 3-5) for each location has been mapped to the 17 IECC climate zones defined in Section 3.2. 
Table 3-5 2003 IECC Energy Code Requirements for Exterior Envelope

\begin{tabular}{|c|c|c|c|c|c|c|}
\hline \multicolumn{7}{|c|}{ Building Envelope Requirements } \\
\hline Climate Zone & Heating Degree Days & U-Factor & $\begin{array}{l}\text { Ceiling } \\
\text { R-value } \\
\end{array}$ & $\begin{array}{c}\text { Wall } \\
\text { R-value }\end{array}$ & $\begin{array}{c}\text { Slab } \\
\text { R-value }\end{array}$ & $\begin{array}{c}\text { Slab } \\
\text { Depth }\end{array}$ \\
\hline 1 & 0 to 499 & NR & $2.3(13)$ & $1.9(11)$ & $0(0)$ & $0(0)$ \\
\hline 2 & 500 to 999 & $5.1(0.90)$ & $3.4(19)$ & $1.9(11)$ & $0(0)$ & $0(0)$ \\
\hline 3 & 1000 to 1499 & $4.3(0.75)$ & $3.4(19)$ & $1.9(11)$ & $0(0)$ & $0(0)$ \\
\hline 4 & 1500 to 1999 & $4.3(0.75)$ & $4.6(26)$ & $2.3(13)$ & $0(0)$ & $0(0)$ \\
\hline 5 & 2000 to 2499 & $3.7(0.65)$ & $5.3(30)$ & $2.3(13)$ & $0(0)$ & $0(0)$ \\
\hline 6 & 2500 to 2999 & $3.4(0.60)$ & $5.3(30)$ & $2.3(13)$ & $0.7(4)$ & $0.6(2)$ \\
\hline 7 & 3000 to 3499 & $3.1(0.55)$ & $5.3(30)$ & $2.3(13)$ & $0.7(4)$ & $0.6(2)$ \\
\hline 8 & 3500 to 3999 & $2.8(0.50)$ & $5.3(30)$ & $2.3(13)$ & $0.9(5)$ & $0.6(2)$ \\
\hline 9 & 4000 to 4499 & $(0.45)$ & $6.7(38)$ & $2.3(13)$ & $0.9(5)$ & $0.6(2)$ \\
\hline 10 & 4500 to 4999 & $(0.45)$ & $6.7(38)$ & $2.8(16)$ & $1.1(6)$ & $0.6(2)$ \\
\hline 11 & 5000 to 5499 & $(0.45)$ & $6.7(38)$ & $3.2(18)$ & $1.1(6)$ & $0.6(2)$ \\
\hline 12 & 5500 to 5999 & $2.3(0.40)$ & $6.7(38)$ & $3.2(18)$ & $1.6(9)$ & $1.2(4)$ \\
\hline 13 & 6000 to 6499 & $2.0(0.35)$ & $6.7(38)$ & $3.2(18)$ & $1.6(9)$ & $1.2(4)$ \\
\hline 14 & 6500 to 6999 & $2.0(0.35)$ & $8.6(49)$ & $3.7(21)$ & $1.9(11)$ & $1.2(4)$ \\
\hline 15 & 7000 to 8499 & $2.0(0.35)$ & $8.6(49)$ & $3.7(21)$ & $2.3(13)$ & $1.2(4)$ \\
\hline 16 & 8500 to 8999 & $2.0(0.35)$ & $8.6(49)$ & $3.7(21)$ & $2.5(14)$ & $1.2(4)$ \\
\hline 17 & 9000 to 12999 & $2.0(0.35)$ & $8.6(49)$ & $3.7(21)$ & $3.2(18)$ & $1.2(4)$ \\
\hline
\end{tabular}

The values defined in 2003 IECC were simplified in Table 402.1.1 of Chapter 4: Residential Energy Efficiency of newer editions of IECC. Table 3-6 shows the window U-factor and solar heat gain coefficient (SHGC) requirements for 2006 IECC, 2009 IECC, and 2012 IECC.

Although EnergyPlus requires three parameters for defining window performance (U-factor, SHGC, and visual transmittance), IECC only specifies two: U-factor and SHGC. In general, the 
U-factor and SHGC maximum requirements decrease in newer editions of IECC and as the climate zone gets colder. ${ }^{8}$

Table 3-6 2006, 2009, 2012 IECC Energy Code Requirements for Windows

\begin{tabular}{|c|c|c|c|c|c|c|}
\hline \multicolumn{7}{|c|}{ Glazed Fenestration } \\
\hline \multirow[b]{2}{*}{ Climate Zone } & \multicolumn{3}{|c|}{$\begin{array}{l}\text { U-Factor } \\
\left(\mathrm{W} / \mathbf{m}^{2} \cdot \mathbf{K}\right)\end{array}$} & \multicolumn{3}{|c|}{ SHGC } \\
\hline & 2006 & 2009 & 2012 & 2006 & 2009 & 2012 \\
\hline 1 & $6.8(1.2)$ & $6.8(1.2)$ & NR & 0.40 & 0.30 & 0.25 \\
\hline 2 & $4.3(0.75)$ & $3.7(0.65)$ & $2.3(0.40)$ & 0.40 & 0.30 & 0.25 \\
\hline 3 & $3.7(0.65)$ & $2.8(0.50)$ & $2.0(0.35)$ & 0.40 & 0.30 & 0.25 \\
\hline 4 except Marine & $2.3(0.40)$ & $2.0(0.35)$ & $2.0(0.35)$ & $\mathrm{NR}^{*}$ & $\mathrm{NR}^{*}$ & 0.40 \\
\hline 5 and 4 Marine & $2.0(0.35)$ & $2.0(0.35)$ & $1.8(0.32)$ & NR* & $\mathrm{NR}^{*}$ & NR \\
\hline 6 & $2.0(0.35)$ & $2.0(0.35)$ & $1.8(0.32)$ & $\mathrm{NR}^{*}$ & $\mathrm{NR}^{*}$ & NR \\
\hline 7 and 8 & $2.0(0.35)$ & $2.0(0.35)$ & $1.8(0.32)$ & $\mathrm{NR}^{*}$ & $\mathrm{NR}^{*}$ & NR \\
\hline $\begin{array}{l}* \mathrm{NR}=\text { No Requir } \\
* * \text { Conversion: } 5\end{array}$ & nt & $\mathrm{tu} / \mathrm{ll}$ & & & & \\
\hline
\end{tabular}

Table 3-7 shows the ceiling and wall insulation R-value requirements for 2006 IECC, 2009 IECC, and 2012 IECC. The minimum insulation R-value requirements for the exterior walls and ceilings increase for newer editions of IECC and as the climate zone gets colder. The exterior wall R-value ranges from $\mathrm{R}_{\mathrm{SI}}-2.3$ (R-13) to $\mathrm{R}_{\mathrm{SI}}-3.5+0.9 / \mathrm{R}_{\mathrm{SI}}-2.3+1.8(\mathrm{R}-20+5 / \mathrm{R}-13+10)$ (wall cavity + exterior continuous). The first $\mathrm{R}_{\mathrm{SI}}-2.3$ (R-13) is met with high density cavity insulation in the wall cavity. Additional R-value is met by adding rigid insulation to the exterior of the wall. The ceiling R-value requirement ranges from $\mathrm{R}_{\mathrm{SI}}-5.3$ (R-30) to $\mathrm{R}_{\mathrm{SI}}-8.6(\mathrm{R}-49)$. Additional cellulose blown-in insulation is used to reach the required R-value.

\footnotetext{
${ }^{8}$ Visible transmittance values are based on window characteristics defined in the ASHRAE Fundamentals Handbook (2009).
} 
Table 3-7 2006, 2009, 2012 IECC Energy Code Requirements for Exterior Envelope

\begin{tabular}{|c|c|c|c|c|c|c|}
\hline \multicolumn{7}{|c|}{ Insulation R-Values } \\
\hline & \multicolumn{3}{|c|}{ Ceiling } & \multicolumn{3}{|c|}{ Wall } \\
\hline Climate Zone & 2006 & 2009 & 2012 & 2006 & 2009 & 2012 \\
\hline 1 & $5.3(30)$ & $5.3(30)$ & $5.3(30)$ & $2.3(13)$ & $2.3(13)$ & $2.3(13)$ \\
\hline 2 & $5.3(30)$ & $5.3(30)$ & $6.7(38)$ & $2.3(13)$ & $2.3(13)$ & $2.3(13)$ \\
\hline 3 & $5.3(30)$ & $5.3(30)$ & $6.7(38)$ & $2.3(13)$ & $2.3(13)$ & $\begin{array}{c}3.5(20) \text { or } \\
2.3+0.9(13+5)^{* *}\end{array}$ \\
\hline $\begin{array}{l}4 \text { except } \\
\text { Marine }\end{array}$ & $6.7(38)$ & $6.7(38)$ & $8.6(49)$ & $2.3(13)$ & $2.3(13)$ & $\begin{array}{c}3.5(20) \\
\text { or } 2.3+0.9(13+5)^{* *}\end{array}$ \\
\hline 5 and 4 Marine & $6.7(38)$ & $6.7(38)$ & $8.6(49)$ & $\begin{array}{c}\text { (19) or } \\
2.3+0.9(13+5)^{* *}\end{array}$ & $\begin{array}{c}3.5(20) \text { or } \\
2.3+0.9(13+5)^{* *}\end{array}$ & $\begin{array}{c}3.5(20) \\
\text { or } 2.3+0.9(13+5)^{* *}\end{array}$ \\
\hline 6 & $8.6(49)$ & $8.6(49)$ & $8.6(49)$ & $\begin{array}{c}\text { (19) or } \\
2.3+0.9(13+5)^{* *}\end{array}$ & $\begin{array}{c}3.5(20) \text { or } \\
2.3+0.9(13+5)^{* *}\end{array}$ & $\begin{array}{c}3.5+0.9(20+5) \\
\text { or } 2.3+1.8(13+10)^{* *}\end{array}$ \\
\hline 7 and 8 & $8.6(49)$ & $8.6(49)$ & $8.6(49)$ & $3.7(21)$ & $3.7(21)$ & $\begin{array}{c}3.5+0.9(20+5) \\
\text { or } 2.3+1.8(13+10)^{* *} \\
\end{array}$ \\
\hline \multicolumn{7}{|c|}{$\begin{array}{l}* \mathrm{NR}=\mathrm{No} \text { Requirement } \\
* * \text { Internal Cavity Insulation }+ \text { Exterior Continuous Insulation R-values } \\
\text { Note: R-value Units }=\mathrm{m}^{2} \cdot \mathrm{K} / \mathrm{W}\left(\mathrm{ft}^{2}{ }^{20} \mathrm{~F} \cdot \mathrm{h} / \mathrm{Btu}\right)\end{array}$} \\
\hline
\end{tabular}

Table 3-8 shows the slab edge insulation requirements (R-value and depth) for 2006 IECC, 2009 IECC, and 2012 IECC, which are the same for all 3 editions of IECC. $\mathrm{R}_{\mathrm{SI}}-1.8$ (R-10) insulation under the foundation is required in Zone 4 through Zone 8 only, which is met by adding $5.1 \mathrm{~cm}$ ( $2 \mathrm{in}$ ) of extruded polystyrene (XPS) below the slab.

Table 3-8 2006, 2009, 2012 IECC Energy Code Requirements for Foundation

\begin{tabular}{|c|c|c|c|c|c|c|}
\hline \multicolumn{7}{|c|}{ Insulation R-Values } \\
\hline & \multicolumn{3}{|c|}{ Slab Edge } & \multicolumn{3}{|c|}{ Slab Depth } \\
\hline Climate Zone & 2006 & 2009 & 2012 & 2006 & 2009 & 2012 \\
\hline 1 & $0(0)$ & $0(0)$ & $0(0)$ & $0(0)$ & $0(0)$ & $0(0)$ \\
\hline 2 & $0(0)$ & $0(0)$ & $0(0)$ & $0(0)$ & $0(0)$ & $0(0)$ \\
\hline 3 & $0(0)$ & $0(0)$ & $0(0)$ & $0(0)$ & $0(0)$ & $0(0)$ \\
\hline 4 except & $1.8(10)$ & $1.8(10)$ & $1.8(10)$ & $0.61 \mathrm{~m}(2 \mathrm{ft})$ & $0.61 \mathrm{~m}(2 \mathrm{ft})$ & $0.61 \mathrm{~m}(2 \mathrm{ft})$ \\
\hline 5 and 4 Marine & $1.8(10)$ & $1.8(10)$ & $1.8(10)$ & $0.61 \mathrm{~m}(2 \mathrm{ft})$ & $0.61 \mathrm{~m}(2 \mathrm{ft})$ & $0.61 \mathrm{~m}(2 \mathrm{ft})$ \\
\hline 6 & $1.8(10)$ & $1.8(10)$ & $1.8(10)$ & $1.21 \mathrm{~m}(4 \mathrm{ft})$ & $1.21 \mathrm{~m}(4 \mathrm{ft})$ & $1.21 \mathrm{~m}(4 \mathrm{ft})$ \\
\hline 7 and 8 & $1.8(10)$ & $1.8(10)$ & $1.8(10)$ & $1.21 \mathrm{~m} \mathrm{(4 \textrm {ft } )}$ & $1.21 \mathrm{~m}(4 \mathrm{ft})$ & $1.21 \mathrm{~m}(4 \mathrm{ft})$ \\
\hline
\end{tabular}




\subsubsection{Heating, Ventilation, and Air Conditioning Equipment}

The HVAC system in the prototype building design is a single-speed unitary system with an air conditioner with a seasonal energy efficiency ratio (SEER) rating of $13,{ }^{9}$ and a gas furnace with annual fuel utilization efficiency (AFUE) of $78 \%$ (both current minimum federal energy efficiency requirements). No dehumidification option or economizer is included in the system. The supply fan is assumed to cycle, and has a total efficiency of $70 \%$. The supply fan motor efficiency is $90 \%$. The ductwork is assumed to be within the conditioned space, which leads to zero energy loss from the ductwork. This assumption assists in simplifying the model, and will be relaxed in future research to account for split systems and the resulting duct leakage. ${ }^{10}$ For the 2-story prototypes, the first and second floors are assumed to be a single zone, with the HVAC equipment located on the first floor. The thermostat setpoints for all conditioned floor area are based on the standard reference designs defined in 2012 IECC, which are $23.9^{\circ} \mathrm{C}\left(75^{\circ} \mathrm{F}\right)$ cooling and $22.2^{\circ} \mathrm{C}\left(72{ }^{\circ} \mathrm{F}\right)$ heating.

\subsubsection{Outdoor Air Ventilation and Infiltration}

Table 3-9 shows the maximum allowable building envelope infiltration rates for 2003 IECC, 2006 IECC, 2009 IECC, and 2012 IECC. The requirements are defined as the air changes per hour at 50 Pascal (Pa). There were no infiltration testing requirements for 2003 IECC and 2006 IECC.

Table 3-9 IECC Energy Code Requirements for Infiltration

\begin{tabular}{|c|c|c|c|c|}
\hline \multicolumn{5}{|c|}{ Infiltration (Effective Leakage Area - ACH50) } \\
\hline Climate Zone & $\mathbf{2 0 0 3}$ & $\mathbf{2 0 0 6}$ & $\mathbf{2 0 0 9}$ & $\mathbf{2 0 1 2}$ \\
\hline 1 & NR & NR & 7.0 & 5.0 \\
\hline 2 & NR & NR & 7.0 & 5.0 \\
\hline 3 & NR & NR & 7.0 & 3.0 \\
\hline 4 except Marine & NR & NR & 7.0 & 3.0 \\
\hline 5 and 4 Marine & NR & NR & 7.0 & 3.0 \\
\hline 6 & NR & NR & 7.0 & 3.0 \\
\hline 7 and 8 & NR & NR & 7.0 & 3.0 \\
\hline *NR = No Requirement & & \\
\hline
\end{tabular}

\footnotetext{
${ }^{9}$ The 13 SEER rating converts to a Coefficient of Performance (COP) of 3.28 for the EnergyPlus simulation based on the following equation: $C O P=\left(-0.02 * S E E R^{2}+1.12 * S E E R\right) / 3.412$.

${ }^{10}$ The 2009 IECC prescriptive requirements include a duct tightness post-construction test showing duct leakage less than or equal to $226.5 \mathrm{~L} / \mathrm{min}(8 \mathrm{CFM})$ per $9.29 \mathrm{~m}^{2}\left(100 \mathrm{ft}^{2}\right)$ at $25 \mathrm{Pascal}(\mathrm{Pa})$.
} 
The prescriptive maximum air changes per hour at 50 pascals $\left(\mathrm{ACH}_{50}\right)$ specified in Section 402.4.2.1 of the 2009 IECC and 2012 IECC is not defined under normal operating conditions. The air infiltration rate must be converted into effective leakage area (ELA) to represent infiltration in the $E+$ simulation, which requires two conversions. First, the $\mathrm{ACH}_{50}$ is converted into cubic feet per minute at 50 pascals $\left(\mathrm{CFM}_{50}\right)$ based on the following equation from Lawrence Berkeley Laboratory (LBL) (2012).

$$
C F M_{50}=A C H_{50} * \frac{\text { Volume }\left[f t^{3}\right]}{60}
$$

Second, the following equation converts the $\mathrm{CFM}_{50}$ into an ELA.

$$
E L A=\frac{C F M_{50}}{2700} * \frac{c m^{2}}{f t^{2}}
$$

Example: 2009 IECC requirement $\left(7.0 \mathrm{ACH}_{50}\right)$ for 1-story house with $148.6 \mathrm{~m}^{2}\left(1600 \mathrm{ft}^{2}\right)$ of conditioned floor area and $12800 \mathrm{ft}^{3}$ of conditioned space volume.

$$
\begin{gathered}
C F M_{50}=A C H_{50} * \frac{\text { Volume }\left[\mathrm{ft}^{3}\right]}{60}=7 * \frac{12800}{60}=1493 \\
E L A=\frac{C F M_{50}}{2700}=0.55 \mathrm{ft}^{2}=520 \mathrm{~cm}^{2}
\end{gathered}
$$

Previous editions of the IECC do not specify the air infiltration rate. The air infiltration rate for these prototypes will use the following equation from Hendron and Engebrecht (2010), where the ELA is the specific leakage area (SLA) as defined in the 2012 IECC standard reference building design multiplied by the conditioned floor area (CFA). ${ }^{11}$

$$
E L A=S L A * C F A
$$

Table 405.5.2(1) of the 2009 IECC specifies that for "residences with mechanical ventilation that are tested in accordance with ASHRAE 119, Section 5.1, the measured air exchange rate combined with the mechanical ventilation rate...shall not be less than" the ASHRAE 62.2-2010 minimum outdoor air flow rate.

The minimum air exchange rates for the 10 prototypes shown in Table 3-10 are calculated using ASHRAE 62.2-2010 equation 4.1b (liters per second):

$$
0.05 * m^{2}+3.5 *\left(N_{B R}+1\right)
$$

Where $\mathrm{N}_{\mathrm{BR}}=$ number of bedrooms

${ }^{11}$ All values in the same units. 


\section{Table 3-10 62.2-2010 Minimum Air Exchange Rate Requirements}

\begin{tabular}{ccccccc} 
Floors & $\begin{array}{c}\text { Conditioned } \\
\text { Floor Area }\end{array}$ & Bedrooms & \multicolumn{2}{c}{$\begin{array}{c}\text { Conditioned } \\
\text { Volume }\end{array}$} & \multicolumn{3}{c}{$\begin{array}{c}\text { A2.2-2010 } \\
\text { Air Exchange Rate }\end{array}$} \\
& $\mathbf{~ m}^{\mathbf{2}\left(\mathbf{f t}^{\mathbf{2}}\right)}$ & & $\mathbf{m}^{\mathbf{3}}\left(\mathbf{f t}^{\mathbf{3}}\right)$ & $\mathbf{L} / \mathbf{s}$ & $\mathbf{C F M}$ & $\mathbf{A C H}$ \\
1 & $111.9(1205)$ & 3 & $273(9636)$ & 19.6 & 41.5 & 0.15 \\
1 & $148.6(1600)$ & 3 & $362(12796)$ & 21.4 & 45.4 & 0.13 \\
1 & $176.6(1901)$ & 3 & $431(15207)$ & 22.8 & 48.4 & 0.11 \\
1 & $215.8(2323)$ & 3 & $526(18583)$ & 24.8 & 52.5 & 0.10 \\
1 & $292.8(3152)$ & 3 & $714(25213)$ & 28.6 & 60.7 & 0.09 \\
2 & $148.8(1602)$ & 3 & $363(12813)$ & 21.4 & 45.4 & 0.13 \\
2 & $204.9(2205)$ & 3 & $500(17644)$ & 24.2 & 51.4 & 0.10 \\
2 & $251.2(2704)$ & 3 & $613(21631)$ & 26.6 & 56.3 & 0.09 \\
2 & $311.0(3348)$ & 3 & $758(26781)$ & 29.6 & 62.6 & 0.08 \\
2 & $420.2(4523)$ & 3 & $1025(36184)$ & 35.0 & 74.2 & 0.07 \\
\hline
\end{tabular}

For a $148.6 \mathrm{~m}^{2}\left(1600 \mathrm{ft}^{2}\right), 3$ bedroom house, the total outdoor air rate is $0.021 \mathrm{~m}^{3} / \mathrm{s}(45 \mathrm{CFM})$, which converts to $0.13 \mathrm{ACH}$. The 2009 IECC maximum air infiltration rate of $7.0 \mathrm{ACH}_{50}$ can be converted into a relative natural air change per hour $\left(\mathrm{ACH}_{\mathrm{NAT}}\right)$ with the following equation from Environmental Protection Agency (EPA) (2001), where the LBL Factor ranges from 14 to 26 and the Location Factor ranges from 0.72 to 1.00 .

$$
A C H_{N A T}=\frac{A C H_{50}}{\text { LBL Factor } * \text { Location Factor }}
$$

The $\mathrm{ACH}_{\mathrm{NAT}}$ will range between 0.27 and 0.50 for a 2009 IECC design. Since the air infiltration is always greater than the minimum ventilation rate defined in ASHRAE 62.2-2010, no mechanical ventilation is required.

The 2012 IECC requirements of $5.0 \mathrm{ACH}_{50}$ or $3.0 \mathrm{ACH}_{50}$ lead to natural infiltration rates that are lower than the ASHRAE 62.2-2010 minimum outdoor air requirements $(0.19 \mathrm{ACH}$ or $0.50 \mathrm{ACH}$ and $0.12 \mathrm{ACH}$ to $0.30 \mathrm{ACH}$, respectively). As a result, the estimated infiltration from leakage is nearly always greater than the ASHRAE 62.2 required levels, and mechanical ventilation is not likely to be required to reach the outdoor air requirements.

Based on ASHRAE 90.2-2007, an additional 0.15 ACH is added to the model for occupant activity, such as window and door operation and running exhaust fans. ${ }^{12}$

Based on Hendron and Engebrecht (2010) and the 2012 IECC, the attic ventilation for a standard reference building design is used in the model, which is equivalent to 1 unit per 300 units of the ceiling area, which converts to an effective leakage area (ELA) of $4955 \mathrm{~cm}^{2}\left(5.33 \mathrm{ft}^{2}\right)$ for a $148.6 \mathrm{~m}^{2}\left(1600 \mathrm{ft}^{2}\right)$ house.

\footnotetext{
${ }^{12}$ According to the ASHRAE Fundamentals Handbook, "In residences....air exchange associated with a door can be estimated based on air leakage through cracks between door and frame."
} 


\subsubsection{Domestic Hot Water}

The BA Protocol functions from Hendron and Engebrecht (2010), defined in Table 3-11, are used instead of $I E C C$ requirements for a standard reference building design to estimate the hot water consumption of each piece of equipment and activities. Total hot water consumption based on the BA Protocol is 228 liters (60 gallons) for all prototypes. These estimates are used for the analysis because they break down consumption by end use; the IECC estimate is for total hot water consumption only. The clothes washer and dishwasher use only hot water at $48.9^{\circ} \mathrm{C}$ $\left(120^{\circ} \mathrm{F}\right)$ while the showers, baths, and sinks use hot water that is tempered to $43.3^{\circ} \mathrm{C}\left(110^{\circ} \mathrm{F}\right)$, as shown in Table 3-11.

Table 3-11 Hot Water Consumption

\begin{tabular}{lccc}
\hline \multicolumn{1}{c}{ Equipment } & Water Temp. & $\begin{array}{c}\text { Function } \\
\text { Liters (Gallons) }\end{array}$ & $\begin{array}{c}\text { Liters (Gallons) } \\
\text { Per Day }\end{array}$ \\
\hline Clothes Washer & $48.9^{\circ} \mathrm{C}\left(120^{\circ} \mathrm{F}\right)$ & $8.9+3.0 \cdot \mathrm{N}_{\mathrm{BR}}\left(2.35+0.78 \cdot \mathrm{N}_{\mathrm{BR}}\right)$ & $19(5)$ \\
Dishwasher & $48.9^{\circ} \mathrm{C}\left(120^{\circ} \mathrm{F}\right)$ & $8.6+2.8 \cdot \mathrm{N}_{\mathrm{BR}}\left(2.26+0.75 \cdot \mathrm{N}_{\mathrm{BR}}\right)$ & $19(5)$ \\
Showers & $43.3^{\circ} \mathrm{C}\left(110^{\circ} \mathrm{F}\right)$ & $53.0+17.7 \cdot \mathrm{N}_{\mathrm{BR}}\left(14+4.67 \cdot \mathrm{N}_{\mathrm{BR}}\right)$ & $68(18)$ \\
Baths & $43.3^{\circ} \mathrm{C}\left(110^{\circ} \mathrm{F}\right)$ & $13.2+4.4 \cdot \mathrm{N}_{\mathrm{BR}}\left(3.5+1.17 \cdot \mathrm{N}_{\mathrm{BR}}\right)$ & $27(7)$ \\
Sinks & $43.3^{\circ} \mathrm{C}\left(110^{\circ} \mathrm{F}\right)$ & $47.3+15.7 \cdot \mathrm{N}_{\mathrm{BR}}\left(12.5+4.16 \cdot \mathrm{N}_{\mathrm{BR}}\right)$ & $95(25)$ \\
& & & \multicolumn{2}{c}{ Total: } & $228(60)$ \\
\hline
\end{tabular}

The BA Protocol total water use, daily water use load profiles, and sensible (temperature-based) and latent (humidity-based) loads for hot water use are used to estimate the real time hot water use and the resulting internal heat gains. The daily load profile, or proportion of peak flow rate by hour of the day, for each hot water use category can be seen in Figure 3-7. 

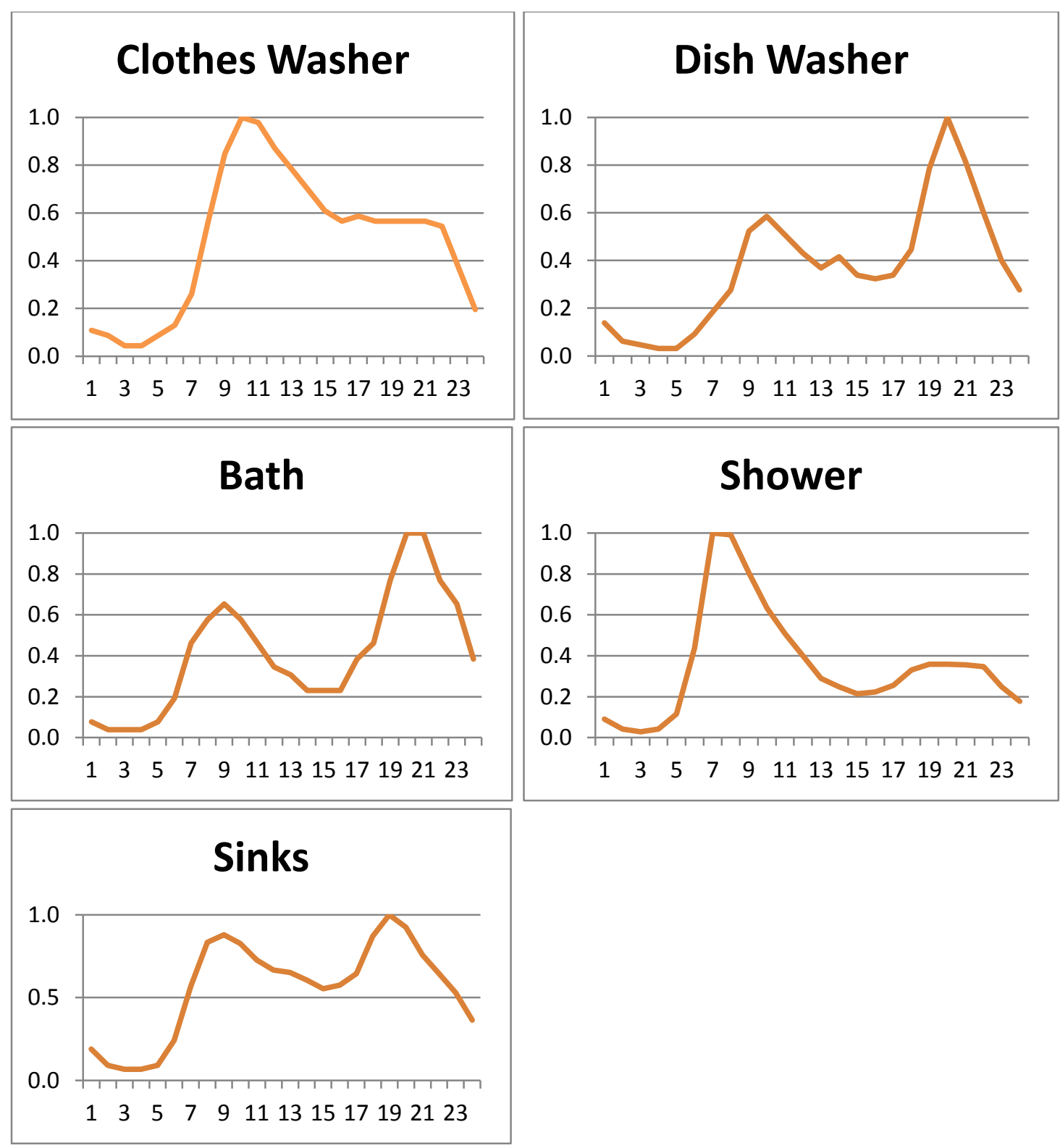

Figure 3-7 Domestic Hot Water Load Profiles as a Proportion of Peak Flow Rate, By Hour

Based on the BA Protocol, internal heat gains from hot water for the clothes washer and dishwasher are assumed to be zero for both sensible and latent loads. Any heat gains for this equipment are included in the equipment electricity use heat gains. The sensible and latent load fractions for shower, bath, and sinks are reverse engineered from internal heat gains estimated using the BA Protocol functions in Table 3-12. 
Table 3-12 Domestic Hot Water Daily Internal Heat Gains

\begin{tabular}{|l|c|c|c|c|c|c|}
\hline \multirow{2}{*}{$\begin{array}{c}\text { Equipment } \\
\text { End Use }\end{array}$} & \multicolumn{3}{|c|}{ Sensible Load } & \multicolumn{3}{c|}{ Latent Load } \\
\cline { 2 - 7 } & $\begin{array}{c}\text { Heat Gain } \\
\text { Function } \\
\text { kWh (Btu) }\end{array}$ & $\begin{array}{c}\text { Heat Gain } \\
\text { kWh (Btu) }\end{array}$ & $\begin{array}{c}\text { Load } \\
\text { Fraction }\end{array}$ & $\begin{array}{c}\text { Heat Gain } \\
\text { Function } \\
\text { kWh (Btu) }\end{array}$ & $\begin{array}{c}\text { Heat Gain } \\
\text { kWh (Btu) }\end{array}$ & $\begin{array}{c}\text { Load } \\
\text { Fraction }\end{array}$ \\
\hline Showers & $\begin{array}{c}0.22+0.07 \cdot \mathrm{N}_{\mathrm{BR}} \\
\left(741+247 \cdot \mathrm{N}_{\mathrm{BR}}\right)\end{array}$ & $0.4(1482)$ & 0.1947 & $\begin{array}{c}0.21+0.07 \cdot \mathrm{N}_{\mathrm{BR}} \\
\left(703+235 \cdot \mathrm{N}_{\mathrm{BR}}\right)\end{array}$ & $0.4(1408)$ & 0.0055 \\
\hline Baths & $\begin{array}{c}0.05+0.02 \cdot \mathrm{N}_{\mathrm{BR}} \\
\left(185+62 \cdot \mathrm{N}_{\mathrm{BR}}\right)\end{array}$ & $0.4(1371)$ & 0.7262 & $0(0)$ & $0(0)$ & 0.0000 \\
\hline Sinks & $\begin{array}{c}0.09+0.03 \cdot \mathrm{N}_{\mathrm{BR}} \\
\left(310+103 \cdot \mathrm{N}_{\mathrm{BR}}\right)\end{array}$ & $0.2(619)$ & 0.0917 & $\begin{array}{c}0.04+0.01 \cdot \mathrm{N}_{\mathrm{BR}} \\
\left(140+47 \cdot \mathrm{N}_{\mathrm{BR}}\right)\end{array}$ & $0.1(281)$ & 0.0012 \\
\hline
\end{tabular}

Based on IECC, the water heater must meet federal energy efficiency requirements. The water heater is assumed to be a gas water heater with a perfectly mixed storage tank and an efficiency of $76 \%,{ }^{13}$ a firing rate based on the number of bedrooms and bathrooms, ${ }^{14}$ and a setpoint temperature of $48.9^{\circ} \mathrm{C}\left(120^{\circ} \mathrm{F}\right)$. The heat loss coefficient from the water heater to the ambient temperature in the internal space is assumed to be $2.1 \mathrm{~W} / \mathrm{K} .{ }^{15}$

\subsubsection{Lighting}

The lighting load profiles and electricity consumption are based on the simplest profile in the BA Protocol, which varies by time of day, but not from day to day. Total electricity use is estimated based on the two-stage process defined in the BA Protocol as expressed in Table 3-13. The baseline lighting estimate is based on $66 \%$ incandescent, $21 \%$ compact fluorescent (CFL), and $13 \%$ T-8 linear fluorescent use. The lighting requirements in 2009 IECC require $50 \%$ high efficiency lights for all hard-wired lighting, which is met by shifting $16 \%$ of all hard-wired lighting from incandescent to CFL. An additional $25 \%$ of incandescent lighting must be shifted to high efficiency lights for all hard-wired lighting to meet the 2012 IECC requirement of $75 \%$. The BA Protocol adjustment functions shown on the right in Table 3-13 are used to adjust the total electricity consumption estimate to represent the greater efficiency required by 2009 IECC (50\% efficient lighting fixtures) and 2012 IECC (75\% efficient lighting fixtures).

\footnotetext{
${ }^{13}$ Minimum federal efficiency requirement for gas water heaters.

${ }^{14}$ Based on the BA Benchmark for a 3 bedroom/2 bathroom house with a gas unit.

${ }^{15}$ Based on NIST expert recommendation.
} 
Table 3-13 Annual Lighting Electricity Consumption

\begin{tabular}{|c|c|c|}
\hline \multirow{2}{*}{$\begin{array}{l}\text { Lighting Use } \\
\text { Category }\end{array}$} & Baseline & Efficiency Conversion \\
\hline & Function & Function \\
\hline Hard-wired & $0.8 \cdot($ CFA $\cdot 0.542+334)$ & 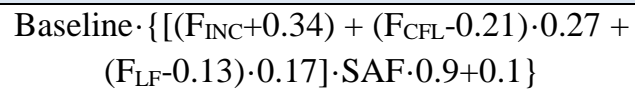 \\
\hline Plug-In & $0.2 \cdot($ CFA $\cdot 0.542+334)$ & \\
\hline Exterior & CFA. 0.145 & $\begin{array}{c}\text { Baseline } \cdot\left\{\left[\left(F_{\mathrm{INC}}+0.34\right)+\left(\mathrm{F}_{\mathrm{CFL}}-0.21\right) \cdot 0.27+\right.\right. \\
\left.\left.\left(\mathrm{F}_{\mathrm{LF}}-0.13\right) \cdot 0.17\right] \cdot 0.9+0.1\right\}\end{array}$ \\
\hline \multicolumn{3}{|c|}{ FINC $=$ Fraction incandescent } \\
\hline \multicolumn{3}{|c|}{$\mathrm{F}_{\mathrm{CFL}}=$ Fraction compact fluorescent } \\
\hline \multicolumn{3}{|c|}{$F_{L F}=$ Fraction linear fluorescent } \\
\hline \multicolumn{3}{|c|}{$\mathrm{SAF}=$ Smart replacement algorithm factor $=1.1 \cdot \mathrm{F}_{\mathrm{Inc}}{ }^{4}-1.9 \cdot \mathrm{F}_{\mathrm{Inc}}{ }^{3}+1.5 \cdot \mathrm{F}_{\mathrm{Inc}}{ }^{2}-0.7 \cdot \mathrm{F}_{\mathrm{Inc}}+1$} \\
\hline
\end{tabular}

The load profile (proportion of peak wattage in use) for interior lighting can be seen in Table 3-14. The total wattage parameter for lighting in $E+$ is reverse engineered from the peak consumption load profile and the total electricity consumption estimate. The load profile for exterior lighting assumes the lights are on sunset to sunrise.

Table 3-14 Lighting Load Profile as Proportion of Peak Wattage in Use, By Hour

\begin{tabular}{|c|c|}
\hline Hour & Load Profile \\
\hline $1: 00$ & 0.067 \\
\hline $2: 00$ & 0.067 \\
\hline $3: 00$ & 0.067 \\
\hline $4: 00$ & 0.067 \\
\hline $5: 00$ & 0.187 \\
\hline $6: 00$ & 0.394 \\
\hline $7: 00$ & 0.440 \\
\hline $8: 00$ & 0.393 \\
\hline $9: 00$ & 0.172 \\
\hline $10: 00$ & 0.119 \\
\hline $11: 00$ & 0.119 \\
\hline $12: 00$ & 0.119 \\
\hline
\end{tabular}

\begin{tabular}{|c|c|}
\hline Hour & Load Profile \\
\hline $13: 00$ & 0.119 \\
\hline $14: 00$ & 0.119 \\
\hline $15: 00$ & 0.119 \\
\hline $16: 00$ & 0.206 \\
\hline $17: 00$ & 0.439 \\
\hline $18: 00$ & 0.616 \\
\hline $19: 00$ & 0.829 \\
\hline $20: 00$ & 0.986 \\
\hline $21: 00$ & 1.000 \\
\hline $22: 00$ & 0.692 \\
\hline $23: 00$ & 0.384 \\
\hline $24: 00$ & 0.16 \\
\hline
\end{tabular}

Monthly multipliers defined in Hendron and Engebrecht (2010) are used to account for the variation across the year in lighting use. The load profile in Table 3-14 is adjusted by the multiplier for each month. 


\subsubsection{Appliances and Miscellaneous Electrical Loads}

The electrical equipment in the house includes a refrigerator, clothes washer, clothes dryer, dishwasher, electric range, and a combination of variable miscellaneous electrical loads (MELs). MELs encompass electronics such as computers, televisions, stereos, and other plug loads. The electricity consumption for each category is based on the BA Protocol functions seen in Table $3-15$. Electricity consumption is usually a function of the number of bedrooms in the home $\left(\mathrm{N}_{\mathrm{BR}}\right)$. The only category that will see a change in electrical consumption over the 10 prototypes is MELs because it includes the conditioned floor area (CFA).

\section{Table 3-15 Appliance and MEL Electricity Consumption}

\begin{tabular}{|l|c|r|}
\hline \multicolumn{1}{|c|}{ Equipment } & Function & kWh \\
\hline Refrigerator & Constant & 434 \\
\hline Clothes Washer & $38.8+12.9 \cdot \mathrm{N}_{\mathrm{BR}}$ & 78 \\
\hline Clothes Dryer & $538.2+179.4 \cdot \mathrm{N}_{\mathrm{BR}}$ & 1076 \\
\hline Dishwasher & $87.6+29.2 \cdot \mathrm{N}_{\mathrm{BR}}$ & 175 \\
\hline Electric Range & $250+83 \cdot \mathrm{N}_{\mathrm{BR}}$ & 499 \\
\hline Variable MELs & $1703+\left(266 \cdot \mathrm{N}_{\mathrm{BR}}\right)+(0.454 \cdot \mathrm{CFA})$ & Varies \\
\hline Source: Hendron and Engebrecht $(2010)$ & \\
\hline
\end{tabular}

The BA Protocol load profiles in Figure 3-8 create a real-time variation in electricity consumption for each category. Appliances such as the electric range and dishwasher have a significant variation in time-of-day use while refrigerator use only varies slightly over a day. The variations are implemented through "schedules" in $E+$. 


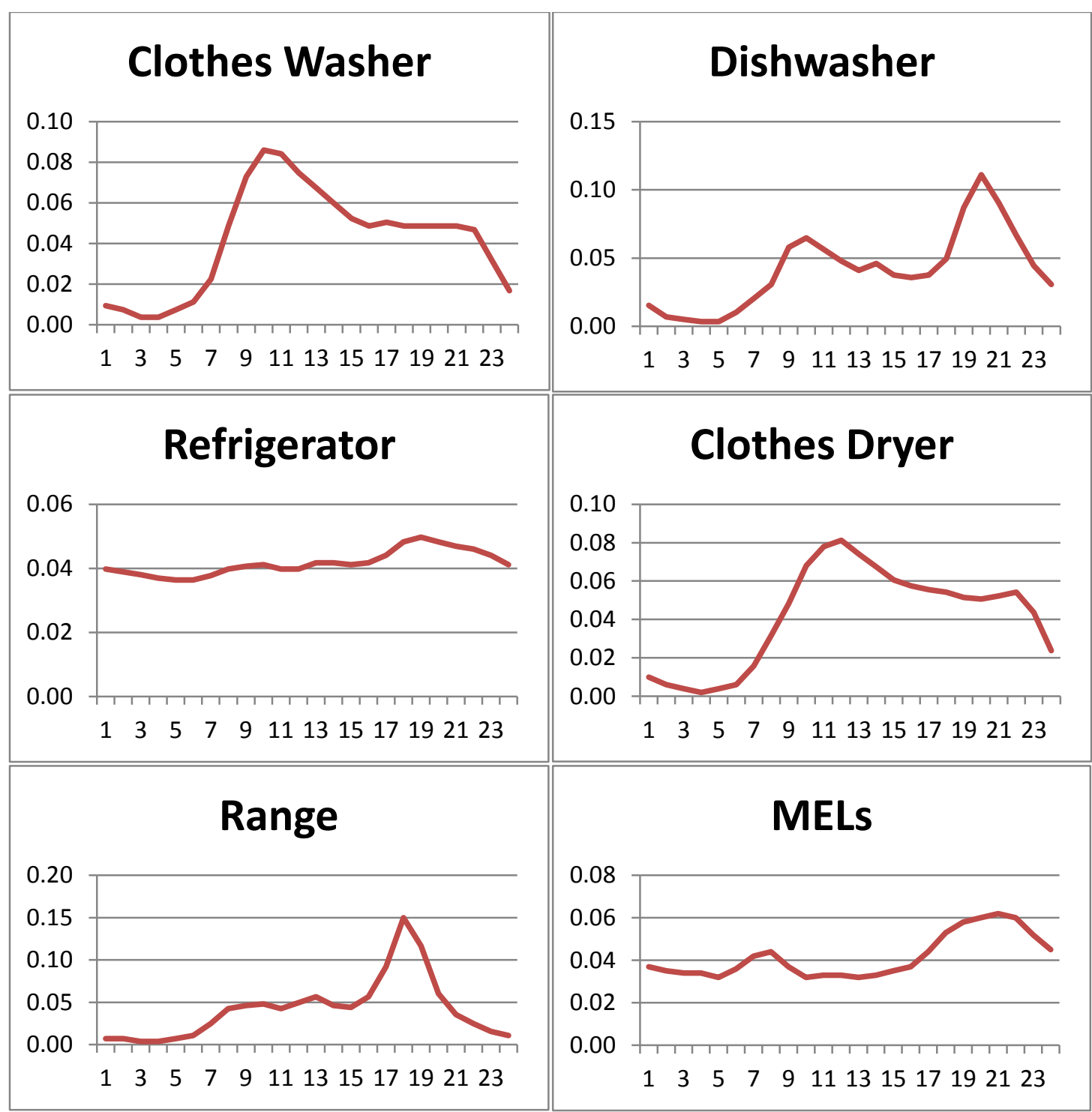

Figure 3-8 Electrical Equipment Load Profiles as a Proportion of Peak Wattage, By Hour

\subsubsection{Internal Mass}

Instead of defining individual interior surfaces and furniture, internal mass is estimated based on ASHRAE 90.2-2007 recommendations. There is assumed to be $3.6 \mathrm{~kg}(8 \mathrm{lb})$ of $5 \mathrm{~cm}(2 \mathrm{in})$ thick wood per square foot of conditioned space for contents. There is assumed to be $2.3 \mathrm{~kg}(5 \mathrm{lb})$ of $1.3 \mathrm{~cm}(0.5 \mathrm{in})$ gypsum wall board (GWB) per square foot of conditioned space for the internal structure.

$E+$ estimates internal mass in terms of square meters of material open to the zone air. Based on the total weight of the two materials (wood and GWB) and their weight per unit of thickness, it is possible to determine the comparable surface area needed to match the amount of internal mass required. Assuming the wood density is equivalent to that of white oak, $753 \mathrm{~kg} / \mathrm{m}^{3}\left(47 \mathrm{lb} / \mathrm{ft}^{3}\right)$, the 
$5 \mathrm{~cm}$ ( 2 in) thick wood weighs $38 \mathrm{~kg} / \mathrm{m}^{2}\left(7.833 \mathrm{lb} / \mathrm{ft}^{2}\right)$. Assuming GWB density of $10 \mathrm{~kg} / \mathrm{m}^{2}$ $\left(2.08 \mathrm{lb} / \mathrm{ft}^{2}\right)$, a total of $357.3 \mathrm{~m}^{2}\left(3846 \mathrm{ft}^{2}\right)$ of structural mass is required to meet the standard recommendation.

\subsubsection{Occupancy}

Occupancy is based on the BA Protocol constant daily occupancy load profile seen in Table 3-16. The profile changes over the hours of the day, but does not vary across days. The house is treated as a single zone with an average internal heat gain of 113 watts per person ( $385.8 \mathrm{Btu} /$ person/hr). The average number of people varies between all three family members being at home during the night to only 0.73 people present during the middle of the day.

Table 3-16 Occupancy Load Profile as a Proportion of Maximum Occupancy and Total Occupants, by Hour

\begin{tabular}{|c|c|c|}
\hline Hour & Load Profile & People \\
\hline $1: 00$ & 1.000 & 3.00 \\
\hline $2: 00$ & 1.000 & 3.00 \\
\hline $3: 00$ & 1.000 & 3.00 \\
\hline $4: 00$ & 1.000 & 3.00 \\
\hline $5: 00$ & 1.000 & 3.00 \\
\hline $6: 00$ & 1.000 & 3.00 \\
\hline $7: 00$ & 1.000 & 3.00 \\
\hline $8: 00$ & 0.883 & 2.65 \\
\hline $9: 00$ & 0.409 & 1.23 \\
\hline $10: 00$ & 0.242 & 0.73 \\
\hline $11: 00$ & 0.242 & 0.73 \\
\hline $12: 00$ & 0.242 & 0.73 \\
\hline
\end{tabular}

\begin{tabular}{|c|c|c|}
\hline Hour & Load Profile & People \\
\hline 13:00 & 0.242 & 0.73 \\
\hline 14:00 & 0.242 & 0.73 \\
\hline 15:00 & 0.242 & 0.73 \\
\hline $16: 00$ & 0.242 & 0.73 \\
\hline $17: 00$ & 0.295 & 0.89 \\
\hline $18: 00$ & 0.553 & 1.66 \\
\hline 19:00 & 0.897 & 2.69 \\
\hline $20: 00$ & 0.897 & 2.69 \\
\hline $21: 00$ & 0.897 & 2.69 \\
\hline $22: 00$ & 1.000 & 3.00 \\
\hline $23: 00$ & 1.000 & 3.00 \\
\hline $24: 00$ & 1.000 & 3.00 \\
\hline
\end{tabular}

\subsubsection{Internal Heat Gains}

Internal heat gains originate from domestic hot water use, electrical equipment use, lighting, and human occupancy. Previous sections have addressed specific internal heat gain categories, but it is of interest to summarize these heat gains and determine if they are comparable to the IECC standard reference design specifications. The total internal heat gains specified by $I E C C$ are based on the following equation from the 2012 IECC standard reference design specifications:

$$
\text { IGain }=17900+23.8 \cdot C F A+29.565 \cdot\left(N_{B R}+1\right)
$$

For the 1-story, $148.6 \mathrm{~m}^{2}\left(1600 \mathrm{ft}^{2}\right)$ prototype, total internal heat gains based on IECC, IGain, should be $20.0 \mathrm{kWh} /$ day (68 $292 \mathrm{Btu} /$ day) for the one-story prototype. The internal heat gains resulting from each category based on an EnergyPlus simulation of the prototype are shown in Table 3-17. The simulated internal heat gains of $19.0 \mathrm{kWh} / \mathrm{day}$ (64 $905 \mathrm{Btu} / \mathrm{day})$ are comparable, 
though slightly lower, than the IECC standard reference design (5\%). The minimal difference shows that the $E+$ model performs similar to the heat gain targets for IECC.

Table 3-17 Daily Heat Gain Comparison-Reference

\begin{tabular}{|l|c|c|c|}
\hline Equipment & $\begin{array}{c}\text { BA Protocol } \\
\mathbf{k W h}(\mathbf{B t u})\end{array}$ & $\begin{array}{c}\text { 2009 IECC } \\
\mathbf{k W h}(\mathbf{B t u})\end{array}$ & $\begin{array}{c}\text { Prototype Design } \\
\mathbf{k W h} \text { (Btu) }\end{array}$ \\
\hline Lighting & Not Specified & Not Specified & $2.7(9266)$ \\
\hline Equipment & $11.2(38142)$ & Not Specified & $10.7(36511)$ \\
\hline Occupancy & $5.6(19140)$ & Not Specified & $5.6(19128)$ \\
\hline Hot Water & $1.2(4161)$ & Not Specified & $1.3(4420)$ \\
\hline Total & Not Specified & $20.0(68292)$ & $19.0(64905)$ \\
\hline
\end{tabular}




\section{Environmental Performance Measurement}

BIRDS evaluates the environmental performance of whole buildings using a life-cycle assessment (LCA) approach, which is based on International Organization for Standardization (ISO) standards. The general LCA methodology involves four steps (ISO 2006). The goal and scope definition step spells out the purpose of the study and its breadth and depth. The inventory analysis step identifies and quantifies the environmental inputs and outputs associated with a building over its entire life-cycle. Environmental inputs include water, energy, land, and other resources; outputs include releases to air, land, and water. However, it is not these inputs and outputs, or inventory flows, which are of primary interest. We are more interested in their consequences, or impacts on the environment. Thus, the next LCA step, impact assessment, characterizes these inventory flows in relation to a set of environmental impacts. For example, the impact assessment step might relate carbon dioxide emissions, a flow, to global warming, an impact. Finally, the interpretation step combines the environmental impacts in accordance with the goals of the LCA study.

\subsection{Goal and Scope Definition}

The goal of BIRDS LCAs is to generate environmental performance scores for a range of U.S. building types, each designed to meet four alternative levels of operating energy efficiency. These results will be reported alongside economic performance scores to help designers, investors, and policymakers develop business cases for high-performance green buildings.

The scoping phase of any LCA involves defining the boundaries of the product system - or, in the case of BIRDS, the building - under study. In traditional bottom-up LCAs, boundary setting requires expert judgment by the analyst. The construction of a building involves a number of unit processes (e.g., asphalt production for input to the manufacture of facing for fiberglass batt insulation). Each unit process involves many inventory flows, some of which themselves involve other, subsidiary unit processes. Because including an ever-expanding number of unit processes in LCAs is not feasible, the product system's supply chain links are truncated at some point to include only those judged to make non-negligible contributions to the product system. The analyst typically uses mass, energy, and/or cost contributions as decision criteria. Use of different boundary setting criteria is one of the main reasons LCA results from different studies are often found incomparable.

One important advantage of the BIRDS hybrid approach is that it addresses the bottom-up issue of truncation in supply chain links, thereby improving consistency in system boundary selections. Through the hybridization process, truncated supply chain links are connected to the background U.S. economic system represented by the top-down data. These linkages follow the metabolic structure of the U.S. economy, thereby benefitting from a more complete system definition including potentially thousands of supply chain interactions. 
Due to their long service lives, buildings are somewhat unique when it comes to the end-of-life stage of the life-cycle. For most non-consumable product LCAs, end-of-life waste flows are included in the inventory analysis for full coverage of the life-cycle. If there is an active recycling market that diverts some of the product from the waste stream, that portion of the product's end-of-life flows can be ignored. In BIRDS, however, a residential building lifetime is 65 years, much longer than the 40-year maximum length for the study period considered in BIRDS. Therefore, $100 \%$ of each building is considered to be "recycled" at the end of the study period and there are no end-of-life waste flows allocated to the building at the end of the BIRDS study period. Rather, end-of-life waste flows should be allocated to a different "product," representing use of the building from the end of the study period to the end of the building service life. Similarly, the environmental burdens from building construction are allocated only to its first use (equally distributed across each year of the selected study period); LCAs for all subsequent uses should be treated as free of these initial construction burdens. This effectively credits the use of existing buildings over new construction and ensures there will be no double counting once existing building LCAs are included in future versions of BIRDS as planned.

Defining the unit of comparison is an important task in the goal and scoping phase of LCA. The basis for all units of comparison is the functional unit, defined so that the systems compared are true substitutes for one another. In the BIRDS model, the functional unit is construction and use of one building prototype over a user-defined study period. The functional unit provides the critical reference point to which the LCA results are scaled.

Scoping also involves setting data requirements. With respect to geographic coverage, the BIRDS inventory data are generally U.S. average data. An exception is made for the electricity production inventory data applied to a building's use of electricity. These data are customized to each U.S. state. In terms of technology coverage, the top-down inventory data represent the mix of technologies in place as of 2002, the year of the most recent top-down data available from the U.S. Economic Census. For the bottom-up inventory data on building energy technologies, the most representative technology for which data are available is evaluated.

\subsection{Life-cycle Inventory Analysis}

BIRDS applies a hybridized life-cycle assessment approach. The approach is hybridized in the sense that a mixture of top-down and bottom-up data are collected and systematically integrated in the inventory analysis LCA step. Traditional process-based LCAs gather data by modeling all the in-scope industrial processes involved in a product's production (raw materials acquisition, materials processing, manufacture, transportation), use, and waste management. For each industrial process, the analyst collects very detailed, bottom-up data on all its inputs from the environment (e.g., materials, fuel, water, land) and outputs to the environment (e.g., products, water effluents, air emissions, waste). This process is summarized in Figure 4-1. 
To address the complexities of a whole building, BIRDS takes a new, multi-layered approach to inventory analysis. Since a building's operating energy efficiency has an important influence on its sustainability performance, and energy efficiency is largely driven by the building's energy technologies, BIRDS pays special attention to the materials used in them. Specifically, BIRDS uses detailed life-cycle inventory data for a range of energy technology packages that have been analyzed at the traditional, bottom-up LCA level. These energy technology packages are used to meet the 4 levels of energy efficiency simulated for each building type in 228 different U.S. locations. The bottom-up approach is also used to gather inventory data for a building's use of electricity and natural gas over the study period. These bottom-up BIRDS data were developed under contract to NIST by Four Elements Consulting, LLC, of Seattle, Washington, and are documented in Section 4.5. For all other building constituents, industry average life-cycle inventory data are gathered from the top-down and then systematically combined with bottom-up data into a comprehensive, hybrid life-cycle inventory for a whole building.

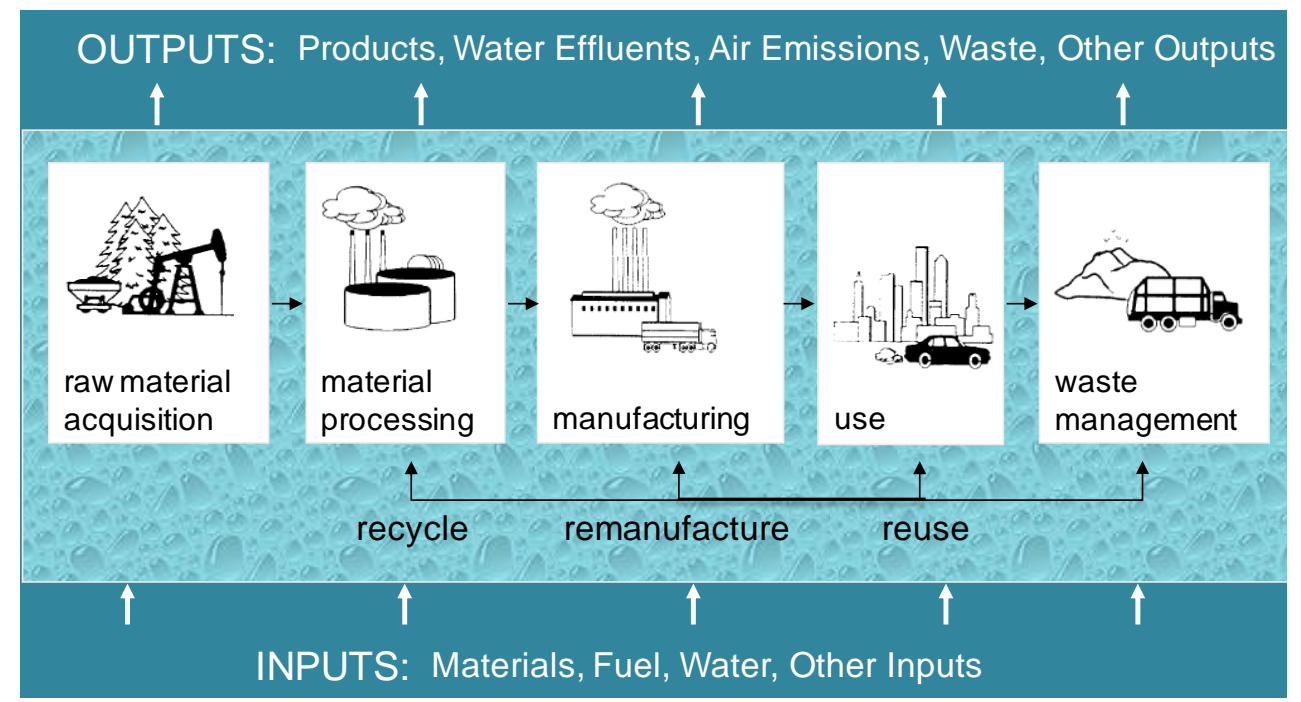

Figure 4-1 Compiling LCA Inventories of Environmental Inputs and Outputs

The inventory data items collected through the bottom-up and top-down approaches are identical — for example, kg carbon dioxide, $\mathrm{kWh}$ primary energy consumption — but some of the data sources are quite different. The systematic hybridization of the data sets bridges these differences to yield coherent and consistent BIRDS life-cycle inventories for a wide variety of new commercial buildings. The LCAs for the buildings are then completed by applying conventional methods of life-cycle impact assessment and interpretation to the hybrid inventory data.

Top-Down Inventory Analysis. An economy's accounting structure provides a cost-effective top-down approach to LCA inventory data collection. Many developed economies maintain economic input-output (I-O) accounts that trace the flow of goods and services throughout industries. Much the same way that a product's production can be traced upstream through its 
supply chain, an industry's production can be traced upstream through its supply chain. The U.S. Census Bureau conducts an Economic Census of U.S. industry every five years that does just that. Covering $97 \%$ of business receipts, the census reaches nearly all U.S. business establishments. Based on the detailed data collected, the U.S. Bureau of Economic Analysis (BEA) creates what are called Input-Output Accounts, or "I-O tables," for the U.S. economy.

The U.S. I-O tables show how around 500 industries provide input to, and use output from, each other to produce Gross Domestic Product (GDP). These tables, for example, can show how \$100 million of U.S. economic output in the residential building construction sector traces back through its direct monetary inputs - from the construction process itself - to its indirect inputs from contributing sectors such as the steel, concrete, lumber, and plastics industries. Economic output from the steel, concrete, lumber, and plastics industries, in turn, can be traced back through those supply chains such as mining, forestry, and fuel extraction. And so on.

While BEA provides these I-O tables in purely monetary terms, academics have successfully developed "environmentally-extended" I-O tables (Suh 2005; Hendrickson 2006; Suh 2010). These top-down tables tap into a wide range of national environmental statistics to associate environmental inputs and outputs with economic activity in industry sectors, including use of raw materials, fuel, water, and land and releases of water effluents, air emissions, and waste. BIRDS uses environmentally-extended I-O tables for the U.S. construction industry developed under contract to NIST by Industrial Ecology Research Services of Goleta, California. These tables are based on the 2007 release of the 2002 BEA I-O data, the latest available, and quantify 6204 environmental inputs and outputs occurring throughout production supply chains.

To understand the contribution of building construction to the nation's environmental footprint (impact), it is useful to focus on the concept of "final demand." The BEA's monetary I-O tables use GDP - the total value of the consumption of goods and services in a year - to measure final demand. This value consists of spending and investment by consumers, businesses, and government, as well as net exports. Since final demand is satisfied through annual productiongoods and services need to be produced before they can be bought - each industry's value-added, or "direct" contribution to GDP, reflects its share of final demand.

The environmentally-extended I-O tables translate economic activity into environmental terms, or monetary GDP into environmental GDP (eGDP). In LCA terms, the construction industry's contribution to eGDP is not limited to the direct impact from value-added construction processes and activities. Its contribution to eGDP also includes the indirect impacts stemming from contributions by upstream construction supply chains up to and including raw materials acquisition. The supply chain relationships built into the environmentally-extended I-O tables enable estimation of construction industry impacts on this cumulative, life-cycle basis. Figure 4-2 illustrates these supply chain relationships for some of the inputs to ready-mix concrete manufacturing, an indirect construction industry input. 


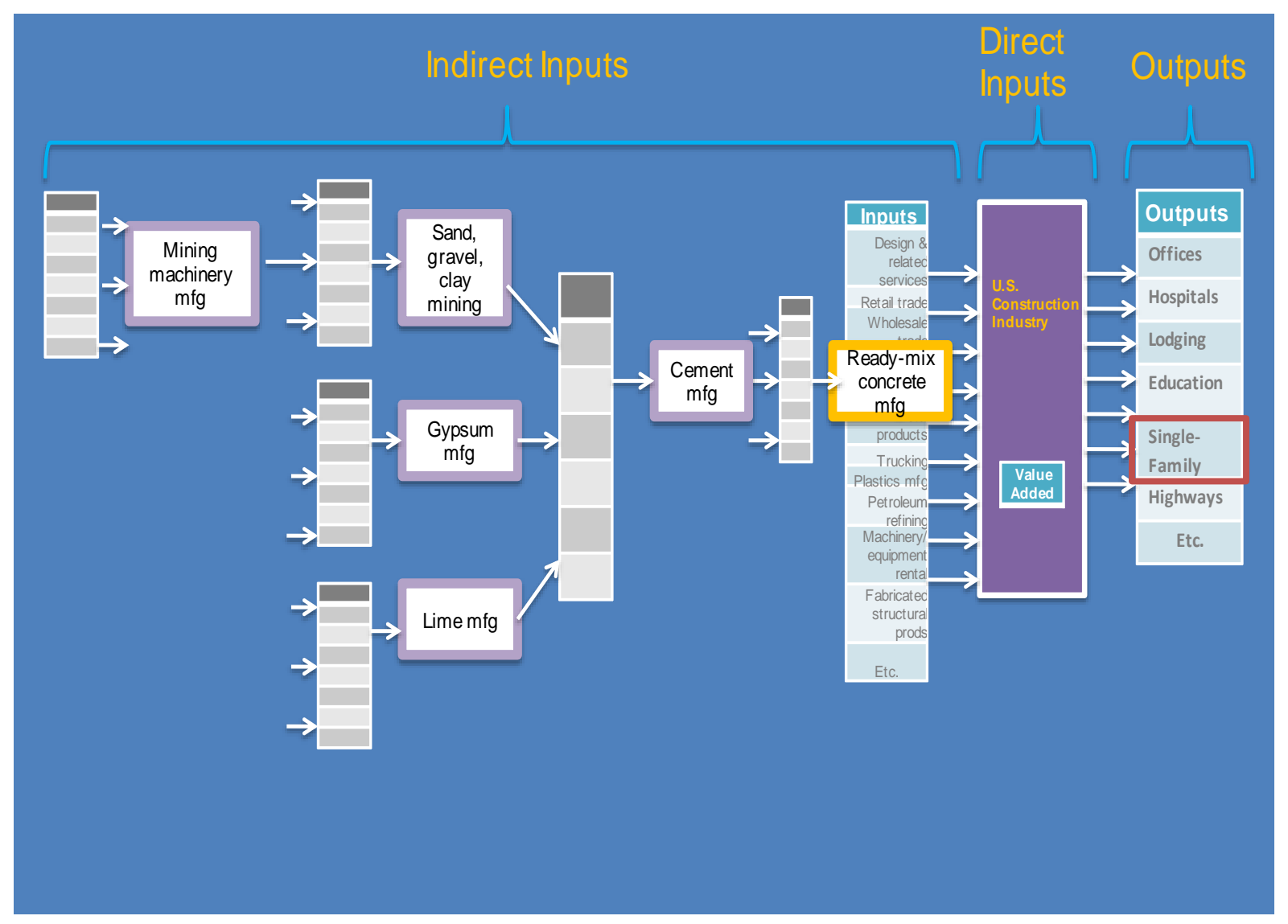

Figure 4-2 Illustration of Supply Chain Contributions to U.S. Construction Industry

The environmentally extended I-O tables classify U.S. construction into 42 distinct industry outputs. In this new residential database of BIRDS, top-down inventory data represent the extended I-O table level of detail for the construction, maintenance, and repair associated with the two residential construction industry outputs shown in Table 4-1. The first output corresponds to the residential new construction. The second corresponds to maintenance and repair $(M \& R)$ activities in residential buildings. For both construction industry outputs, the baseline top-down inventory data are expressed in terms of life-cycle environmental flows per dollar of construction.

Table 4-1 Construction Industry Outputs Mapped to BIRDS Building Types

\begin{tabular}{|l|l|}
\hline Construction Type & \multicolumn{1}{|c|}{ Industry Output } \\
\hline New Construction & New Residential Construction \\
\hline M\&R Construction & Residential maintenance and repair construction \\
\hline
\end{tabular}


One advantage of the BIRDS approach is the economic dimension built into the top-down inventory data. These data are directly associated with U.S. economic data, permitting seamless integration of the economic dimension in the BIRDS sustainability measurement system. The top-down inventory values on a per-dollar basis are multiplied by the corresponding BIRDS construction, maintenance, and repair costs to translate them into the LCA functional unit representing the whole building over a user-defined study period.

For more information on the mathematics, accounting structure, and step-by-step process under which the BIRDS hybrid environmental database is built, see Suh and Lippiatt (2012).

\subsection{Life-cycle Impact Assessment}

Environmental impacts from building construction and use derive from the 6204 inputs and outputs occurring throughout production supply chains, as quantified in the hybrid BIRDS lifecycle inventory. The impact assessment step of LCA quantifies the potential contribution of these inventory items to a range of environmental impacts. The approach preferred by most LCA practitioners and scientists today involves a two-step process:

- Classification of inventory flows that contribute to specific environmental impacts. For example, greenhouse gases such as carbon dioxide, methane, and nitrous oxide are classified as contributing to global warming.

- Characterization of the potential contribution of each classified inventory flow to the corresponding environmental impact. This results in a set of indices, one for each impact, which is obtained by weighting each classified inventory flow by its relative contribution to the impact. For instance, the Global Warming Potential index is derived by expressing each greenhouse gas in terms of its equivalent amount of carbon dioxide heat trapping potential.

There are two general applications of this life-cycle impact assessment (LCIA) approach: midpoint-level and endpoint-level analyses. An endpoint-level analysis attempts to measure the ultimate damage that each environmental input and output in the inventory will have along the cause-effect chain. Methods of this type include just a few impact categories, such as damage to human health, ecosystems, and resource availability, that are easier to interpret in the final step of life-cycle assessment. This approach is criticized for the numerous assumptions, value judgments, and gaps in coverage of the underlying damage models. A midpoint-level analysis, on the other hand, selects points along the cause-effect chain at which more certain and comprehensive assessments may be carried out. While this approach generates many impact categories and makes life-cycle interpretation more difficult, it is more scientifically defensible. Even so, a midpoint-level analysis does not offer the same degree of relevance for all environmental impacts. For global and regional effects (e.g., global warming and acidification) the method provides an accurate description of the potential impact. For impacts dependent upon local conditions (e.g., smog), it may result in an oversimplification of the actual impacts because 
the indices are not tailored to localities. Note that some impact assessments apply a mix of midpoint and endpoint approaches.

\subsubsection{BIRDS Impact Assessment}

BIRDS uses a midpoint-level analysis to translate its 6204 environmental inputs and outputs into a manageable set of science-based measurements across 12 environmental impacts. BIRDS primarily uses the U.S. Environmental Protection Agency's TRACI (Tool for the Reduction and Assessment of Chemical and other environmental Impacts) version 2.0 set of state-of-the-art, peer-reviewed U.S. life-cycle impact assessment methods (Bare 2011). Since TRACI 2.0 does not include land and water use, these two important resource depletion impacts are assessed using other characterization methods (Guinee 2002, Goedkoop 2009). Together these methods are used to develop BIRDS performance metrics indicating the degree to which construction and use of a building contributes to each environmental impact. Following are brief descriptions of the 12 BIRDS impact categories.

\subsubsection{Impact Categories}

Global Warming. The Earth absorbs radiation from the Sun, mainly at the surface. This energy is then redistributed by the atmosphere and ocean and re-radiated to space at longer wavelengths. Some of the thermal radiation is absorbed by "greenhouse" gases in the atmosphere, principally water vapor, but also carbon dioxide, methane, the chlorofluorocarbons, and ozone. The absorbed energy is re-radiated in all directions, downwards as well as upwards, such that the radiation that is eventually lost to space is from higher, colder levels in the atmosphere. The result is that the surface loses less heat to space than it would in the absence of the greenhouse gases and consequently stays warmer than it would be otherwise. This phenomenon, which acts rather like a 'blanket' around the Earth, is known as the greenhouse effect.

The greenhouse effect is a natural phenomenon. The environmental issue is the change in the greenhouse effect due to emissions (an increase in the effect) and absorptions (a decrease) attributable to humans. A general increase in temperature can alter atmospheric and oceanic temperatures, which can potentially lead to alteration of circulation and weather patterns. A rise in sea level is also predicted from an increase in temperature due to thermal expansion of the oceans and melting of polar ice sheets.

Primary Energy Consumption. Primary energy consumption leads to fossil fuel depletion when fossil fuel resources are consumed at rates faster than nature renews them. Some experts believe fossil fuel depletion is fully accounted for in market prices. That is, market price mechanisms are believed to take care of the scarcity issue, price being a measure of the level of depletion of a resource and the value society places on that depletion. However, price is influenced by many factors other than resource supply, such as resource demand and non-perfect markets (e.g., monopolies and subsidies). The primary energy consumption metric is used to account for the resource depletion aspect of fossil fuel extraction. 
Human Health-Criteria Air Pollutants can arise from many activities including combustion, vehicle operation, power generation, materials handling, and crushing and grinding operations. They include coarse particles known to aggravate respiratory conditions such as asthma, and fine particles that can lead to more serious respiratory symptoms and disease.

Human Health-Cancer Effects can arise from exposure to industrial and natural substances, and can lead to illness, disability, and death. Its assessment is based on the global consensus model known as USEtox, which describes the fate, exposure and effects of thousands of chemicals.

Water Consumption. Water resource depletion has not been routinely assessed in LCAs to date, but researchers are beginning to address this issue to account for areas where water is scarce, such as the Western United States. While some studies use water withdrawals to evaluate this impact, a more refined analysis considers that a portion of water withdrawn may be returned through evapotranspiration (the sum of evaporation from surface water, soil, and plant leaves). BIRDS uses the latter approach to measure water consumption, or water withdrawn net of evapotranspiration. BIRDS evaluates water consumption from cradle to grave, including water consumption during building use.

Ecological Toxicity measures the potential of pollutants from industrial sources to harm landand water-based ecosystems. Its assessment is based on the global consensus model known as USEtox, which describes the fate, exposure and effects of thousands of chemicals.

Eutrophication Potential. Eutrophication is the addition of mineral nutrients to the soil or water. In both media, the addition of large quantities of mineral nutrients, such as nitrogen and phosphorous, results in generally undesirable shifts in the number of species in ecosystems and a reduction in ecological diversity. In water, it tends to increase algae growth, which can lead to lack of oxygen and therefore death of species like fish.

Land Use. This impact category measures the use of land resources by humans which can lead to undesirable changes in habitats. Note that the BIRDS land use approach does not consider the original condition of the land, the extent to which human activity changes the land, or the length of time required to restore the land to its original condition. As impact assessment science continues to evolve, it is hoped that these potentially important factors will become part of BIRDS land use assessment.

Human Health-Noncancer Effects can arise from exposure to industrial and natural substances, and range from transient irritation to permanent disability and even death. Its assessment is based on the global consensus model known as USEtox, which describes the fate, exposure and effects of thousands of chemicals.

Smog Formation. Smog forms under certain climatic conditions when air emissions from industry and transportation are trapped at ground level where they react with sunlight. Smog leads to harmful impacts on human health and vegetation. 
Acidification Potential. Acidifying compounds may in a gaseous state either dissolve in water or fix on solid particles. They reach ecosystems through dissolution in rain or wet deposition. Acidification affects trees, soil, buildings, animals, and humans. The two compounds principally involved in acidification are sulfur and nitrogen compounds. Their principal human source is fossil fuel and biomass combustion. Other compounds released by human sources, such as hydrogen chloride and ammonia, also contribute to acidification.

Ozone Depletion, or a thinning of the stratospheric ozone layer, allows more harmful short wave radiation to reach the Earth's surface, potentially causing undesirable changes in ecosystems, agricultural productivity, skin cancer rates, and eye cataracts, among other issues.

\subsubsection{Computational Algorithms}

There are six building components represented in the BIRDS life-cycle impact assessment (LCIA) calculations for whole buildings:

- Baseline building: new construction (Base_New)

- Baseline building: maintenance and repair over study period (Base_M\&R)

- Energy technology package: new construction (ETP_New)

- Energy technology package: annual maintenance and repair (ETP_M\&R)

- Annual operating energy use: electricity (ELEC)

- Annual operating energy use: natural gas (NG)

The hybridized life-cycle inventory data for each component are expressed in different units. For example, the baseline building inventories are given on a per-dollar basis, the energy technology package inventories on a per-physical unit basis (usually area), and the operating energy use inventories on a per-unit of energy basis. Thus, each requires its own LCIA computational algorithm as shown in Table 4-2. These calculations ensure that after adjusting for study period length, all LCIA results are expressed in the consistent functional unit defined for BIRDS: construction and use of one building prototype over a user-defined study period. 
Table 4-2 BIRDS Life-cycle Impact Assessment Calculations by Building Component

\begin{tabular}{|c|c|c|c|c|}
\hline Building & \multicolumn{3}{|c|}{ LCIA Equation } & \multirow{2}{*}{$\begin{array}{l}\text { Notation } \\
\text { LCIA=classified and characterized } \\
\text { life-cycle inventories }\end{array}$} \\
\hline Base_New & $\operatorname{LCIA}_{i, j, \mathrm{c}=1}$ & $=$ & $\left(\operatorname{LCIA}_{\mathrm{i}, \mathrm{j}, \mathrm{c}=1} / \$\right) \cdot \$_{\mathrm{i}, \mathrm{c}=1}$ & \\
\hline Base_M\&R & LCIA $_{\mathrm{i}, \mathrm{j}, \mathrm{c}=2, \mathrm{yr}}$ & $=$ & $\left(\operatorname{LCIA}_{\mathrm{i}, \mathrm{j}, \mathrm{c}=2} / \$\right) \cdot \$_{\mathrm{i}, \mathrm{c}=2, \mathrm{yr}}$ & $\begin{array}{l}\mathrm{c}=\text { construction type code }, 1=\text { new, } \\
2=\mathrm{M} \& \mathrm{R}\end{array}$ \\
\hline ETP_New & $\operatorname{LCIA}_{\mathrm{i}, \mathrm{j}, \mathrm{c}=1, \mathrm{x}, \mathrm{K}, \mathrm{T}}$ & & $\begin{array}{l}\sum\left(\mathrm{LCIA}_{\mathrm{j}, \mathrm{c}=1, \mathrm{ET}(\mathrm{i}, \mathrm{x}, \mathrm{K}, \mathrm{T})} / \mathrm{FU}\right) \cdot \mathrm{FU}_{\mathrm{i}, \mathrm{T}} \\
\text { from } \mathrm{T}=1 \text { to } 6\end{array}$ & $\mathrm{E}=$ electricity \\
\hline ETP_M\&R & $\operatorname{LCIA}_{\mathrm{i}, \mathrm{j}, \mathrm{c}=2, \mathrm{x}, \mathrm{K}, \mathrm{T}} / \mathrm{yr}$ & $=$ & $\begin{array}{l}\sum\left(\mathrm{LCIA}_{\mathrm{j}, \mathrm{c}=2, \mathrm{ET}(\mathrm{i}, \mathrm{x}, \mathrm{K}, \mathrm{T})} / \mathrm{FU} / \mathrm{yr}\right) \cdot \mathrm{FU}_{\mathrm{i}, \mathrm{T}} \\
\text { from } \mathrm{T}=1 \text { to } 6\end{array}$ & ET=energy technology product \\
\hline ELEC & $\operatorname{LCIA}_{\mathrm{i}, \mathrm{j}, \mathrm{x}, \mathrm{K}} / \mathrm{yr}$ & $=$ & $\left(\mathrm{LCIA}_{\mathrm{j}, \mathrm{s}} / \mathrm{BTU}_{\mathrm{E}}\right) \cdot\left(\mathrm{BTU}_{\mathrm{E}, \mathrm{i}, \mathrm{x}, \mathrm{K}} / \mathrm{yr}\right)$ & $\mathrm{FU}=$ functional unit ${ }^{*}$ \\
\hline NG & $\operatorname{LCIA}_{\mathrm{i}, \mathrm{j}, \mathrm{x}, \mathrm{K}} / \mathrm{yr}$ & $=$ & $\left(\mathrm{LCIA}_{\mathrm{j}} / \mathrm{BTU}_{\mathrm{NG}}\right) \cdot\left(\mathrm{BTU}_{\mathrm{NG}, \mathrm{i}, \mathrm{x}, \mathrm{K}} / \mathrm{yr}\right)$ & $\begin{array}{l}\mathrm{i}=\text { building type, } \mathrm{i}=1 \text { to } 11 \\
\mathrm{j}=\text { environmental impact, } \mathrm{j}=1 \text { to } 12 \\
\mathrm{~K}=\text { energy standard, } \mathrm{K}=1 \text { to } 5 \\
\mathrm{n}=\text { study period length in years, } \mathrm{n}=1 \\
\text { to } 40 \\
\mathrm{NG}=\text { natural gas } \\
\mathrm{s}=\mathrm{U} . \mathrm{S} \text {. state, } \mathrm{s}=1 \text { to } 50 \\
\mathrm{~T}=\text { energy technology group, } \mathrm{T}=1 \text { to } \\
6^{*} \\
\mathrm{x}=\text { building location, } \mathrm{x}=1 \text { to } 228\end{array}$ \\
\hline
\end{tabular}

\subsubsection{BIRDS Normalization}

Once impacts have been classified and characterized, the resulting LCIA metrics are expressed in incommensurate units. Global warming is expressed in carbon dioxide equivalents, acidification in hydrogen ion equivalents, eutrophication in nitrogen equivalents, and so on. In order to assist in the next LCA step, interpretation, these metrics are often placed on the same scale through normalization.

The U.S. EPA has developed "normalization references" corresponding to its TRACI set of impact assessment methods (Bare et al. 2006). These U.S. data are updated and expanded for use in BIRDS. Shown in Table 4-3, these values quantify the U.S. economy's annual contributions to 
each impact category. As such, they represent a "U.S. impact yardstick" against which to evaluate the significance of building-specific impacts. Normalization is accomplished by dividing BEES building-specific impact assessment results by the fixed U.S.-scale normalization references, expressed in the same units, yielding an impact category score for a building that has been placed in the context of annual U.S. contributions to that impact. By placing each buildingspecific impact result in the context of its associated U.S. impact result, the measures are all reduced to the same scale, allowing comparison across impacts.

\section{Table 4-3 BIRDS Normalization References}

\begin{tabular}{|c|c|c|}
\hline Impact Category & $\begin{array}{r}\text { Normalizati } \\
\text { reference }\end{array}$ & Units \\
\hline Global Warming & $7.16 \mathrm{E}+12$ & $\mathrm{~kg}$ carbon dioxide equivalents \\
\hline Primary Energy Consumption & $\begin{array}{l}3.52 \mathrm{E}+13 \\
(1.20 \mathrm{E}+14)\end{array}$ & $\begin{array}{l}\mathrm{kWh} \\
(\mathrm{kBTU})\end{array}$ \\
\hline HH Criteria Air & $2.24 \mathrm{E}+10$ & $\begin{array}{l}\mathrm{kg} \text { particulate matter } 10 \text { equivalents } \\
(\mathrm{PM} 10=\text { particulate matter }<10 \text { microns })\end{array}$ \\
\hline HH Cancer & $1.05 \mathrm{E}+04$ & comparative human toxicity units \\
\hline Water Consumption & $1.69 \mathrm{E}+14$ & $\mathrm{~L}$ \\
\hline Ecological Toxicity & $3.82 \mathrm{E}+13$ & comparative ecotoxicity units \\
\hline Eutrophication & $1.01 \mathrm{E}+10$ & $\mathrm{~kg}$ nitrogen equivalents \\
\hline Land Use & $\begin{array}{l}7.32 \mathrm{E}+08 \\
(1.81 \mathrm{E}+09)\end{array}$ & $\begin{array}{l}\text { hectare } \\
\text { (acre) }\end{array}$ \\
\hline HH Noncancer & $5.03 \mathrm{E}+05$ & comparative human toxicity units \\
\hline Smog Formation & $4.64 \mathrm{E}+11$ & kg ozone equivalents \\
\hline Acidification & $1.66 \mathrm{E}+12$ & moles hydrogen ion equivalents \\
\hline Ozone Depletion & $5.10 \mathrm{E}+07$ & $\begin{array}{l}\text { kg CFC-11 equivalents (CFC-11 = } \\
\text { trichlorofluoromethane) }\end{array}$ \\
\hline
\end{tabular}

Normalized BIRDS impact scores have powerful implications. By evaluating a building's impacts with reference to their importance in a larger context, an impact to which one building 
design contributes little will not appear important when, by comparison, competing designs contribute even less to that impact.

\subsection{Life-cycle Interpretation}

At the BIRDS LCA interpretation step, a building's normalized impact scores are evaluated. The midpoint-level impact assessment yields scores for twelve impact categories, making interpretation at this level difficult. To enable comparisons across buildings, the scores across impact categories may be synthesized. Note that in BIRDS, synthesis of impact scores is optional.

Impact scores may be synthesized by weighting each impact category by its relative importance to overall environmental performance, then computing the weighted average impact score. In the BIRDS software, the set of importance weights is selected by the user. Several alternative weight sets are provided as guidance, and may be either used directly or as a starting point for developing user-defined weights. The alternative weights sets are based on an EPA Science Advisory Board study, a BEES Stakeholder Panel's structured judgments, a set of equal weights, and a set exclusively focusing on the global warming impact, representing a spectrum of ways in which people value diverse aspects of the environment.

\subsubsection{EPA Science Advisory Board Study}

In 1990 and again in 2000, EPA's Science Advisory Board (SAB) developed lists of the relative importance of various environmental impacts to help EPA best allocate its resources. (U.S. EPA 1990, 2000). The following criteria were used to develop the lists:

- The spatial scale of the impact

- The severity of the hazard

- The degree of exposure

- The penalty for being wrong

Ten of the twelve BIRDS impact categories were covered by the SAB lists of relative importance:

- Highest-Risk Problems: global warming, land use

- High-Risk Problems: ecological toxicity, human health (cancer and noncancer effects)

- Medium-Risk Problems: ozone depletion, smog, acidification, eutrophication, human health-criteria air pollutants

The SAB did not explicitly consider primary energy consumption or water consumption. For this exercise, these impacts are assumed to be relatively medium-risk and low-risk problems, respectively, based on other relative importance lists. (Levin 1996). 
Verbal importance rankings, such as "highest risk," may be translated into numerical importance weights by following ASTM International standard guidance for applying a Multiattribute Decision Analysis method known as the Analytic Hierarchy Process (AHP) (ASTM 2011). The AHP methodology suggests the following numerical comparison scale:

1 Two impacts contribute equally to the objective (in this case environmental performance)

3 Experience and judgment slightly favor one impact over another

5 Experience and judgment strongly favor one impact over another

7 One impact is favored very strongly over another, its dominance demonstrated in practice

9 The evidence favoring one impact over another is of the highest possible order of affirmation

$2,4,6$, and 8 can be selected when compromise between values of $1,3,5,7$, and 9 , is needed.

Through an AHP process known as pairwise comparison, numerical comparison values are assigned to each possible pair of environmental impacts. Relative importance weights can then be derived by computing the normalized eigenvector of the largest eigenvalue of the matrix of pairwise comparison values. Table 4-4 and Table 4-5 list the pairwise comparison values assigned to the verbal importance rankings, and the resulting SAB importance weights computed for the BIRDS impacts, respectively. Note that the pairwise comparison values were assigned through an iterative process based on NIST's background and experience in applying the AHP technique. Furthermore, while the SAB evaluated cancer and noncancer effects as a group, the resulting $13 \%$ weight was apportioned between the two based on the relative judgments of the BEES Stakeholder Panel discussed in the next section.

Table 4-4 Pairwise Comparison Values for Deriving Impact Category Importance Weights

\begin{tabular}{lc}
\hline $\begin{array}{c}\text { Verbal Importance } \\
\text { Comparison }\end{array}$ & $\begin{array}{c}\text { Pairwise } \\
\text { Comparison Value }\end{array}$ \\
\hline Highest vs. Low & 6 \\
Highest vs. Medium & 3 \\
\hline Highest vs. High & 1.5 \\
\hline High vs. Low & 4 \\
\hline High vs. Medium & 2 \\
\hline Medium vs. Low & 2 \\
\hline
\end{tabular}




\section{Table 4-5 Relative Importance Weights based on Science Advisory Board Study}

\begin{tabular}{lc}
\hline Impact Category & $\begin{array}{c}\text { Relative Importance } \\
\text { Weight (\%) }\end{array}$ \\
\hline Global Warming & 18 \\
\hline Primary Energy Consumption & 7 \\
\hline HH Criteria Air & 8 \\
\hline HH Cancer & 3 \\
\hline Water Consumption & 12 \\
\hline Ecological Toxicity & 5 \\
\hline Eutrophication & 18 \\
\hline Land Use & 5 \\
\hline HH Noncancer & 7 \\
\hline Smog Formation & 5 \\
\hline Acidification & 5 \\
\hline Ozone Depletion & \\
\hline
\end{tabular}

\subsubsection{BEES Stakeholder Panel Judgments}

While the derived EPA SAB-based weight set is helpful and offers expert guidance, several interpretations and assumptions were required in order to translate $\mathrm{SAB}$ findings into numerical weights for interpreting LCA-based analyses. A more direct approach to weight development would consider a closer match to the context of the application; that is, environmentally preferable purchasing in the United States based on life-cycle impact assessment results, as reported by BIRDS.

In order to develop such a weight set, NIST assembled a volunteer stakeholder panel that met at its facilities in Gaithersburg, Maryland, for a full day in May 2006. To convene the panel, invitations were sent to individuals representing one of three "voting interests:" producers (e.g., building product manufacturers), users (e.g., green building designers), and LCA experts. Nineteen individuals participated in the panel: seven producers, seven users, and five LCA experts. These "voting interests" were adapted from the groupings ASTM International employs for developing voluntary standards, in order to promote balance and support a consensus process.

The BEES Stakeholder Panel was led by Dr. Ernest Forman, founder of the AHP firm Expert Choice Inc. Dr. Forman facilitated panelists in weighting the BEES impact categories using the 
AHP pairwise comparison process. The panel weighted all impacts in the Short Term (0 years to 10 years), Medium Term (10 years to 100 years), and Long Term ( $>100$ years). One year's worth of U.S. flows for each pair of impacts was compared, with respect to their contributions to environmental performance. For example, for an impact comparison over the Long Term, the panel was evaluating the effect that this year's U.S. emissions would have more than 100 years hence.

Once the panel pairwise-compared impacts for the three time horizons, its judgments were synthesized across these time horizons. Note that when synthesizing judgments across voting interests and time horizons, all panelists were assigned equal importance, while the short, medium, and long-term time horizons were assigned by the panel to carry $24 \%, 31 \%$, and $45 \%$ of the weight, respectively.

The environmental impact importance weights developed through application of the AHP technique at the facilitated BEES Stakeholder Panel event are shown in Table 4-6. These weights reflect a synthesis of panelists' perspectives across all combinations of stakeholder voting interest and time horizon. The weight set draws on each panelist's personal and professional understanding of, and value attributed to, each impact category. While the synthesized weight set may not equally satisfy each panelist's view of impact importance, it does reflect contemporary values in applying LCA to real world decisions. This synthesized BEES Stakeholder Panel weight set is offered as an option in BIRDS online.

The panel's application of the AHP process to derive environmental impact importance weights is documented in an appendix to ASTM (2011) and in Gloria et al. (2007). 
Table 4-6 Relative Importance Weights based on BEES Stakeholder Panel Judgments

\begin{tabular}{lr}
\hline Impact Category & $\begin{array}{r}\text { Relative Importance } \\
\text { Weight }(\%)\end{array}$ \\
\hline Global Warming & 29.9 \\
\hline Primary Energy Consumption & 10.3 \\
\hline HH Criteria Air & 9.3 \\
\hline HH Cancer & 8.2 \\
\hline Water Consumption & 8.2 \\
\hline Ecological Toxicity & 7.2 \\
\hline Eutrophication & 6.2 \\
\hline Land Use & 6.2 \\
\hline HH Noncancer & 5.2 \\
\hline Smog Formation & 4.1 \\
\hline Acidification & 3.1 \\
\hline Ozone Depletion & 2.1 \\
\hline $\begin{array}{l}\text { Note: Since BIRDS does not currently include an Indoor Air } \\
\text { weight has been redistributed among the remaining 12 impacts. }\end{array}$ \\
\hline
\end{tabular}

The three figures below display in graphical form the BEES Stakeholder Panel weights used in BIRDS. Figure 4-3 displays the synthesized weight set, Figure 4-4 the weights specific to panelist voting interest, and Figure 4-5 the weights specific to time horizon. The BIRDS user is free to interpret results using either of the weight sets displayed in Figure 4-4 and Figure 4-5 by entering them as a user-defined weight set. 


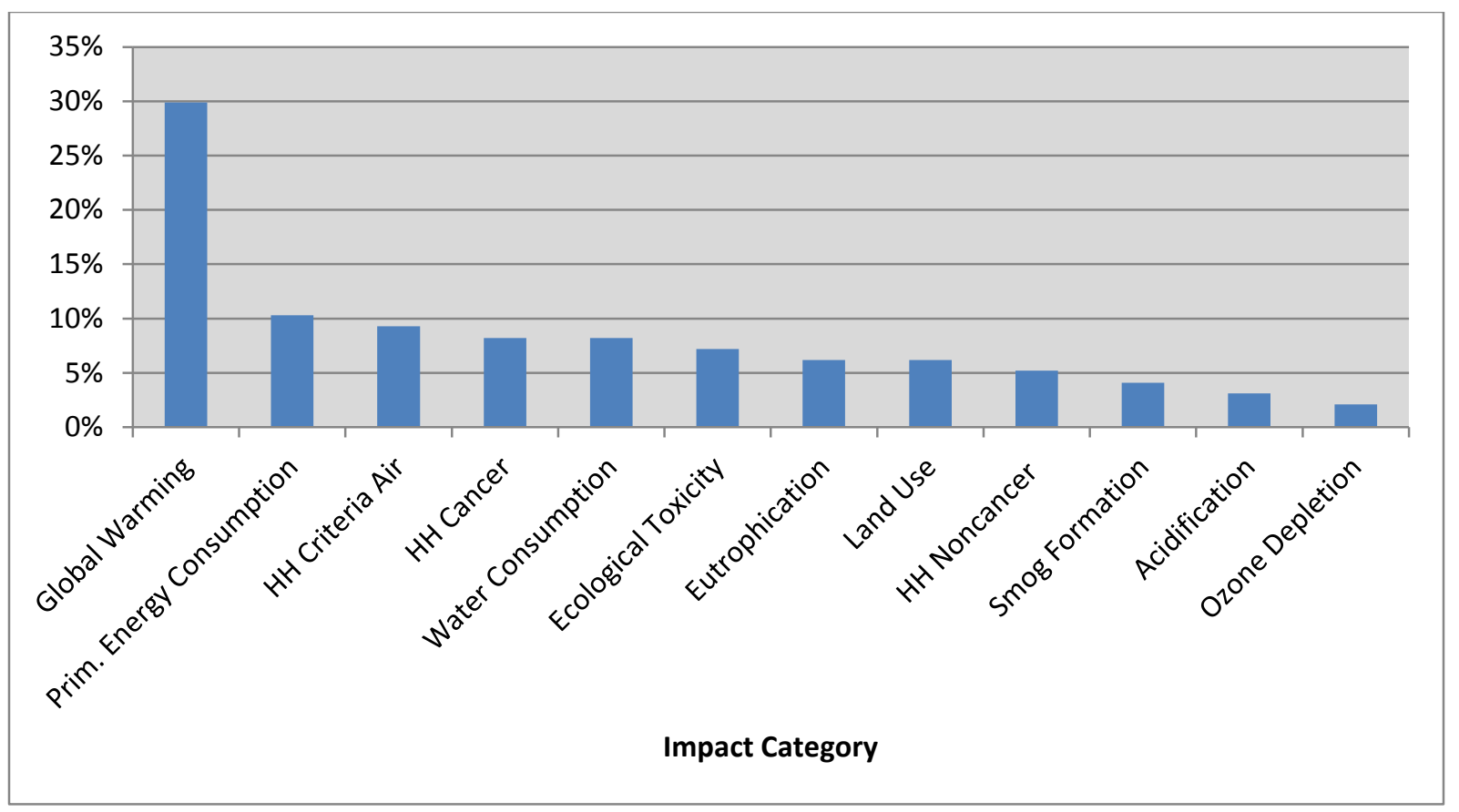

Figure 4-3 BEES Stakeholder Panel Importance Weights Synthesized across Voting Interest and Time Horizon

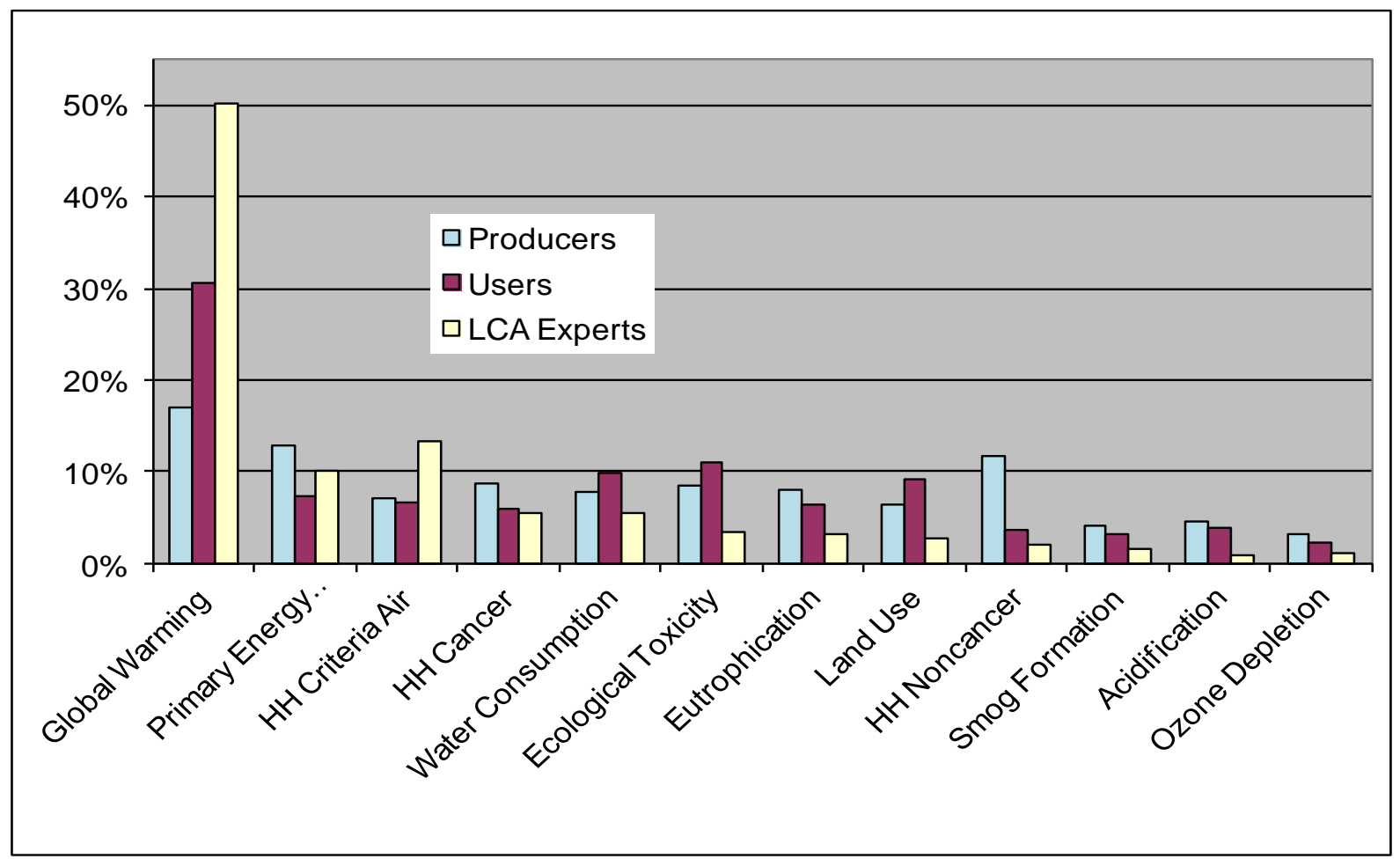

Figure 4-4 BEES Stakeholder Panel Importance Weights by Stakeholder Voting Interest 


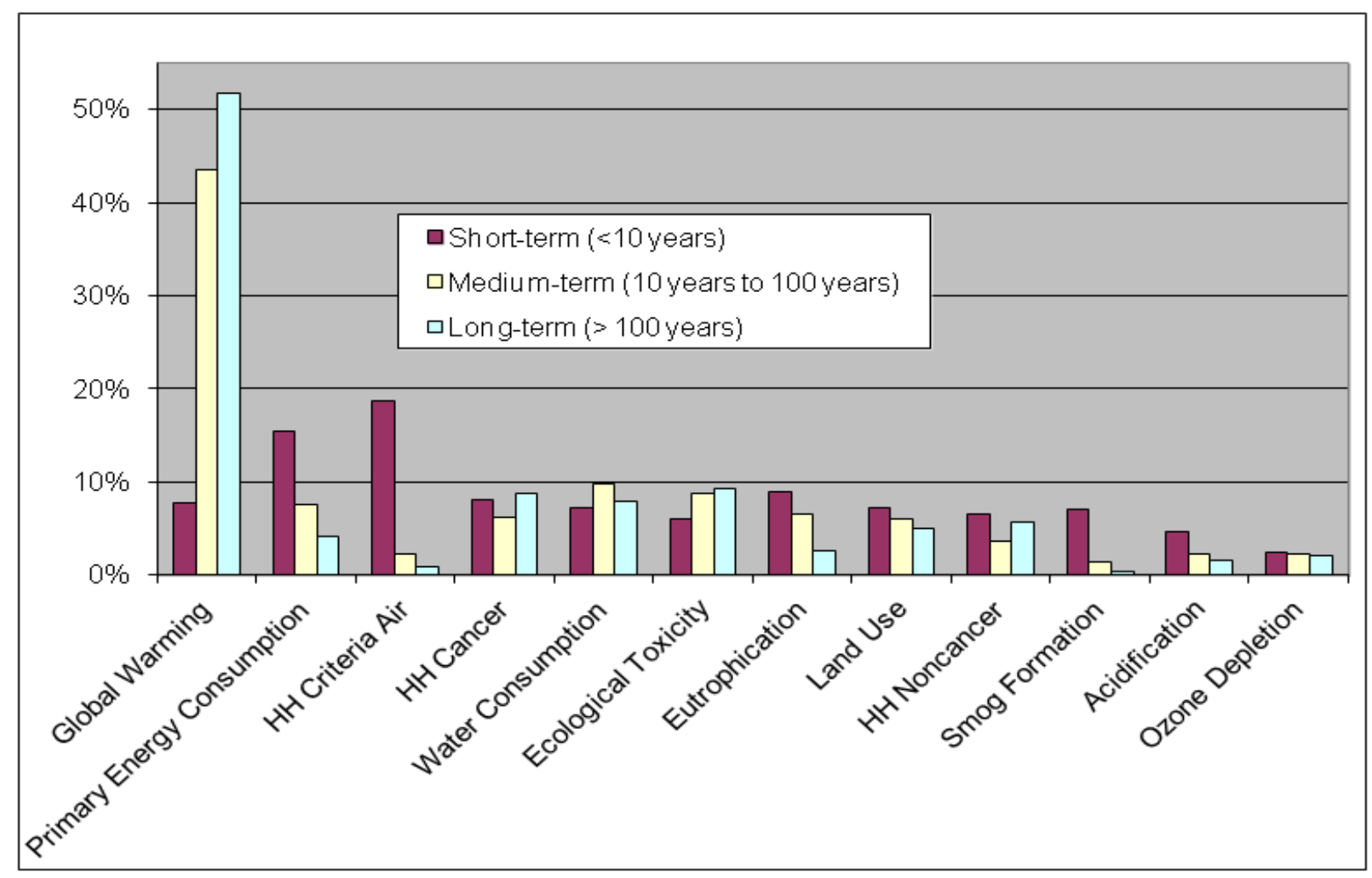

Figure 4-5 BEES Stakeholder Panel Importance Weights by Time Horizon

\subsection{BIRDS Residential Energy Technologies}

Since buildings have very long lives, operating energy efficiency has an important influence on their sustainability performance. Energy efficiency is largely driven by a building's energy technologies, but top-down inventory data are not readily available at this level of resolution. Therefore, BIRDS includes detailed life-cycle inventory data for a range of energy technology packages that have been compiled at the traditional, bottom-up LCA level. These energy technology packages are used to meet the 4 levels of energy efficiency based on the IECC for Residential Buildings simulated for each of 10 building types in 228 different U.S. locations. The bottom-up BIRDS data were developed under contract to NIST by Four Elements Consulting, LLC, of Seattle, Washington. Energy technologies include wall and ceiling insulation, windows, HVAC equipment, water heaters, lighting, and interior and exterior sealants.

\subsubsection{General Information Regarding the Energy Technology LCIs}

\subsubsection{Standards Used}

The LCAs in BIRDS have been built based on the principles and framework in the ISO 14040 (2006a) and the guidelines specified in ISO 14044 (2006b).

\subsubsection{Primary and Secondary Data Sources}


Both primary data (collected directly from a manufacturing facility) and secondary data (publicly-available literature sources) can be used to build LCAs, and it is common to see a combination of both data types based on the desire for organizations or companies to disclose data pertaining to their data. Sources of data on the energy technologies in BIRDS vary from one category to the next, and within categories themselves for the different products. Data were based on one or more of the following:

- Primary data from a group of companies and/or an industry association, compiled into an industry average product;

- Primary data on a product provided by one company;

- Secondary data that represent an average or typical product; and/or

- Secondary data that represent one product in a category.

For optimal data quality, the preference is to have the most representative data - temporally, technologically, and geographically - on a product or system, so that the model produced most closely represents the product. But this is often not possible to achieve due to data constraints. It is also not always possible to have a data set that represents an entire category of products. For example, high quality, current, company-specific data might be collected and used to build the LCA for a given product. Likewise, data for another product might be compiled from literature sources due to lack of other available data. In both cases, the LCI profiles may be being used to represent the full product category, even though they may not be representative of all products within the category, based on market share, technology, geographical location, etc. The reader should be aware of this limitation.

\subsubsection{Data Sources Used for the Background Data}

Secondary data have been applied to production of material inputs, production and combustion of fuels used for process energy, and transportation processes. The U.S. LCI Database (NREL, 2005-present, hereinafter referred to as "U.S. LCI Database") and the ecoinvent Data v.2.2 database (ecoinvent 2007) are the main sources of background data throughout the various lifecycle stages. Other sources of data are used where data were not available from U.S. LCI Database or ecoinvent, and/or where they were deemed to be of better quality than these sources.

The following subsections describe modeling, assumptions, and data sources of the product lifecycle data. Data for the production of material inputs for each product are described in the subchapters since these may vary for different industries. The following data aspects are consistent for all products except where noted differently in the subchapters:

- All energy production, including production of fuels and conversion into energy and electricity production come from the U.S. LCI Database.

- All transportation data come from the U.S. LCI Database. 
- Where possible, where ecoinvent or other non-North American data sets were used, they were customized into North American processes by switching out foreign energy, electricity, transportation, and other processes for comparable North American based data sets from the U.S. LCI databases. Exceptions to this are noted.

- Data for parts forming, e.g., forming of metal parts and pieces, injection molding of plastic parts, etc., are modeled with raw materials production. Most of these data come from ecoinvent.

\subsubsection{Wall and Ceiling Insulation}

The insulation categories considered for the residential walls and ceilings are presented in Table 4-7. BIRDS performance data for the insulation types was provided on the basis of $2.54 \mathrm{~cm}$ (1 in) or $0.09 \mathrm{~m}^{2}\left(1 \mathrm{ft}^{2}\right)$, which was then multiplied by the area and required thickness to meet the requirements of the home's design and energy code edition. Table 4-7 presents the thermal resistance in $\mathrm{R}_{\mathrm{SI}}$-value per-cm ( $\mathrm{R}$-value per in) for each.

Table 4-7 Specified Insulation Types and R-Values

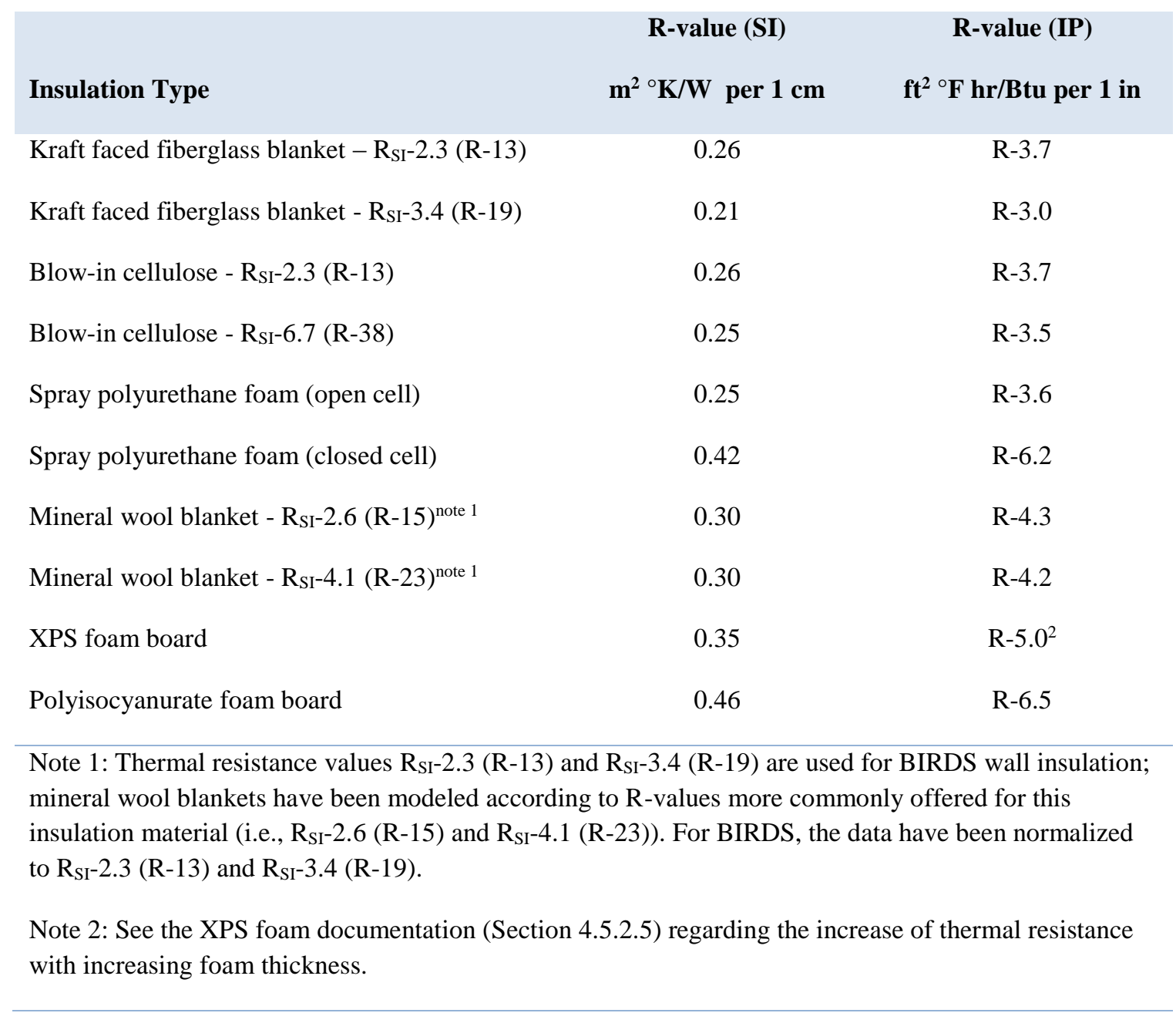


Figure 4-6 presents the general system boundaries for the insulation category as it is modeled for BIRDS.

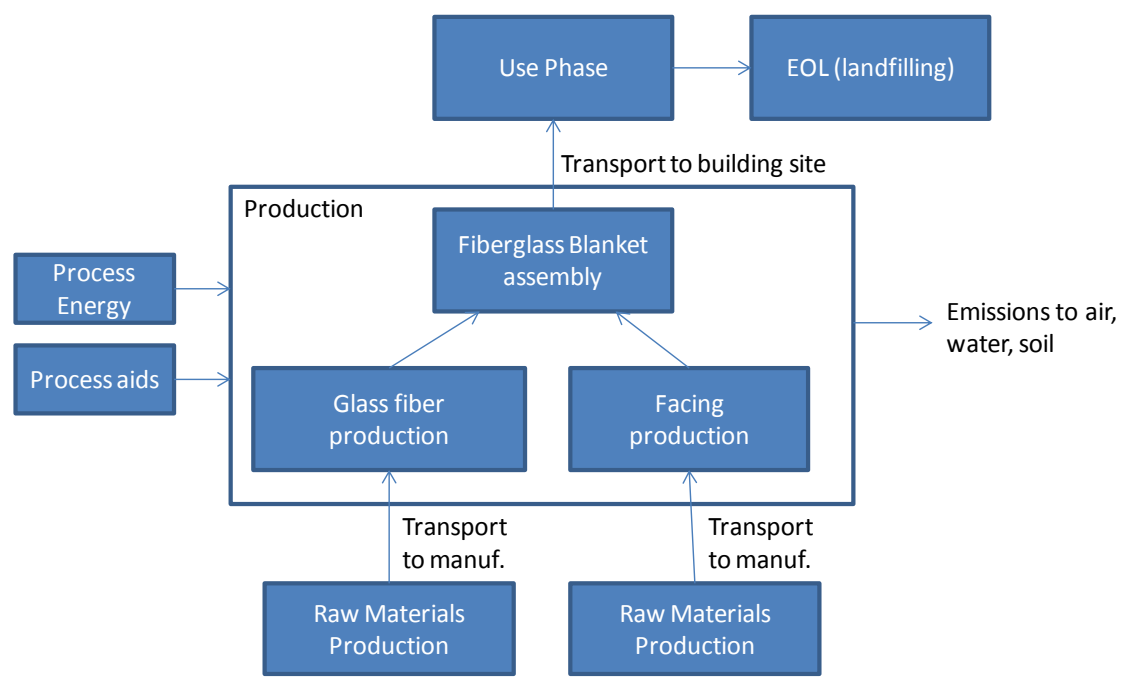

Figure 4-6 Insulation System Boundaries - Fiberglass Blanket Example

The modeling and assumptions for each type of insulation are presented below.

\subsubsection{Fiberglass Blanket}

Fiberglass blanket, or batt, insulation is made by forming spun-glass fibers into batts. At an insulation plant, the product feedstock is weighed and sent to a melting furnace. The raw materials are melted in a furnace at very high temperatures. Streams of the resulting vitreous melt are either spun into fibers after falling onto rapidly rotating flywheels or drawn through tiny holes in rapidly rotating spinners. This process shapes the melt into fibers. Glass coatings are added to the fibers that are then collected on conveyers. The structure and density of the product is continually controlled by the conveyer speed and height as it passes through a curing oven. The cured product is then sawn or cut to the required size. Off-cuts and other scrap material are recycled back into the production process.

Thermal resistance values of $\mathrm{R}_{\mathrm{SI}}-2.3$ (R-13) and $\mathrm{R}_{\mathrm{SI}}-3.4$ (R-19) are used for wall insulation, and Table 4-8 specifies fiberglass insulation by type and R-value. Most of the fiberglass insulation data is based on the model in BEES Online (2010). 
Table 4-8 Fiberglass Blanket Mass by Application

\begin{tabular}{|c|c|c|c|c|c|}
\hline Application & $\begin{array}{l}\text { Thickness } \\
\text { cm (in) }\end{array}$ & $\begin{array}{c}\text { Density } \mathbf{~ k g} / \mathbf{m}^{3} \\
\left(\mathrm{lb} / \mathbf{f t}^{3}\right)\end{array}$ & $\begin{array}{c}\text { Mass per } 1 \text { in } \\
\text { Functional } \\
\text { Unit kg/m } \mathbf{m}^{2} \\
\left(\mathrm{oz} / \mathrm{ft}^{2}\right)\end{array}$ & $\begin{array}{c}\text { R-Value per } \\
\text { Reference } \\
\text { Flow }\left(\mathbf{m}^{2}{ }^{\circ} \mathrm{K} / \mathrm{W}\right. \\
\text { per } 1 \mathbf{c m})\end{array}$ & $\begin{array}{c}\text { R-Value per } \\
\text { Reference Flow } \\
\left(\mathbf{f t}^{2}{ }^{\circ} \mathbf{F} \text { hr/Btu }\right. \\
\text { per } 1 \text { in) }\end{array}$ \\
\hline $\begin{array}{l}\text { Wall - } \mathrm{R}_{\mathrm{SI}}-2.3 \\
(\mathrm{R}-13)\end{array}$ & $8.9(3.5)$ & $12.1(0.76)$ & $0.31(1.01)$ & $\mathrm{R}-0.26$ & $\mathrm{R}-3.7$ \\
\hline $\begin{array}{l}\text { Wall - R RI-3.4 } \\
\text { ( R-19) }\end{array}$ & $15.9(6.25)$ & $7.0(0.44)$ & $0.18(0.58)$ & R- 0.21 & R-3.0 \\
\hline
\end{tabular}

\section{Upstream Materials Production through Manufacturing}

Fiberglass insulation is made with a blend of sand, limestone, soda ash, and recycled glass cullet. Recycled window, automotive, or bottle glass is used in the manufacture of glass fiber; it accounts for 30 to $50 \%$ of the raw material input. The recycled content is limited by the amount of usable recycled material available in the market - not all glass cullet is of sufficient quality to be used in the glass fiber manufacturing process. The use of recycled material has helped to steadily reduce the energy required to produce insulation products. The raw materials used to produce fiberglass insulation are broken down by the glass and facing contents, shown in Table 4-9. 


\begin{tabular}{lc} 
Table 4-9 Fiberglass Insulation Constituents \\
Glass Constituent & Mass Fraction (\%) \\
Soda Ash & 9.0 \\
Borax & 12.0 \\
Glass Cullet & 34.0 \\
Limestone & 9.0 \\
Phenolic resin (binder coating) & 5.0 \\
Sand & 31.0 \\
Total & $\mathbf{1 0 0}$ \\
Facing & Mass Fraction (\%) \\
Kraft paper & 25.0 \\
Asphalt & 75.0 \\
Total & $\mathbf{1 0 0}$ \\
\hline
\end{tabular}

The production data for the soda ash, limestone, and phenol formaldehyde resin come from the U.S. LCI Database. The borax, glass cullet, and silica sand come from ecoinvent. For the facing, Kraft paper comes from ecoinvent and the asphalt comes from U.S. LCI Database.

The raw materials are transported to the manufacturing plant via diesel truck. Materials are sourced domestically, and transportation distances range on average from $161 \mathrm{~km}$ (100 mi) to $805 \mathrm{~km}$ (500 mi).

The energy requirements for melting the glass constituents into fibers and drying of the completed blanket involve use of natural gas and electricity, shown in Table 4-10.

\section{Table 4-10 Energy Requirements for Fiberglass Insulation Manufacturing}

$\begin{array}{lc}\text { Energy Carrier } & \mathbf{M J} / \mathbf{k g}(\mathbf{B t u} / \mathbf{l b}) \\ \text { Natural Gas } & 1.99(857) \\ \text { Electricity } & 1.37(591) \\ \text { Total } & \mathbf{3 . 3 6}(\mathbf{1 ~ 4 4 8})\end{array}$


Besides combustion emissions from fuel usage at manufacturing, particulates are emitted at a rate of $2.38 \mathrm{~g} / \mathrm{kg}(4.76 \mathrm{lb} / \mathrm{ton})$ of bonded blankets and volatile organic compounds (VOCs) are emitted at a rate of $0.76 \mathrm{~g} / \mathrm{kg}(1.52 \mathrm{lb} / \mathrm{ton})$ of bonded blankets.

All waste produced during the cutting and blending process is either recycled into other insulation materials or added back into the glass mix. Thus, no solid waste is assumed to be generated during the production process.

\section{Transportation to the Building Site through End-of-Life}

Transportation of the insulation to the building site is modeled as an assumed average of $805 \mathrm{~km}$ (500 mi) by heavy-duty diesel-fueled truck.

Installing fiberglass blanket insulation is primarily a manual process, with no energy or emissions are included in the model. During installation, any waste material is added into the building shell where the insulation is installed - there is effectively no installation waste.

Fiberglass insulation has a functional lifetime of over 50 years so no replacement is needed during the 40 year study period. How this product affects operating energy during the home's use phase is addressed in other sections of this report.

While fiberglass insulation is recyclable, it is assumed that it is disposed of in a landfill at endof-life. End-of-life modeling includes transportation by heavy-duty diesel-fuel powered truck approximately $80 \mathrm{~km}(50 \mathrm{mi})$ to a construction \& demolition (C\&D) landfill. Insulation in a landfill is modeled based on ecoinvent end-of-life waste management process data.

\subsubsection{Blown Cellulose Insulation}

Thermal resistance values of $\mathrm{R}_{\mathrm{SI}}-3.4$ (R-13) for a wall application and $\mathrm{R}_{\mathrm{SI}}-6.7$ (R-38) for a ceiling application of blown cellulose have been used in BIRDS. The models for BIRDS are largely based on the blown cellulose in BEES Online (2010). Table 4-11 specifies blown cellulose insulation by type and R-value.

Table 4-11 Blown Cellulose Insulation by Application

\begin{tabular}{|c|c|c|c|c|c|}
\hline Application & $\begin{array}{c}\text { Thickness } \\
\text { cm (in) }\end{array}$ & $\begin{array}{c}\text { Density } \\
\mathrm{kg} / \mathrm{m}^{3} \\
\left(\mathbf{l b} / \mathrm{ft}^{3}\right)\end{array}$ & $\begin{array}{c}\text { Mass per } 1 \text { in } \\
\text { Functional Unit } \\
\text { kg/m² }\left(\mathbf{l b} / \mathbf{f t}^{2}\right)\end{array}$ & $\begin{array}{c}\text { R-Value per } \\
\text { Reference } \\
\text { Flow }\left(\mathbf{m}^{2}{ }^{\circ} \mathrm{K} / \mathrm{W}\right. \\
\text { per } 1 \mathrm{~cm})\end{array}$ & $\begin{array}{c}\text { R-Value per } \\
\text { Reference Flow } \\
\left(\mathrm{ft}^{2}{ }^{\circ} \mathrm{F} \text { hr/Btu per }\right. \\
1 \text { in })\end{array}$ \\
\hline $\begin{array}{l}\text { Wall }-\mathrm{R}_{\mathrm{SI}}-2.3 \\
(\mathrm{R}-13)\end{array}$ & $8.9(3.5)$ & $35.3(2.20)$ & $0.89(0.18)$ & $\mathrm{R}_{\mathrm{SI}}-0.26$ & $\mathrm{R}-3.7$ \\
\hline $\begin{array}{l}\text { Ceiling }-\mathrm{R}_{\mathrm{SI}}-6.7 \\
(\mathrm{R}-38)\end{array}$ & $\begin{array}{c}27.6 \\
(10.9)\end{array}$ & $27.2(1.70)$ & $0.69(0.14)$ & $\mathrm{R}_{\mathrm{SI}}-0.24$ & R-3.5 \\
\hline
\end{tabular}




\section{Upstream Materials Production through Manufacturing}

Cellulose insulation is essentially shredded, recovered wastepaper that is coated with fire retardants. Blown cellulose insulation is produced primarily from post-consumer wood pulp (newspapers), typically accounting for roughly $85 \%$ of the insulation by weight. Ammonium sulfate, borates, and boric acid are the fire retardants used most commonly and account for the other $15 \%$ of the cellulose insulation by weight. The mix of these materials is provided in Table 4-12; while the relative proportions of the fire retardants vary among manufacturers, they are assumed to be mixed in equal proportions for BIRDS.

\section{Table 4-12 Cellulose Insulation Constituents}

\begin{tabular}{lc} 
Constituent & Mass Fraction (\%) \\
Recovered Newspaper & 85 \\
Ammonium Sulfate & 7.5 \\
Boric Acid & 7.5 \\
Total & $\mathbf{1 0 0}$ \\
\hline
\end{tabular}

BIRDS recovered newspaper data includes impacts from wastepaper collection, sorting, and subsequent transportation to the insulation manufacturer. Since it is a recovered product, the impacts from upstream production of the pulp are not included in the system boundaries. Data for ammonium sulfate and boric acid come from ecoinvent. The raw materials are all assumed to be shipped $161 \mathrm{~km}(100 \mathrm{mi})$ to the manufacturing plant via diesel truck.

The manufacturing process includes shredding the wastepaper and blending it with the different fire retardants. Manufacturing energy is assumed to be purchased electricity in the amount of $0.35 \mathrm{MJ} / \mathrm{kg}(150 \mathrm{Btu} / \mathrm{lb})$. Any waste produced during the production process is recycled back into other insulation materials. Therefore, no solid waste is generated during the production process.

\section{Transportation to the Building Site through End-of-Life}

Transportation of the insulation to the building site is modeled an assumed average of $805 \mathrm{~km}$ (500 mi) by heavy-duty diesel-fueled truck.

At installation, a diesel generator is used to blow the insulation material into the space. For one hour of operation, a typical $18 \mathrm{~kW}(25 \mathrm{hp})$ diesel engine can blow $818 \mathrm{~kg}(1800 \mathrm{lb})$ of insulation. The emissions and energy use for this generator are included in the system boundaries for this product. No other installation energy is required. Any waste material during installation 
is added into the building shell where the insulation is installed, so there is effectively no installation waste.

Cellulose insulation has a functional lifetime of over 50 years so no replacement is needed during the 40 year study period. How this product affects operating energy during the home's use phase is addressed in other sections of this report.

While cellulose insulation is mostly recyclable, it is assumed that all of the insulation is disposed of in a landfill at end-of-life. End-of-life modeling includes transportation approximately $80 \mathrm{~km}$ (50 mi) to a C\&D landfill. Insulation in the landfill is modeled based on ecoinvent end-of-life waste management process data.

\subsubsection{Spray Polyurethane Foam Insulation}

Spray polyurethane foam (SPF) is an insulation and roofing material that is formulated at the building installation site using a combination of an isocyanate, or "A-side," with an equal volume of a polyol blend, or "B-side." For SPF, the A-side is a blend of monomeric and polymeric methylene diphenyl diisocyanate (pMDI). The B-side formulation varies based on formulator and desired properties, and includes at least five different types of chemical ingredients: polyols, blowing agents, flame retardants, catalysts, and surfactants. When the A and $\mathrm{B}$ side are mixed, it expands in place providing both insulation and an air barrier; some SPF types deliver other performance properties including a vapor retarder, water resistance and structural enhancement.

Two classifications for SPF insulation used in the U.S. construction industry are open-cell (lowdensity) and closed-cell (medium-density) SPF. Open-cell has a nominal density ranging from 6.4 to $11.1 \mathrm{~kg} / \mathrm{m}^{3}$ (0.4 to $\left.0.7 \mathrm{lb} / \mathrm{ft}^{3}\right) ; 7.9 \mathrm{~kg} / \mathrm{m}^{3}\left(0.5 \mathrm{lb} / \mathrm{ft}^{3}\right)$ has been assumed for the LCA. Opencell foam is formed using water as a reactive blowing agent. Water reacts with the A-side methylene diphenyl diisocyanate (MDI) to create $\mathrm{CO}_{2}$ gas that expands the curing liquid into a cellular foam material. Thermal resistance per inch is in the range of $\mathrm{R}_{\mathrm{SI}}-0.25$ to $\mathrm{R}_{\mathrm{SI}}-0.28 \mathrm{per} \mathrm{cm}$ (R-3.6 to R-4.0 per inch); $\mathrm{R}_{\mathrm{SI}}-0.25$ (R-3.6) has been assumed.

Closed-cell foam has a nominal density ranging from 27.0 to $36.5 \mathrm{~kg} / \mathrm{m}^{3}$ (1.7 to $\left.2.3 \mathrm{lb} / \mathrm{ft}^{3}\right)$; $31.8 \mathrm{~kg} / \mathrm{m}^{3}\left(2.0 \mathrm{lb} / \mathrm{ft}^{3}\right)$ has been assumed. Fluorocarbon (physical) blowing agents are used to expand closed-cell foams: the fluorocarbon liquid in the B-side converts to a gas from the heat of the reaction to expand the cells. The low thermal conductivity fluorocarbon gas yields an Rvalue ranging from $\mathrm{R}_{\mathrm{SI}}-0.07$ to $\mathrm{R}_{\mathrm{SI}}-0.08$ per $\mathrm{cm}$ (R-5.8 to R-6.8 per in); $\mathrm{R}_{\mathrm{SI}}-0.43$ (R-6.2) has been assumed. Emissions from the HFC-245fa were included in the LCA, and the assumptions around its release are stated in this documentation.

The information provided in this summary is based on a comprehensive LCA study on SPF (PE 2012). The quantitative data come mainly from a Spray Polyurethane Foam Alliance (SPFA) 
summary report (SPFA 2012) and SPFA's Environmental Product Declaration (EPD), both based on PE International (2012).

\section{Upstream Materials Production through Manufacturing}

SPF's A-side is MDI. The B-side is made up of a number of combinations and types of chemicals. Primary data for the year 2010 were collected from six formulation plants to attain an industry average. Table 4-13 provides the material constituent percentages of the B-side formulations. (SPFA 2012, Table 2-3) These data are assumed to be representative of SPF in the U.S., based on input and consensus by SPFA members. Nonetheless, these formulations are generic and thus do not represent one specific producer's formulation.

\section{Table 4-13 B-Side Formulation - Material Constituent Percentages}

$\begin{array}{lcc}\text { Constituent } & \begin{array}{c}\text { Low density (open } \\ \text { cell foam) } \%\end{array} & \begin{array}{c}\text { Medium density } \\ \text { (closed cell foam) } \%\end{array} \\ \text { Polyol - polyester } & \mathrm{n} / \mathrm{a} & 45.0 \\ \text { Polyol - Mannich } & 10.0 & 30.0 \\ \text { Polyol - compatibilizer } & 35.0 & \mathrm{n} / \mathrm{a} \\ \text { Polyol - polyether } & 25.0 & \mathrm{n} / \mathrm{a} \\ \text { Fire retardent - TCPP } & \mathrm{n} / \mathrm{a} & 4.0 \\ \text { Fire retardent - brominated } & 23.5 & 6.0 \\ \text { Blowing agent - reactive (de-ionized H2O) } & \mathrm{n} / \mathrm{a} & 2.0 \\ \text { Blowing agent - physical (HFC 245fa) } & 6.0 & 8.5 \\ \text { Catalyst - amine } & \mathrm{n} / \mathrm{a} & 3.0 \\ \text { Catalyst - metal } & 0.5 & 0.5 \\ \text { Surfactant - silicone } & \mathbf{1 0 0} & 1.0 \\ \text { Total } & & \mathbf{1 0 0}\end{array}$

The reference flows used for the original LCA were based on the functional unit defined by UL Environment (2011) Product Category Rules (PCR) on U.S. insulation: one square meter of foam provides an R-value of $1.00 \mathrm{~m}^{2}{ }^{\circ} \mathrm{K} / \mathrm{W}\left(5.68 \mathrm{~h} \cdot \mathrm{ft}^{2} \cdot{ }^{\circ} \mathrm{F} / \mathrm{Btu}\right)$. The specifications for the original LCA and the BIRDS LCA are shown together in Table 4-14. 
Table 4-14 SPF Insulation Reference Unit Parameters for Original and BIRDS LCAs

\begin{tabular}{|c|c|c|c|c|}
\hline & & Unit & $\begin{array}{l}\text { Low-density } \\
\text { Open-Cell }\end{array}$ & $\begin{array}{l}\text { Medium-density } \\
\text { Closed-Cell }\end{array}$ \\
\hline Foam R-Value & & $\begin{array}{c}\mathrm{m}^{2}{ }^{\circ} \mathrm{K} / \mathrm{W}\left(\mathrm{h} \cdot \mathrm{ft}^{2} \cdot{ }^{\circ} \mathrm{F} / \mathrm{Btu}\right) \text { per } \\
\mathrm{cm}(\text { per in) }\end{array}$ & $0.25(3.6)$ & $0.43(6.2)$ \\
\hline \multirow[t]{4}{*}{ Original LCA } & Foam area & $\mathrm{m}^{2}\left(\mathrm{ft}^{2}\right)$ & $1.0(10.76)$ & $1.0(10.76)$ \\
\hline & Target R-value & $\mathrm{m}^{2}{ }^{\circ} \mathrm{K} / \mathrm{W}\left(\mathrm{h} \cdot \mathrm{ft}^{2} \cdot{ }^{\circ} \mathrm{F} / \mathrm{Btu}\right)$ & $1.00(5.68)$ & $1.00(5.68)$ \\
\hline & $\begin{array}{l}\text { Thickness per } \\
\text { reference unit }\end{array}$ & cm (in) & $4.0(1.58)$ & $2.3(0.92)$ \\
\hline & $\begin{array}{l}\text { Mass per } \\
\text { reference unit }\end{array}$ & $\operatorname{kg}(\mathrm{lb})$ & $0.59(1.31)$ & $1.16(2.55)$ \\
\hline \multirow[t]{4}{*}{ BIRDS LCA } & Foam area & $\mathrm{m}^{2}\left(\mathrm{ft}^{2}\right)$ & $0.09(1.0)$ & $0.09(1.0)$ \\
\hline & $\begin{array}{l}\text { R-value per } \mathrm{cm} \\
\text { (per in) }\end{array}$ & $\mathrm{m}^{2}{ }^{\circ} \mathrm{K} / \mathrm{W}\left(\mathrm{h} \cdot \mathrm{ft}^{2} \cdot{ }^{\circ} \mathrm{F} / \mathrm{Btu}\right)$ & $0.25(3.6)$ & $0.43(6.2)$ \\
\hline & $\begin{array}{l}\text { Thickness per } \\
\text { reference unit }\end{array}$ & cm (in) & $2.54(1.0)$ & $2.54(1.0)$ \\
\hline & $\begin{array}{l}\text { Mass per } \\
\text { reference unit }\end{array}$ & $\mathrm{kg}(\mathrm{lb})$ & $0.035(0.077)$ & $0.117(0.26)$ \\
\hline
\end{tabular}

Based on the percentages of the B-side material constituents (presented in Table 4-13) and the mass per reference unit for the BIRDS LCA, the masses of materials in the foam shown in Table 4-15 were modeled for BIRDS. The quantities of the pMDI were calculated based on SPFA (2012), which provided the masses of A-side and B-side from a drum set at installation. 
Table 4-15 Material Constituents for Open-Cell and Closed-Cell SPF Insulation

\begin{tabular}{|c|c|c|c|c|}
\hline \multirow{2}{*}{ Constituent } & \multicolumn{2}{|c|}{$\begin{array}{c}\text { Low Density (Open-Cell) } \\
\text { Foam }\end{array}$} & \multicolumn{2}{|c|}{$\begin{array}{l}\text { Medium Density } \\
\text { (Closed-Cell) Foam }\end{array}$} \\
\hline & kg & lb & kg & lb \\
\hline Polyol - polyester & $\mathrm{n} / \mathrm{a}$ & $\mathrm{n} / \mathrm{a}$ & 0.026 & 0.057 \\
\hline Polyol - Mannich & $\mathrm{n} / \mathrm{a}$ & $\mathrm{n} / \mathrm{a}$ & 0.017 & 0.038 \\
\hline Polyol - compatibilizer & 0.002 & 0.004 & $\mathrm{n} / \mathrm{a}$ & $\mathrm{n} / \mathrm{a}$ \\
\hline Polyol - polyether & 0.006 & 0.013 & $\mathrm{n} / \mathrm{a}$ & $\mathrm{n} / \mathrm{a}$ \\
\hline Fire retardent - TCPP & 0.004 & 0.009 & 0.002 & 0.005 \\
\hline Fire retardent - brominated & $\mathrm{n} / \mathrm{a}$ & $\mathrm{n} / \mathrm{a}$ & 0.003 & 0.008 \\
\hline Blowing agent - reactive (deionized $\mathrm{H} 2 \mathrm{O}$ ) & 0.004 & 0.009 & 0.001 & 0.003 \\
\hline Blowing agent - physical (HFC 245fa) & $\mathrm{n} / \mathrm{a}$ & $\mathrm{n} / \mathrm{a}$ & 0.005 & 0.011 \\
\hline Catalyst - amine & 0.001 & 0.002 & 0.002 & 0.004 \\
\hline Catalyst - metal & $\mathrm{n} / \mathrm{a}$ & $\mathrm{n} / \mathrm{a}$ & 0.0003 & 0.001 \\
\hline Surfactant - silicone & $\mathrm{n} / \mathrm{a}$ & $\mathrm{n} / \mathrm{a}$ & 0.001 & 0.001 \\
\hline pMDI - A-Side & 0.018 & 0.040 & 0.060 & 0.131 \\
\hline Total & 0.035 & 0.077 & 0.117 & 0.258 \\
\hline
\end{tabular}

Data for the MDI comes from the U.S. LCI Database. Data for the polyester polyol comes from PE International (2010). Due to lack of other available data, proxies were used for the other polyols: polyether polyol was used for the Mannich polyol and ethylene glycol was used for compatibilizer polyol. Both come from the U.S. LCI Database.

Data for Tris(2-chloroisopropyl)phosphate (TCPP) are U.S. data compiled from PE International (2011). Due to lack of specific data on the brominated fire retardant, ecoinvent's data set on diphenyl ether compounds was used as a proxy, since brominated fire retardants may be part of a group called polybrominated diphenyl ethers (PBDEs).

Deionized water blowing agent comes from ecoinvent. Data for the HFC $245 \mathrm{fa}$ are based on stoichiometry and information from McCulloch (2010). Dimethylamine from ecoinvent was used for the amine catalyst, and the silicone surfactant was modeled using tetrachlorosilane as a proxy. Both these data sets come from ecoinvent. No data were available to include the metal catalyst. 
Transport distances and modes of transportation of raw materials to the formulation plants were provided in the original LCA; these distances were used in the BIRDS LCA but are not included in this text.

Weighted average process energy data from the six formulation sites were provided in Table 3.1 of PE International (2012). Data included electric and other fuel energy sources, waste quantities and their fates, packaging in steel drums, plastic drums and totes, plastic wrap, and pallets, plus direct process emissions from foam reactions. These data were included in the BIRDS LCA but are not provided in this summary to protect confidentiality.

\section{Transportation to the Building Site through End-of-Life}

According to PE International (2012), transportation to the building site of the A- and B-side drums is modeled as a weighted industry average of $1287 \mathrm{~km}$ (800 mi) by heavy-duty dieselfueled truck.

On-site application is nearly identical for all high-pressure SPF materials. The A- and B-side chemicals are delivered to the SPF contractor in pairs (sets) of 208-liter (55-gal) drums from the formulator. These unpressurized drum sets are stored at the contractor's facility at room temperature conditions until taken to the jobsite in a spray rig.

At the jobsite, the chemicals are heated and pressurized by specialized equipment. The chemicals are aerosolized by a spray gun and combined by impingement mixing during application. Weighted average data from six installation contractors from across NA were provided in Table 3.3 of PE International (2012). Data included electricity, diesel fuel, and waste materials. These data were included in BIRDS but are not provided in this summary to protect confidentiality. According to the UL Environment (2013) EPD, it is assumed that $50 \%$ of the original HFC-245fa blowing agent in the closed-cell foam will stay with the product. The remaining original amount of the blowing agent is released as follows, according to the EPD:

- $10 \%$ emitted at installation;

- $24 \%$ emitted over its lifetime in the building;

- $16 \%$ emitted at end-of-life.

SPF insulation has a functional lifetime of 60 years so no replacement is needed during the BIRDS' 40 year study period. Installed SPF insulation normally requires no maintenance and has no impacts associated with it besides the release of blowing agent as mentioned above. How insulation in the building affects operating energy during the use phase is addressed in other sections of this report.

SPF insulation is assumed to be disposed of in a landfill at end-of-lifeend-of-life. The foam is inert in the landfill, except for the release of the HFC-245fa, as stated above. End-of-life 
modeling includes transportation by heavy-duty diesel-fuel powered truck approximately $80 \mathrm{~km}$ (50 mi) to a C\&D landfill. Insulation in a landfill is modeled based on ecoinvent end-of-life waste management process data.

\subsubsection{Mineral Wool Blanket Insulation}

Mineral wool insulation is made by spinning fibers from natural rock like diabase or basalt (rock wool) or iron ore blast furnace slag (slag wool). Rock wool and slag wool are manufactured by melting the constituent raw materials in a cupola. A molten stream is created and poured onto a rapidly spinning wheel or wheels. The viscous molten material adheres to the wheels and the centrifugal force throws droplets of melt away from the wheels, forming fibers. A binder, used to stabilize the fibers, and a de-dusting agent to reduce free, airborne wool during use, are applied during this process. The material is heated to cure the binder and stabilize the material, and is then cooled. The blankets are then cut to size and packaged. Some of the data on mineral wool insulation come from BEES Online (2010).

Thermal resistance values of $\mathrm{R}_{\mathrm{SI}}-2.3(\mathrm{R}-13)$ and $\mathrm{R}_{\mathrm{SI}}-3.4(\mathrm{R}-19)$ are used for BIRDS wall insulation but data used for this LCA have been modeled according to thermal resistances more commonly offered for mineral wool blankets (i.e., $\mathrm{R}_{\mathrm{SI}}-2.6(\mathrm{R}-15)$ and $\mathrm{R}_{\mathrm{SI}}-4.1$ (R-23)). Table 4-16 specifies mineral wool blanket insulation by type and R-value. (Roxul, 2013).

Table 4-16 Mineral Wool Blanket Mass by Application

\begin{tabular}{|c|c|c|c|c|}
\hline Application & $\begin{array}{c}\text { Thickness } \\
\text { cm (in) }\end{array}$ & $\begin{array}{c}\text { Density } \\
\mathrm{kg} / \mathrm{m}^{3} \\
\left(\mathbf{l b} / \mathbf{f t}^{3}\right)\end{array}$ & $\begin{array}{c}\text { Mass per } 1 \text { in } \\
\text { Functional Unit } \\
\text { kg/m² }\left(\mathbf{l b} / \mathbf{f t}^{2}\right)\end{array}$ & $\begin{array}{c}\text { R-Value per } \\
\text { Reference Flow } \\
\mathbf{m}^{2}{ }^{\circ} \mathrm{K} / \mathrm{W} \text { per } \mathrm{cm} \\
\left(\mathbf{h} \cdot \mathbf{f t}^{2} \cdot{ }^{\circ} \mathbf{F} / \mathbf{B t u} \text { per in }\right)\end{array}$ \\
\hline Wall - $\mathrm{R}_{\mathrm{SI}}-2.6(\mathrm{R}-15)$ & $8.9(3.5)$ & $31.5(2.0)$ & $0.074(0.16)$ & $0.30(4.3)$ \\
\hline Wall - $\mathrm{R}_{\mathrm{SI}}-4.1$ (R-23) & $14.0(5.5)$ & $34.3(2.1)$ & $0.081(0.18)$ & $0.30(4.2)$ \\
\hline
\end{tabular}

\section{Upstream Materials Production through Manufacturing}

Mineral wool can be manufactured using slag wool or rock wool. Some products contain both materials; about $80 \%$ of North American mineral wool is manufactured using iron ore slag. The binder is modeled as phenol formaldehyde resin. Quantities of resin vary for different manufacturers and performance characteristics; eight percent was modeled for BIRDS. Additionally, a small amount of mineral oil was added to seal the surface against dust production (Defra 2008). Table 4-17 presents the weighted mix of the different types of mineral wool feedstock representing production in North America, plus the additional materials used in blankets. 


\section{Table 4-17 Mineral Wool Insulation Constituents}

$\begin{array}{lc}\text { Constituent } & \text { Mass Fraction (\%) } \\ \text { Diabase Rock/Basalt } & 20.2 \\ \text { Iron Ore Slag } & 71.5 \\ \text { Phenol formaldehyde resin } & 8.0 \\ \text { Mineral oil } & 0.3 \\ \text { Total } & \mathbf{1 0 0}\end{array}$

Data for rock mining and grinding come from ecoinvent. Slag is produced during steel production, when molten iron and slag are produced together in the blast furnace. The slag is recovered and can be used to produce mineral wool, as an additive to cement, etc. For mineral wool, the production of slag is considered to be environmentally "free" of upstream impacts. However, it accounts for the transportation to fiber production and the processing into fiber. The data for phenol formaldehyde resin and mineral oil come from the U.S. LCI database.

The raw materials are transported to the manufacturing plant via diesel truck. Materials are sourced domestically, and transportation distances range on average from $161 \mathrm{~km}$ (100 mi) to $805 \mathrm{~km}$ (500 mi).

The energy requirements for melting the product constituents into fibers and drying of the fibers involve a mixture of coke and electricity. The energy demands are outlined in Table 4-18. (BEES Online, 2010)

\section{Table 4-18 Energy Requirements for Mineral Wool Insulation Manufacturing}

$\begin{array}{lc}\text { Energy Source } & \mathbf{M J} / \mathbf{k g}(\mathbf{B t u} / \mathbf{l b}) \\ \text { Coke } & 6.38(2740) \\ \text { Electricity } & 1.0(430) \\ \text { Total } & \mathbf{7 . 3 8 ( 3 ~ 1 7 0 )}\end{array}$

The manufacturing process generates air emissions from energy use, particulates and fluorides during melting and spinning of the mineral feedstocks, and phenol and formaldehyde during melting and binding. These emissions are included in the model. All waste produced during the production process is either recycled into other insulation materials or added back into the melt. Therefore, no solid waste is generated during production. 


\section{Transportation to the Building Site through End-of-Life}

Transportation of the insulation to the building site is modeled an assumed average of $805 \mathrm{~km}$ (500 $\mathrm{mi}$ ) by heavy-duty diesel-fueled truck. Installation is primarily a manual process; no energy or emissions are included in the model. During installation, any waste material is added into the building shell where the insulation is installed - there is effectively no installation waste.

Mineral wool insulation has a functional lifetime of over 50 years so no replacement is needed during the 40 year study period. How this product affects operating energy during the home's use phase is addressed in other sections of this report.

While mineral wool insulation may be recyclable, it is assumed that it is disposed of in a landfill at end-of-life. End-of-life modeling includes transportation by heavy-duty diesel-fuel powered truck approximately $80 \mathrm{~km}(50 \mathrm{mi})$ to a $C \& D$ landfill. Insulation in a landfill is modeled based on ecoinvent end-of-life waste management process data.

\subsubsection{XPS Foam Insulation}

Extruded Polystyrene (XPS) foam insulation has been modeled for the residential exterior wall. Type IV and Type XPS may be used for residential applications; the data in this document is representative of Type IV XPS, which has a typical average density of $26.2 \mathrm{~kg} / \mathrm{m}^{3}\left(1.63 \mathrm{lb} / \mathrm{ft}^{3}\right)$. The foam has the following R-values, depending on thickness: ${ }^{16}$

- $2.5 \mathrm{~cm}(1 \mathrm{in}): \mathrm{R}_{\mathrm{SI}}=0.9(\mathrm{R}=5.0)$

- $5.1 \mathrm{~cm}(2$ in $): \mathrm{R}_{\mathrm{SI}}=1.9(\mathrm{R}=10.6)$

- $7.6 \mathrm{~cm}(3 \mathrm{in}): \mathrm{R}_{\mathrm{SI}}=2.9(\mathrm{R}=16.2)$

- $10.2 \mathrm{~cm}(4$ in $): \mathrm{R}_{\mathrm{SI}}=3.9(\mathrm{R}=22.0)$

\section{Upstream Materials Production through Manufacturing}

Extruded Polystyrene Foam Association (XPSA) member companies provided representative industry average production data on XPS foam boards. XPSA represents the three largest producers in North America and accounts for over $95 \%$ of XPS products produced and sold. Table 4-19 provides a 2010 representative average of the raw material and processing energy inputs and process outputs to produce one $\mathrm{kg}$ XPS foam board.

\footnotetext{
${ }^{16}$ Extruded Polystyrene Foam Association (XPSA) website, found at http://www.xpsa.com. Values are based on a round-robin study in 2003 using the CAN/ULC S770-00 LTTR standard.
} 
Table 4-19 XPS Foam Board Production Data

\begin{tabular}{lllc} 
Inputs & & Unit & Quantity per kg (per lb) \\
Blowing agents & HFC-134a & $\mathrm{kg}(\mathrm{lb})$ & $0.060(0.060)$ \\
& HFC-152a & $\mathrm{kg}(\mathrm{lb})$ & $0.017(0.017)$ \\
& $\mathrm{CO}_{2}$ & $\mathrm{~kg}(\mathrm{lb})$ & $0.012(0.012)$ \\
Solid additives & PS resin & $\mathrm{kg}(\mathrm{lb})$ & $0.907(0.907)$ \\
& Additives & $\mathrm{kg}(\mathrm{lb})$ & $0.018(0.018)$ \\
Energy & Electricity & $\mathrm{kWh}$ & $1.00(0.454)$ \\
Outputs & & & \\
Air & HFC-134a & $\mathrm{kg}(\mathrm{lb})$ & $0.0105(0.0105)$ \\
& HFC-152a & $\mathrm{kg}(\mathrm{lb})$ & $0.0029(0.0029)$ \\
Waste & Waste & $\mathrm{kg}(\mathrm{lb})$ & $1.0 \mathrm{E}-4(1.0 \mathrm{E}-4)$ \\
\hline
\end{tabular}

The table presents the current representative blowing agent usage. It should be noted that HFCs began to replace HCFC-142b as the principal blowing agent in 2009, as the industry complied with U.S. EPA and Environment Canada ODS phase-out regulations requiring the XPS sector to exit HCFC use by the end of 2009. By 2010, all XPSA members had converted to non-HCFC blowing agents and have been using only HFC materials ever since.

The additives in the table include the flame retardant widely used in all polystyrene foams (hexabromocyclododecane (HBCD)) and colorants or dyes/pigments used to produce the characteristic color of each XPSA member's foam. Additives may also include a nucleation control agent, process lubricant, acid scavenger, or others.

The blowing agent conversion/trim losses during manufacturing are assumed to be on average $17.5 \%$ for North American XPS foam production. (IPCC/TEAP 2005, Table 7.7) All of the polystyrene trim waste at the manufacturing plant is reused internally in the process. Only a very small amount of foam and other materials are occasionally sent off-site for disposal in a landfill.

Data for polystyrene come from the U.S. LCI Database. Data for all three blowing agents and some of the additives come from ecoinvent. Data were not available for all of the additives; where data were not available proxy data were implemented.

All the raw materials are produced in the U.S., and most of the raw materials are centrally located as are the XPS manufacturer's largest plants. The estimated weighted average distance from the main suppliers to the majority of XPS manufacturing plants are $805 \mathrm{~km}(500 \mathrm{mi})$ for 
polystyrene, HFC-134a, flame retardant, and $\mathrm{CO}_{2}$. HFC-152a and other additives are transported an average distance of $1609 \mathrm{~km}$ (1000 mi) to manufacturing plants. All but the blowing agents and polystyrene are transported by diesel truck; the blowing agents and polystyrene are transported by rail.

\section{Transportation to the Building Site through End-of-Life}

Transportation of the insulation to the building site is modeled as $563 \mathrm{~km} \mathrm{(350} \mathrm{mi),} \mathrm{an} \mathrm{average}$ factoring in the various plants around the United States. Transportation is by heavy-duty diesel truck.

Foam boards are installed with installation tape, but tape is excluded since it is considered negligible. Scrap XPS foam board generated at installation is assumed to be $2 \%$ of the total, consistent with other foam products in this category. While the product may be recyclable, it is modeled as being sent to a landfill $32 \mathrm{~km}$ (20 mi) from the building site. Data for the landfill come from waste management datasets in ecoinvent. Blowing agent escape during installation is insignificant. Minimal cutting to size on the jobsite is done and, even then, a sharp tool is typically used so that very few cells are opened.

XPS insulation has a functional lifetime of over 40 years so no replacement is needed during the 40 year study period. How insulation in the buildings affects operating energy during the prototype buildings' use phase is addressed in other sections of this report.

The diffusion of HFC-134a from XPS during use is $0.75 \%+/-0.25 \%$ per year. (IPCC/TEAP, 2005, Table 7.7) The blowing agent emission loss during the use phase is complex and nonlinear but can be represented for simplicity as a linear function after the first year. The rate is a function of the product thickness, properties (density, cell size, skins), blowing agent type(s) and

transport properties (solubility, diffusion coefficient), and the installed application details (mean temperature, permeability of applied facings). The diffusion rate of HFC-152a is $15 \%$ per year. (IPCC/TEAP 2005, Table 7.7)

Reuse of the foam is possible after building decommissioning, but the model assumes that at end-of-life the foam is disposed of in a landfill. End-of-life modeling includes transportation by heavy-duty diesel-fuel powered truck approximately $80 \mathrm{~km}(50 \mathrm{mi})$ to a C\&D landfill. Insulation in a landfill is modeled based on ecoinvent end-of-life waste management process data. For a typical North America building demolition followed by disposal in a landfill, it is reasonable to assume an initial blowing agent end-of-life loss of $20 \%$ followed by annual losses of $1 \%$. (UNEP/TEAP 2005, Table 4.2)

\subsubsection{Polyisocyanurate Foam Insulation}

Polyisocyanurate (polyiso) foam insulation has been modeled for the exterior wall application. The thermal resistance value for wall polyiso board is 6.5 which includes its impermeable board facer. This R-value is based on a 6-month accelerated aging test and was provided by 
representatives at Bayer MaterialScience. ${ }^{17}$ The foam has a wet, or pre-yield, density of $29.2 \mathrm{~kg} / \mathrm{m}^{3}\left(1.82 \mathrm{lb} / \mathrm{ft}^{3}\right)$. The final product, which includes the weight of the facers, has a nominal density of $32.0 \mathrm{~kg} / \mathrm{m}^{3}\left(2.0 \mathrm{lb} / \mathrm{ft}^{3}\right)$.

\section{Upstream Materials Production through Manufacturing}

\section{Upstream Materials Production}

Cradle-to-gate data on production through manufacturing is based on a 2010 study performed for the Polyisocyanurate Insulation Manufacturers Association (PIMA) (Bayer MaterialScience, 2011). The scope of this study included collecting and compiling mostly 2007 production data from the six PIMA member companies and compiling it into an industry average polyiso insulation board. Process energy data came from 29 out of 31 polyiso plants in the U.S. and Canada, representing approximately $94 \%$ of production in those geographies.

The chemicals to produce polyiso foam make up an "A" side (MDI) and a "B" side (polyester polyol with various additives such as catalysts, surfactants and flame retardants) plus a blowing agent (pentane). Table 4-20 presents the raw material inputs associated with polyiso foam production (Bayer MaterialScience $2011 \mathrm{Sec} .7$ ), provided on the basis of $2.54 \mathrm{~cm}$ (1 in) in thickness.

\section{Table 4-20 Raw Material Inputs to Produce Polyiso Foam}

\begin{tabular}{lccc} 
Inputs & $\begin{array}{c}\text { \% in foam } \\
(\mathbf{w t})\end{array}$ & $\begin{array}{c}\mathbf{k g ~ p e r ~} \mathbf{0 . 0 9} \mathbf{~ m}^{\mathbf{2}}, \\
\mathbf{2 . 5 4} \mathbf{~ c m} \text { thick }\end{array}$ & $\begin{array}{c}\mathbf{l b} \text { per } \mathbf{~ \mathbf { f t } ^ { 2 }} \mathbf{1} \\
\text { in thick }\end{array}$ \\
MDI & 55.5 & 0.0382 & 0.0842 \\
Polyester Polyol & 31 & 0.0213 & 0.0470 \\
TCPP & 3.4 & 0.0023 & 0.0051 \\
Catalyst K15 & 1.4 & 0.0010 & 0.0022 \\
Catalyst PC46 & 0.16 & $1.38 \mathrm{E}-04$ & 0.0003 \\
Catalyst PV & 0.08 & $6.90 \mathrm{E}-05$ & 0.0002 \\
Surfactant & 0.63 & $5.51 \mathrm{E}-04$ & 0.0012 \\
Pentane (blowing agent) & 7.5 & 0.0052 & 0.0115 \\
Process water & 0.1 & 0.0001 & 0.0002 \\
\hline
\end{tabular}

${ }^{17}$ Verbal communication with Bayer MaterialScience representatives, July 2013. 
The MDI comes from the U.S. LCI Database. Data for the polyester polyol comes from an ecoprofile study of aromatic polyester polyols (PE International 2010). Data for Tris (2-chloroisopropyl) phosphate (TCPP) are U.S. data compiled from literature sources (PE International 2011). Pentane data come from ecoinvent. No data were available to include the three catalysts or silicone surfactant; they total $2.3 \%$ of the total input, so a total of $97.7 \%$ of the inputs were included in the model.

Polyiso wall applications normally use aluminum Kraft paper (foil) for the facer. The foil facer raw materials include paper, aluminum foil, adhesives and coatings, and has a mass of 0.098 $\mathrm{kg} / \mathrm{m}^{2}\left(0.02 \mathrm{lb} / \mathrm{ft}^{2}\right)$ (Bayer MaterialScience 2008). Data on material composition come from an MSDS; based on this limited data source, the facer is modeled as $77 \%$ foil and $23 \% \mathrm{Kraft}$ (Atlas Roofing Corporation 2012). Data for foil is modeled as 50/50 primary and secondary aluminum from the U.S. LCI Database, plus sheet rolling (ecoinvent). Data for Kraft paper come from ecoinvent.

Raw materials are transported to the manufacturing plant via diesel truck or rail. The following distances and modes of transport were modeled:

- MDI: 2414 km (1 $500 \mathrm{mi})$ by rail;

- Polyester polyol: $1384 \mathrm{~km}$ (860 mi) by rail (90\%), $1384 \mathrm{~km}$ (860 mi) by truck (10\%);

- Pentane: 2414 km (1 $500 \mathrm{mi}$ ) by truck;

- Remaining materials: 1609 km (1 $000 \mathrm{mi})$ by truck.

\section{$\underline{\text { Manufacturing }}$}

According to Bayer MaterialScience (2011), polyiso plants consume primarily electricity and natural gas used to operate the laminator and associated operations support equipment, such as thermal oxidizers, storage areas, packaging machines, raw material pumps, offices, etc. A small amount of propane is used for fork lift trucks. Table 4-21 presents energy inputs and process outputs to produce 1 board-foot of foam, or $0.09 \mathrm{~m}^{2}\left(1 \mathrm{ft}^{2}\right)$ of $2.54 \mathrm{~cm}(1 \mathrm{in})$ thick polyiso foam.

\section{Table 4-21 Energy Inputs and Process Outputs for 1 Board-Foot Polyiso Foam}

\begin{tabular}{lcc} 
Energy inputs & Unit & Quantity \\
Electricity & MJ $(\mathrm{kWh})$ & $0.0497(0.0138)$ \\
Nat gas & $\mathrm{MJ}(\mathrm{Btu})$ & $0.0913(86.55)$ \\
Propane & $\mathrm{kg}(\mathrm{lb})$ & $0.00015(0.00031)$ \\
Outputs & Unit & Quantity \\
Pentane to air & $\mathrm{kg}(\mathrm{lb})$ & $0.00013(0.00030)$ \\
Waste scrap & board-foot & 0.01 \\
\hline
\end{tabular}


Based on review with polyiso plant manufacturers, approximately $2.5 \%$ of the pentane added to the foam is lost to air during manufacturing. Depending on the plant and local regulatory requirements, pentane is emitted directly to the atmosphere or to a thermal oxidizer for combustion. Only 13 plants out of 31 use thermal oxidizers to combust the pentane emissions. Since the majority of polyiso plants in North America do not use thermal oxidizers, the pentane is modeled as going directly to atmosphere (Bayer MaterialScience 2011).

Transportation and disposal of manufacturing waste scrap was modeled as going to an industrial landfill. It is assumed that a landfill for such non-hazardous waste is within $32 \mathrm{~km} \mathrm{(20} \mathrm{mi)} \mathrm{of} \mathrm{the}$ polyiso plant.

\section{Transportation to the Building Site through End-of-Life}

Transportation to the building site is modeled as $400 \mathrm{~km}$ (250 mi) by heavy-duty diesel truck. (Bayer MaterialScience 2011)

Installation tape is used but is excluded since it is considered negligible. Scrap polyiso generated at installation is assumed to be $2 \%$ of the total, consistent with other foam products in this category. While the product may be recyclable, it is modeled as being sent to a landfill $32 \mathrm{~km}(20$ mi) from the building site. Data for the landfill come from waste management datasets in ecoinvent. Pentane release at installation is negligible.

Polyiso insulation has a functional lifetime of over 40 years so no replacement is needed during the 40 year study period. How insulation in the buildings affects operating energy during the prototype buildings' use phase is addressed in other sections of this report.

Polyiso insulation is modeled as disposed of in a landfill at end-of-life. End-of-life modeling includes transportation by heavy-duty diesel truck approximately $80 \mathrm{~km}(50 \mathrm{mi})$ to a C\&D landfill. Insulation in a landfill is modeled based on ecoinvent end-of-life waste management process data. According to Bayer MaterialScience (2011), $50 \%$ of the total pentane in the product will have been released by end-of-life and $50 \%$ remains in the product.

\subsubsection{Windows}

\subsubsection{Introduction}

BIRDS residential tool evaluates double hung and casement windows with specifications complying with different energy code editions. Table 4-22 provides the U-factor and solar heat gain coefficients (SHGCs) used to address different climate zone and code edition requirements, plus the window characteristics and frame type modeled for each. 
Table 4-22 Window Specifications

\begin{tabular}{|c|c|c|c|}
\hline $\begin{array}{c}\text { U-Factor } \\
\mathbf{W} / \mathbf{m}^{2} \cdot \mathbf{K} \\
\left(\mathbf{B t u} / \mathbf{f t}^{2} \cdot{ }^{0} \mathbf{F} \cdot \mathbf{h}\right)\end{array}$ & SHGC & Window characteristics & $\begin{array}{c}\text { Frame Type for } \\
\text { Double Hung and } \\
\text { Casement Windows }\end{array}$ \\
\hline $1.99(0.35)$ & Any & 2 window panes, low-e coating, argon gas & Wood-clad frame \\
\hline $2.27(0.4)$ & Any & 2 window panes, low-e coating, argon gas & Vinyl frame \\
\hline $2.56(0.45)$ & Any & 2 window panes, tint & Wood-clad frame \\
\hline $2.84(0.5)$ & 0.3 & 2 window panes, tint & Wood-clad frame \\
\hline $2.84(0.5)$ & Any & 2 window panes, tint & Wood-clad frame \\
\hline $3.12(0.55)$ & Any & 2 window panes, tint & Wood-clad frame \\
\hline $3.41(0.6)$ & Any & 2 window panes, low-e coating, argon gas & Aluminum frame \\
\hline $3.69(0.65)$ & 0.3 & 2 window panes, low-e coating, argon gas & Aluminum frame \\
\hline $3.69(0.65)$ & 0.4 & 2 window panes, tint & $\begin{array}{l}\text { Aluminum frame, } \\
\text { thermal break }\end{array}$ \\
\hline $3.69(0.65)$ & Any & 2 window panes, low-e coating, argon gas & Aluminum frame \\
\hline $4.26(0.75)$ & 0.4 & 1 window pane, tint & Wood-clad frame \\
\hline $4.26(0.75)$ & Any & 1 window pane, no coating & Wood-clad frame \\
\hline $5.11(0.9)$ & Any & 1 window pane, tint & Wood-clad frame \\
\hline $6.81(1.2)$ & 0.3 & 1 window pane, low-e coating, tint & Aluminum frame \\
\hline $6.81(1.2)$ & 0.4 & 2 window panes, low-e coating, tint & Aluminum frame \\
\hline $6.81(1.2)$ & Any & 1 window pane, no coating & Aluminum frame \\
\hline
\end{tabular}

The compilation of window characteristics and frame types come from a variety of sources, including an online residential window selection tool ${ }^{18}$ and individuals in industry. It is acknowledged that there are many window assembly options (combination of frame material, glass in-fill, and operability) for residential structures in any climate zone; multiple window assembly options can be nearly identical in performance. The window assembly types presented in Table 4-22 represent one of many options available for each. As such, the window assemblies presented here are not endorsed or preferred over any other type of window assembly for a residential home.

${ }^{18}$ Efficient Windows Collaborative tool, found at http://www.efficientwindows.org/selection.cfm. 
BIRDS environmental performance data for the windows category was provided on a per 0.09 $\mathrm{m}^{2}\left(1 \mathrm{ft}^{2}\right)$ of a typical or common size of residential window. Since data were collected on a full window basis, windows were modeled as full windows and then normalized to $0.09 \mathrm{~m}^{2}\left(1 \mathrm{ft}^{2}\right)$. Figure 4-7 presents the general system boundaries for the window category as it is modeled for BIRDS.

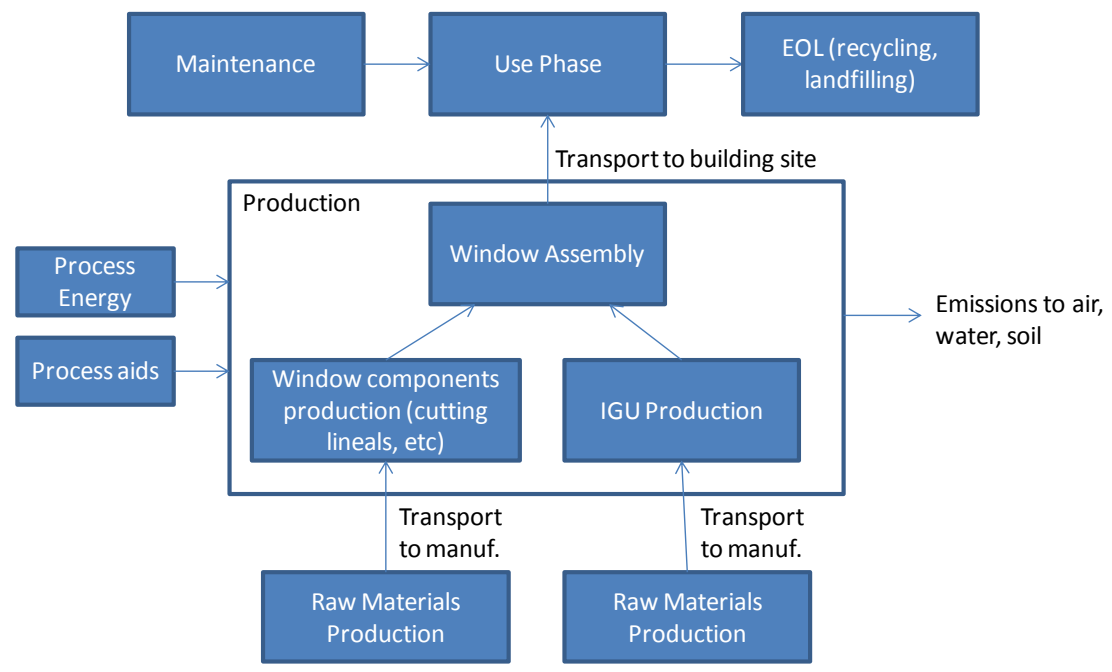

Figure 4-7 Windows System Boundaries

The next sections present the modeling and assumptions for the assemblies of wood clad, vinyl, aluminum, and aluminum with thermal break frames, for casement and double hung windows.

\subsubsection{Casement Windows Bill of Materials}

One North American manufacturer of residential windows provided primary data on wood clad, aluminum, and vinyl casement windows. Data were based on 2012 production, and material data were based on averaged information for all final assembly facilities located in North America. A generic casement window was modeled for each frame type, and the weight of each component was averaged between the plants. The data for the casement windows include:

- Frame and sash - quantities of each material;

- Insulated glass unit (IGU), including quantities and type(s) of glass, spacer, sealants, and gas if applicable;

- Hardware, weatherstrip, fasteners, and other components - quantities and types of each material.

Table 4-23, Table 4-24, and Table 4-25 provide dimensions and masses of the main parts of the casement windows. Due to the proprietary nature of the data, the details of the specific windows have been removed. Note that a thermal break is a material that separates the interior and exterior of a metal frame. The low thermal conductivity of the thermal break material reduces temperature transfer, making the metal window more energy efficient. 


\begin{tabular}{|c|c|c|c|}
\hline Description & Units & Single pane & Double pane \\
\hline Dimension of the window & $\mathrm{m}^{2}\left(\mathrm{ft}^{2}\right)$ & $1(10.76)$ & $1(10.76)$ \\
\hline Weight of the finished sealed unit & $\mathrm{kg}(\mathrm{lb})$ & $17.9(39.4)$ & $23.4(51.6)$ \\
\hline Wood and extruded aluminum (frame) & $\mathrm{kg}(\mathrm{lb})$ & $10.4(22.9)$ & $10.4(22.9)$ \\
\hline IGU & $\mathrm{kg}(\mathrm{lb})$ & $5.0(11)^{*}$ & $10.5(23.2)$ \\
\hline Other components & $\mathrm{kg}(\mathrm{lb})$ & $2.5(5.5)$ & $2.5(5.5)$ \\
\hline
\end{tabular}

\begin{tabular}{|c|c|c|c|c|}
\hline Description & Units & Single pane & Double pane & $\begin{array}{l}\text { Double pane w/ } \\
\text { thermal break }\end{array}$ \\
\hline Dimension of the window & $\mathrm{m}^{2}\left(\mathrm{ft}^{2}\right)$ & $1(10.76)$ & $1(10.76)$ & $1(10.76)$ \\
\hline Weight of the finished sealed unit & $\mathrm{kg}(\mathrm{lb})$ & $16.4(36.2)$ & $20.9(46.1)$ & $21.6(47.6)$ \\
\hline Extruded aluminum (frame) & $\mathrm{kg}(\mathrm{lb})$ & $9.7(21.4)$ & $9.7(21.4)$ & $9.7(21.4)$ \\
\hline IGU & $\mathrm{kg}(\mathrm{lb})$ & $3.9(8.6)^{*}$ & $8.4(18.5)$ & $8.4(18.5)$ \\
\hline Other components & $\mathrm{kg}(\mathrm{lb})$ & $2.8(6.2)$ & $2.8(6.2)$ & $3.6(7.9)$ \\
\hline
\end{tabular}

\section{Table 4-25 Dimensions and Main Parts of the Vinyl Casement Window}

$\begin{array}{lcc}\text { Description } & \text { Units } & \text { Double pane } \\ \text { Dimension of the window } & \mathrm{m}^{2}\left(\mathrm{ft}^{2}\right) & 1(10.76) \\ \text { Weight of the finished sealed unit } & \mathrm{kg}(\mathrm{lb}) & 20.1(44.4) \\ \text { Vinyl (frame) } & \mathrm{kg}(\mathrm{lb}) & 8.0(17.6) \\ \text { IGU } & \mathrm{kg}(\mathrm{lb}) & 10.0(22.1) \\ \text { Other components } & \mathrm{kg}(\mathrm{lb}) & 2.1(4.6)\end{array}$




\subsubsection{Double Hung Window Bill of Materials}

One North American manufacturer of residential windows provided primary data on wood clad double hung windows. Data were based on 2011 North American production, and material data were based on a typical construction of an average sized window. The data for double hung windows include:

- Frame and sash - quantities of each material;

- Insulated glass unit (IGU), including quantities and type(s) of glass, spacer, sealants, and gas if applicable;

- Weatherstrip, fasteners, coatings, and other components - quantities and types of each material, where applicable.

Table 4-26, Table 4-27, and Table 4-28 provide dimensions and masses of the main parts of the double hung windows modeled for BIRDS. Due to the proprietary nature of the data, the details of the specific windows have been removed. Note that data for the aluminum frame windows are based on extrapolation from casement windows data. The mass of framing material per linear foot of the casement's frame was used to calculate the estimated mass of that material in a double-hung window frame, using the perimeters of the double hung window. The same was done for IGU sealants and spacer, using the perimeters of the IGUs. To estimate other IGU materials and glass, the glass area was used. Most of the casement hardware was removed from the data set. The resulting double hung window is therefore comprised of estimated data. Data for the vinyl windows are based on extrapolations as described above.

\section{Table 4-26 Dimensions and Main Parts of the Wood Clad Double Hung Window}

$\begin{array}{lccc}\text { Description } & \text { Units } & \text { Single pane } & \text { Double pane } \\ \text { Dimension of the window } & \mathrm{m}^{2}\left(\mathrm{ft}^{2}\right) & 1.3(14.0) & 1.3(14.0) \\ \text { Weight of the finished sealed unit } & \mathrm{kg}(\mathrm{lb}) & 35.0(77.2) & 43.8(96.5) \\ \text { Wood and extruded aluminum (frame) } & \mathrm{kg}(\mathrm{lb}) & 24.7(54.4) & 24.7(54.4) \\ \text { IGU } & \mathrm{kg}(\mathrm{lb}) & 6.2(13.7)^{*} & 15.0(33.0) \\ \text { Other components } & \mathrm{kg}(\mathrm{lb}) & 4.1(9.1) & 4.1(9.1) \\ \text { * only glass } & & & \end{array}$


Table 4-27 Dimensions and Main Parts of the Aluminum Double Hung Window

$\begin{array}{lcccc}\text { Description } & \text { Units } & \text { Single pane } & \text { Double pane } & \begin{array}{c}\text { Double pane w/ } \\ \text { thermo-br }\end{array} \\ \text { Dimension of the window } & \mathrm{m}^{2}\left(\mathrm{ft}^{2}\right) & 1.3(14.0) & 1.3(14.0) & 1.3(14.0) \\ \text { Weight of the finished sealed unit } & \mathrm{kg}(\mathrm{lb}) & 20.8(45.9) & 25.4(56.0) & 26.7(58.9) \\ \text { Extruded aluminum (frame) } & \mathrm{kg}(\mathrm{lb}) & 15.6(34.4) & 15.6(34.4) & 15.6(34.4) \\ \text { IGU } & \mathrm{kg}(\mathrm{lb}) & 4.0(8.8)^{*} & 8.6(19.0) & 8.6(19.0) \\ \text { Other components } & \mathrm{kg}(\mathrm{lb}) & 1.2(2.7) & 1.2(2.7) & 2.5(5.5) \\ * \text { * only glass } & & & & \end{array}$

Table 4-28 Dimensions and Main Parts of the Vinyl Double Hung Window

$\begin{array}{lcc}\text { Description } & \text { Units } & \text { Double pane } \\ \text { Dimension of the window } & \mathrm{m}^{2}\left(\mathrm{ft}^{2}\right) & 1.3(14.0) \\ \text { Weight of the finished sealed unit } & \mathrm{kg}(\mathrm{lb}) & 23.6(52.0) \\ \text { Vinyl (frame) } & \mathrm{kg}(\mathrm{lb}) & 12.9(28.4) \\ \text { IGU } & \mathrm{kg}(\mathrm{lb}) & 10.2(22.5) \\ \text { Other components } & \mathrm{kg}(\mathrm{lb}) & 0.5(1.1)\end{array}$

\subsubsection{Production Data for the Materials}

Greater than $99 \%$ of the mass of materials in each window were included and modeled for these window systems. While data in the tables represent masses of materials in the finished windows, manufacturers quantified amounts of unusable (i.e., waste) materials and materials recovered, recycled, or reused, including wood and extruded aluminum. Manufacturers noted which materials were reused, recycled, landfilled, or disposed of in another way. Where materials were reused or recycled, the production of that overage was not included in the model. Where material was landfilled or incinerated, the overage was included with the window model and the appropriate waste disposal treatment method was modeled. Some of the information used for the windows modeling was supplemented by Salazar (2007).

Supplier distances to the manufacturing or assembly plant were provided by the manufacturers. Modes of transportation included heavy-duty diesel-fueled truck, ocean freighter and rail. The 
appropriate distances and modes were modeled as such, using data from the U.S. LCI Database. Where transport distances were not given for smaller contributing materials, an average of 965 $\mathrm{km}(600 \mathrm{mi})$ was modeled as transported by diesel truck.

Window frame raw materials. The wood clad frame consists of planed, kiln-dried lumber and extruded aluminum profile. The wood part of the frame is modeled as having equal amounts of planed, kiln-dried wood from the Southeast and Pacific Northwest, and data come from the U.S. LCI Database. The aluminum profile is modeled as $50 \%$ primary and $50 \%$ secondary aluminum, and data come from the U.S. LCI Database. Data for extrusion come from an average of primary data from one window manufacturer and ecoinvent. The thermal break (used in the aluminum windows only) is made up of glass-reinforced polyamide, from ecoinvent, and PUR resin, from U.S. LCI Database and ecoinvent. Where applicable, stains and external coatings were modeled. The paint and primer are modeled as alkyd oil based, and stain is assumed to be latex-based; these data are built using ecoinvent data sets.

IGU raw materials. The data for float glass come from ecoinvent, based on early 2000's European processes and technologies. Due to lack of available data on U.S. float glass production, older European data were implemented. Processes in the data set include melting, cullet addition, forming (on a float bath), annealing by cooling in an oven (lehr), cutting of the glass, and storage. While this data set may not be representative of current U.S. production, it has been customized using U.S. energy and transportation data sets. Also, some transportation impacts have been removed, including transport between manufacturing plants and coating facilities, which, according to U.S. windows industry representatives, exists for European operations but not for U.S. operations. The next version of BIRDS hopes to have more representative data on glass production.

The spacer, which separates the two panes of glass, can be made of an array of materials, including aluminum, stainless steel, and tin-plated steel. A hypothetical mix of equal parts of these three materials was used. Salazar (2007) reported a loss of approximately $10 \%$ of the spacer; this has been factored in to the model. However, the loss is recycled and is, therefore, not waste. The inner primary sealant, commonly polyisobutylene (PIB), is used to prevent leakage of the argon gas as well as penetration of water vapor into the space between the panes. An assumption of 50/50 polysulphide polymer and polyurethane as secondary sealants were implemented. The desiccant in the spacer, a silicone based product, is used to absorb moisture. Salazar (2007) reported a loss of approximately $0.7 \%$ and this has been factored into the model. Salazar (2007) reported an escape of argon when the cavity is flushed prior to being sealed approximately $95 \%$ more than the quantity in the finished unit. The manufacturers did not provide data on material losses. Since it is unknown if the reported quantity of escaped argon is high or low, a $50 \%$ escape is assumed for this model.

Aluminum and PUR data come from the U.S. LCI Database. Data for the other IGU materials come from ecoinvent. Synthetic rubber is used as a general proxy for PIB. 
Other components raw materials. The jambliner, or the lining between the window sash and frame, is modeled as vinyl; data for PVC resin comes from the U.S. LCI Database and extrusion comes from ecoinvent. Other components may include a combination of clips, gaskets, hardware, weatherstrip, and sealant. Clips, and gaskets are modeled as PVC and rubber parts. Weatherstrip is described below. The sealant is assumed to be silicone-based. U.S. LCI Database provided the production data for PVC while the ecoinvent database provided the data for the remaining materials.

Hardware is custom ordered and may vary with the window. For BIRDS, a hypothetical mix of equal parts of stainless steel, cold rolled steel, and bronze has been modeled. The steel in screws and other steel parts is based on data from World Steel Association (2011), with steel profiles customized to U.S. using the U.S. electricity grid; steel product manufacturing, i.e. parts forming, comes from ecoinvent. Stainless steel is from a chromium steel (18/8 grade) stainless steel data set from ecoinvent with a steel product manufacturing data set to account for part forming. Bronze comes from ecoinvent.

Coatings. Low-emissivity (low-E) coatings and tinted windows have been included in the windows modeling to meet different performance characteristics of the windows. Coatings are used to improve the insulation properties of the glass by reflecting visible light and infrared radiation. Low-E coating is modeled using the coating details of ecoinvent's "flat glass, coated" data set as a starting point. The technology used at this plant is based on a cathodic sputtering technology which involves depositing thin silver and other layer(s) on the glass. According to the ecoinvent documentation, the raw materials used for sputtering are bismuth, silver and nickelchrome. The quantity of $1.19 \mathrm{E}-4 \mathrm{~kg}(2.62 \mathrm{E}-4 \mathrm{lb})$ metals per $\mathrm{kg}$ was divided into three to account for $1 / 3$ nickel, $1 / 3$ chromium, and 1/3 silver. These data are approximate.

Tint is obtained by adding small amounts of metal oxides during glass manufacturing, coloring the glass uniformly. For BIRDS, iron oxide has been assumed to be the mineral additive for the tint, and it is modeled as applied at an assumed rate of $0.1 \%$ of the weight of glass.

\subsubsection{Manufacturing}

Manufacturing data is representative of the year 2011 based on total windows manufactured that year. Data include process energy and water consumption. Electricity was reported for material preparation and window assembly, and natural gas was reported for heating and drying ovens. The facility totals were normalized to one window. These data are an average and not specific for the exact window(s) being modeled. For confidentiality purposes, the data are not shared in this documentation, however, they have been included in the models for all of the window types.

\subsubsection{Transportation to the Building Site, Use and Maintenance}

Transportation of the window to the building site is modeled an average of $805 \mathrm{~km}$ (500 mi) by heavy-duty diesel fuel-powered truck. 
Installing windows is primarily a manual process; no energy or emissions are included in the model. Windows come to the construction site fully assembled and custom-ordered to fit so there is generally no installation waste.

Maintenance of the windows includes weatherstripping and sealing. Weatherstrip is modeled as a thermoplastic elastomer. Data for the thermoplast, as ethylene propylene diene monomer (EPDM) rubber, come from ecoinvent (as synthetic rubber). For BIRDS, an EPDM weatherstrip has been modeled in the amount of $0.0064 \mathrm{~kg}$ per $0.3 \mathrm{~m}(0.014 \mathrm{lb}$ per $\mathrm{ft})$. Weatherstrip is assumed to perform at its optimal level an average of 7.5 years (Vigener 2012) so is modeled as replaced every 7.5 years. Different perimeter sealants can be used for different applications. For BIRDS, an acrylic latex sealant with silicone has been modeled in the amount of $0.029 \mathrm{~kg}$ per $\mathrm{m}$ ( $0.31 \mathrm{oz}$ per $\mathrm{ft}$ ), which is based on a $0.47 \mathrm{~cm}$ (0.19 in) diameter bead. (DAP 2011) Data for the sealant is described later in this documentation in Section 4.5.7 and is modeled as being replaced every 15 years (Vigener 2012).

Other maintenance, such as glass and/or window frame cleaning, frame repainting or recoating, hardware adjustment or replacement, are not included in the analysis. All operational energyrelated aspects of the window are addressed in other sections of this report.

The windows are modeled as having a lifetime of 30 years. Lifetime was set based on Earthsure's (2013) draft window industry PCR, even though it is acknowledged that realistically, the lifetime of windows can vary (based on frame type, weather conditions, maintenance, etc.), and that often windows have a longer service life than 30 years.

\subsubsection{End-of-Life}

Wood clad and vinyl windows are modeled as landfilled at end-of-life. The frame of the aluminum window is modeled as recycled at end-of-life, and the 0-100 recycling methodology has been applied. For this, system expansion is applied; the production of the same amount of virgin aluminum that is in the frame is subtracted out of the system, crediting the system with an avoided burden based on the reduced requirement for virgin material production in the next lifecycle. Likewise, recycled content in the aluminum adds some of the burden to the product system in order to share the burden with the previous life-cycle. For more information on the approach to modeling metals at end-of-life, see Atherton (2006) and World Steel Association (2011). The remaining parts of the window, including the IGU, are disposed of in a landfill.

End-of-life modeling includes transportation by diesel-fuel powered truck approximately $80 \mathrm{~km}$ (50 mi) to a C\&D landfill or to recycling. The portions of the window going to landfill are modeled based on ecoinvent end-of-life waste management process data.

\subsubsection{HVAC}

Residential BIRDS evaluates air conditioning systems and gas furnaces. BIRDS environmental performance data for these was provided on a per-unit (or per-system) basis as well as electric 
furnaces for future updates of the BIRDS new residential database. Figure 4-8 presents the general system boundaries for these as they are modeled for BIRDS.

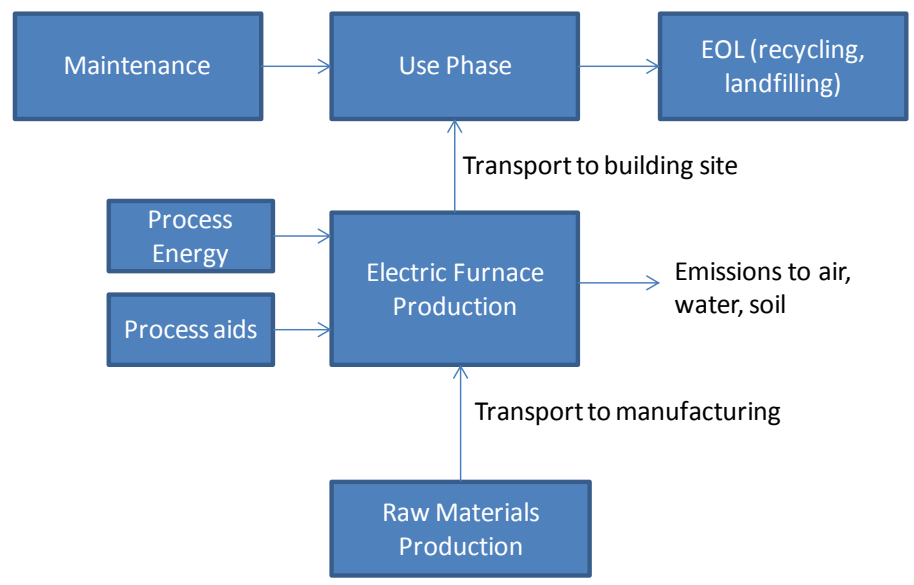

\section{Figure 4-8 HVAC System Boundaries - Electric Furnace Example}

\subsubsection{Natural Gas and Electric Furnaces}

\section{Upstream Materials Production through Manufacturing}

Proxy data were used because no bill of materials data were available for residential furnaces. Athena (2003) provided teardown data for a medium efficiency Lennox sealed combustion furnace, manufactured in 1985. These data were used with adjustments. The mass of the Lennox, $91 \mathrm{~kg}$ (200 lb), was normalized to the mass of an efficient natural gas furnace currently available on the market that weighs approximately $56 \mathrm{~kg}(124 \mathrm{lb}) .{ }^{19,20}$ These data were supplemented by Yang (2008), which provided data for a blower motor, replacing that of the older Lennox, to account for the more efficient furnace. Table 4-29 provides the materials in the natural gas furnace; the notes column identifies the adjustments made.

\footnotetext{
${ }^{19}$ Weight of the Standard Rheem Classic $95 \%$ efficiency natural gas furnace (RGRC-07-RBGS) from Rheem Classic Series, Upflow Gas Furnaces, Physical Data and Specifications, Form No. G11-527, p.4.

20 This source states a total shipping weight of $62.1 \mathrm{~kg}(137 \mathrm{lb})$. The mass of the equipment itself was assumed to be $91 \%$ of the total weight, based on other Rheem product published weights relative to their shipping materials.
} 
Table 4-29 Natural Gas Furnace Bill of Materials

\begin{tabular}{|c|c|c|c|}
\hline \multirow[b]{2}{*}{ Material } & \multicolumn{2}{|c|}{ Mass } & \multirow[b]{2}{*}{ Notes } \\
\hline & kg & lb & \\
\hline Aluminum & 1.02 & 2.25 & $\begin{array}{l}\text { Yang (2008) air blower data, replacing the } \mathrm{Al} \text { in } \\
\text { Athena (2003) }\end{array}$ \\
\hline Brass & 0.05 & 0.11 & \\
\hline Ceramic & 0.04 & 0.08 & \\
\hline Circuit board, transistors & 0.05 & 0.11 & \\
\hline Copper & 2.20 & 4.85 & $\begin{array}{l}\text { Yang (2008) air blower data, replacing the } \mathrm{Cu} \\
\text { in Athena (2003) }\end{array}$ \\
\hline $\begin{array}{l}\text { Fiberglass insulation (foil- } \\
\text { lined) }\end{array}$ & 0.27 & 0.60 & \\
\hline Galvanized Steel & 21.86 & 48.19 & Steel paired down to meet the Rheem weight \\
\hline PET & 0.38 & 0.83 & \\
\hline PVC & 0.45 & 0.99 & \\
\hline Powder coating & 0.19 & 0.42 & \\
\hline Rubber & 0.02 & 0.04 & \\
\hline Steel & 29.79 & 65.66 & $\begin{array}{l}\text { Yang (2008) air blower and Athena (2003). } \\
\text { Steel paired down to meet the Rheem weight }\end{array}$ \\
\hline Total & 56.3 & 124.1 & \\
\hline
\end{tabular}

For the electric furnace, the mass of the Lennox was normalized down to the mass of the electric furnace in BIRDS, a unit currently on the market. ${ }^{21}$ Data for the blower motor were provided by Yang (2008). Table 4-30 presents the bill of materials with data adjustments.

${ }^{21}$ Rheem Air Handlers, Form No. H11-524 REV. 8, Unit Dimensions \& Weights, p.4, model 4221/4821. 
Table 4-30 Electric Furnace Bill of Materials

\begin{tabular}{|c|c|c|c|}
\hline \multirow[b]{2}{*}{ Material } & \multicolumn{2}{|c|}{ Mass } & \multirow[b]{2}{*}{ Notes } \\
\hline & kg & lb & \\
\hline Aluminum & 1.02 & 2.25 & Yang (2008), replacing the $\mathrm{Al}$ in Athena (2003) \\
\hline Brass & 0.05 & 0.11 & \\
\hline Ceramic & 0.04 & 0.08 & \\
\hline Circuit board, transistors & 0.05 & 0.11 & \\
\hline Copper & 2.20 & 4.85 & Yang (2008), replacing the $\mathrm{Cu}$ in Athena (2003) \\
\hline $\begin{array}{l}\text { Fiberglass insulation (foil- } \\
\text { lined) }\end{array}$ & 0.27 & 0.60 & \\
\hline Galvanized Steel & 34.04 & 75.04 & Steel paired down to meet the Rheem weight \\
\hline PET & 0.38 & 0.83 & \\
\hline $\mathrm{PVC}$ & 0.45 & 0.99 & \\
\hline Powder coating & 0.32 & 0.71 & $\begin{array}{l}\text { Model assumes } 0.095 \mathrm{~kg} \text { powder per } \mathrm{m}^{2} \text { (from } \\
\text { ecoinvent) }\end{array}$ \\
\hline Rubber & 0.02 & 0.04 & \\
\hline Steel & 29.17 & 64.31 & $\begin{array}{l}\text { Yang (2008) air blower and Athena (2003). Steel } \\
\text { paired down to meet the Rheem weight }\end{array}$ \\
\hline Total & 68.00 & 149.9 & \\
\hline
\end{tabular}

The steel is assumed to be cold-rolled; this and the galvanized steel come from World Steel Association (2011). Aluminum is modeled as a 50/50 mix of primary and secondary extruded aluminum which come from the U.S. LCI Database. Data for copper come from ICA (2012). Data for PET and PVC come from the US LCI database. Ecoinvent provided the data for brass, ceramics, integrated circuit boards, rubber (as synthetic rubber), and powder coating. The fiberglass insulation was modeled as described in the insulation section of this report.

Raw materials are modeled as transported to the manufacturing plant via diesel truck an assumed average distance of $805 \mathrm{~km}$ (500 mi).

No manufacturing data were available for residential furnaces, so as proxy, an ecoinvent data set for a 10-kW (34-MBH) oil boiler was used (ecoinvent Report No. 6-IV 2007). The ecoinvent dataset description states that the $10 \mathrm{~kW}$ low- $\mathrm{NO}_{\mathrm{x}}$ or condensing boiler data may be applied for residential furnaces. (ecoinvent Report No. 6-IV, 2007, p.2) The production energy is stated to 
be estimated from a 1998 environmental report. In general, the data being estimated and of older vintage are considered to be not representative of current practice. Nonetheless, the use of these data was considered to be better than no data at all and sufficient for comparison purposes.

Table 4-31 shows data for a boiler of approximately $150 \mathrm{~kg}(331 \mathrm{lb})$. Since manufacturing the smaller units is assumed to require less energy, these data were normalized based on the total weights of the natural gas and electric furnaces.

\section{Table 4-31 Furnace Manufacturing}

Energy source

Electricity, medium voltage MJ (Btu)

Natural gas in industrial furnace MJ (Btu)

Light fuel oil in industrial furnace MJ (Btu)

Tap water liter (gal)
Quantity for $10 \mathrm{~kW}$ boiler

294 (81.7)

$424(401874)$

$236(223685)$

$182(48)$

\section{Transportation to the Building Site through End-of-Life}

Transportation of the equipment to the building site is modeled as an assumed average of $644 \mathrm{~km}$ (400 mi) by heavy-duty diesel fuel-powered truck.

It is assumed that a qualified service technician comes to the building site to check and/or service the unit one time every three years to ensure optimal performance and lifetime. It is assumed that the qualified technician is within a $24 \mathrm{~km}(15 \mathrm{mi})$ service radius. This distance, driven in a gasoline-powered van, is allocated amongst other service visits, assuming that the same technician is making more than one service call during that trip. Assuming the technician makes 5 service calls in one day, one-fifth of the impacts from driving $24 \mathrm{~km}(15 \mathrm{mi})$ are allocated to the product, or $4.8 \mathrm{~km}$ (3 mi). Data for a van come from ecoinvent. Unplanned service visits (i.e., unanticipated issues that require a service technician) are not included in the model, assuming that the home owner adequately follows the maintenance and care guidelines.

A lifetime of 18 years has been assumed for both the gas and electric furnaces, based on NAHB (2007), a study on life expectancy of home components. ${ }^{22}$

At the end-of-life, it is assumed that the air conditioners are sent for recycling to recover valuable metal (see Section 4.5.3.7 for the recycling methodology used). What cannot be recovered, i.e., the non-metal parts, are modeled as landfilled, and a distance of $48 \mathrm{~km}$ (30 mi) to the landfill in a heavy-duty diesel truck has been modeled. The landfill is modeled based on ecoinvent end-of-life waste management process data.

\footnotetext{
${ }^{22}$ NAHB (2007), Table 1, Section 15 gives furnaces a life expectancy range of 15 to 20 years.
} 


\subsubsection{Residential Air Conditioners}

Residential air conditioners for BIRDS are modeled as split systems with outdoor and indoor components that provide a condenser and evaporative heat exchanger, respectively. BIRDS includes LCA data for 3-ton residential air conditioners with Seasonal Energy Efficiency Ratios (SEERs) of 13, 14, 18, and 21. SEER is defined by the Air Conditioning, Heating, and Refrigeration Institute (AHRI) as total heat removed from the conditioned space during the annual cooling season, expressed in Btu's, divided by the total electrical energy consumed by the air conditioner or heat pump during the same season, expressed in watt-hours. (AHRI 2008, Def. 3.9) Eighteen SEER is considered to be a high rating relative to other models; based on informal discussions with industry members, only a small percentage of the market is currently at 18 SEER. An even smaller percentage is beyond 18 SEER, so 21 SEER is considered to be exceptionally high, providing an extremely efficient system.

\section{Upstream Materials Production through Manufacturing}

Bill of materials for the inside and outside units shown in Table 4-32 came from De Kleine (2009). The condensing unit is based on a tear-down of a 3-ton, 10 SEER unit manufactured in approximately 2001. The components' materials were assumed by Four Elements, except where noted. 
Table 4-32 Condenser Unit Bill of Materials

\begin{tabular}{|c|c|c|c|c|}
\hline \multicolumn{5}{|c|}{ Mass } \\
\hline Main Component & Material Breakdown & kg & Lb & Notes \\
\hline \multirow[t]{4}{*}{ Compressor } & Aluminum & 0.53 & 1.16 & \multirow{4}{*}{$\begin{array}{l}\text { Compressor breakdown from Biswas (2011), } \\
\text { Fig } 1 .\end{array}$} \\
\hline & Cast iron & 24.74 & 54.54 & \\
\hline & Copper & 1.32 & 2.90 & \\
\hline & Steel & 2.72 & 6.00 & \\
\hline \multirow[t]{2}{*}{ Coil Assembly } & Copper (tubing) & 3.95 & 8.71 & \multirow{2}{*}{$\begin{array}{l}\text { Approx } 50 \% \text { copper tubing, } 50 \% \text { aluminum } \\
\text { fins. (De Kleine, 2009, Sec. } 3.1 .4 \text { ) }\end{array}$} \\
\hline & Aluminum (fins) & 3.95 & 8.71 & \\
\hline \multirow[t]{3}{*}{ Fan Motor } & Copper wire & 1.08 & 2.37 & \multirow{3}{*}{$\begin{array}{l}\text { Assumed to have a composition of } 25 \% \text { copper } \\
\text { wire, } 72 \% \text { steel, and } 3 \% \text { polyamide (De } \\
\text { Kleine, 2009, Sec. 3.1.4) }\end{array}$} \\
\hline & Steel & 3.10 & 6.83 & \\
\hline & Polyamide & 0.13 & 0.28 & \\
\hline Unit Wall & Galvanized steel & 3.10 & 6.83 & \\
\hline Base & Galvanized steel & 2.70 & 5.95 & \\
\hline Top Cover & Galvanized steel & 1.90 & 4.19 & \\
\hline Fan Guard & Stainless steel & 1.60 & 3.53 & \\
\hline \multirow{2}{*}{$\begin{array}{l}\text { Refrigerant Line } \\
\text { service valve }\end{array}$} & Brass (service valves) & 0.75 & 1.65 & \\
\hline & Rubber & 0.25 & 0.55 & \\
\hline Wire Guard & Stainless steel & 0.80 & 1.76 & \\
\hline Fan Blade & Steel & 0.60 & 1.32 & \\
\hline Misc Fasteners & Steel & 0.30 & 0.66 & \\
\hline Capacitor & Sheet metal (steel) & 0.30 & 0.66 & \\
\hline \multirow[t]{2}{*}{ Relay Switch } & Copper wiring & 0.10 & 0.22 & \multirow{2}{*}{$\begin{array}{l}\text { Assumed to be } 50 \% \text { copper wiring and } 50 \% \\
\text { nylon polymer (De Kleine, 2009, Sec. 3.1.4) }\end{array}$} \\
\hline & Nylon polymer & 0.10 & 0.22 & \\
\hline Copper Wiring & Copper wire & 0.20 & 0.44 & \\
\hline Total & & 54.20 & 119.49 & \\
\hline
\end{tabular}


De Kleine's (2009) teardown was for a SEER 10, and he needed the bill of materials for the higher SEERs required for his study. To do this, De Kleine created a weight function using survey data and manufacturer specification sheets on condenser units from several different brands ranging in efficiency from 10 SEER to 18 SEER and ranging in capacity from 1.5 tons to 5 tons of cooling. This weight function was used to calculate the mass of each of the condenser units in BIRDS as follows, enabling the adjustment of the bill of materials to the different masses as shown in Table 4-33. See De Kleine (2009) Sec. 3.1.3 for more detail.

Table 4-33 Condenser Unit Masses

$\begin{array}{lccccc} & \text { SEER 10 } & \text { SEER 13 } & \text { SEER 14 } & \text { SEER 18 } & \text { SEER 21 } \\ \text { Factor } & 1 & 1.36 & 1.49 & 1.98 & 2.34 \\ \text { Mass in kg (lb) } & 54.2(119.5) & 74.1(163.5) & 80.8(178.1) & 107.4(236.7) & 127.3(280.7)\end{array}$

These values corresponded with De Kleine (2009), and are consistent with manufacturers' products of the same SEER ratings.

The evaporator coil indoor unit was modeled as being housed in the electric furnace. De Kleine (2009, Sec 3.1.2) approximated the inside coil assembly for a 13 SEER system to weigh $15.9 \mathrm{~kg}$ (35 lb) and be composed of $50 \%$ copper tubing and $50 \%$ aluminum fins. The refrigerant line, connecting the outdoor and indoor units, was modeled as 20 feet of copper tubing weighing 4.5 $\mathrm{kg}$ (9.9 lb) (De Kleine, 2009, Sec. 3.1.4). The air conditioning system uses R-410a refrigerant, and data for the quantity of refrigerant used in each of the SEERs studied (shown in Table 4-34) was calculated using refrigerant mass function developed by De Kleine (2009, Sec. 3.1.4).

Table 4-34 Refrigerant Quantities

\begin{tabular}{|lcccc|} 
& SEER 13 & SEER 14 & SEER 18 & SEER 21 \\
\hline $\mathbf{R - 4 1 0 a}$ in kg (lb) & $3.3(7.3)$ & $3.6(7.9)$ & $5.0(10.9)$ & $6.5(14.4)$
\end{tabular}

The steel, assumed to be cold-rolled, and the galvanized steel come from World Steel Association (2011). Aluminum is modeled as a 50/50 mix of primary and secondary extruded aluminum which come from the U.S. LCI Database. Data for copper tube, sheet, and wire come from ICA (2012). Ecoinvent provided the data for the cast iron, stainless steel, brass, rubber (as synthetic rubber), and polyamide.

R-410a data are based on a 50/50 share of difluoromethane (R-32) and pentafluoroethane (R125). Due to lack of available production data on both of these chemicals, proxies were implemented. Trifluoromethane (HFC-23) was used as a proxy for difluoromethane and 
1,1,difluoroethane (HFC 152a) was used as proxy for R-125. Note: while proxies were used for the production aspect of the chemicals, any release of these was based on the release of R-32 and $\mathrm{R}-125$, not the proxy chemicals, so that ozone depletion impact remains zero and global warming potential impact is calculated appropriate to R-410a.

Raw materials are modeled as transported to the manufacturing plant via diesel truck an assumed average distance of $805 \mathrm{~km}(500 \mathrm{mi})$.

No manufacturing data were available for residential air conditioners, so as proxy, an ecoinvent data set for a $10 \mathrm{~kW}(34 \mathrm{MBH})$ oil boiler was used. Since manufacturing the smaller units is assumed to require less energy and resources than the $150 \mathrm{~kg}(331 \mathrm{lb})$ boiler, these data were normalized based on the total weights of the air conditioners.

\section{Transportation to the Building Site through End-of-Life}

Transportation of the equipment to the building site is modeled an assumed average of $1287 \mathrm{~km}$ ( $800 \mathrm{mi}$ ) by heavy-duty diesel fuel-powered truck. This distance was estimated by De Kleine (2009) and is based on five manufacturing locations of major residential air conditioner manufacturers.

It is assumed that a qualified service technician comes to the building site to check and service the unit every three years to ensure optimal performance and lifetime. It is assumed that the qualified technician is within a $24 \mathrm{~km}(15 \mathrm{mi})$ service radius. This distance is driven in a gasoline-powered van and is shared amongst other service visits for that technician, assuming that the same technician is making more than one service call during that trip. Assuming the technician makes 5 service calls in one day, one-fifth of the impacts from driving $24 \mathrm{~km}(15 \mathrm{mi})$

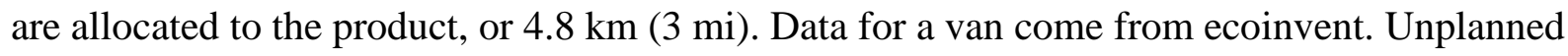
service visits (i.e., unanticipated issues that require a service technician) are not included in the modeling assuming that the home owner adequately follows the maintenance and care guidelines.

A lifetime of 15 years has been assumed for the air conditioners. (NAHB 2007, Table 1) During use, refrigerant is assumed to escape at a rate of $2 \%$ per year of the total refrigerant. (De Kleine 2009, Sec. 3.3. It is recharged every three years during the maintenance visit.

At the end-of-life, it is assumed that the air conditioners are sent for recycling to recover valuable metal (see Section 4.5.3.7 for the recycling methodology used). What cannot be recovered, i.e., the non-metal parts, are modeled as landfilled. A distance of $48 \mathrm{~km}$ (30 mi) to the landfill in a heavy-duty diesel truck has been modeled. The landfill is based on ecoinvent waste management process data. A study prepared for Air-Conditioning, Heating, and Refrigeration Technology Institute (AHRTI, 2011) assumes an overall loss of 15\% of the R-410a refrigerant. This is based on "recovering $90 \%$ of the charge from $95 \%$ of the field units, but allowing for a $100 \%$ charge loss from about $5 \%$ of the field stock". (AHRTI 2011, p.12) 


\subsubsection{Residential Electric and Gas Water Heaters}

Electric and gas water heaters with 189-liter (50-gal) storage tanks were included in BIRDS.

\section{Upstream Materials Production through Manufacturing}

Bill of materials data for both water heaters came from a comprehensive study by VHK (2007) on the eco-design of water heaters. Table B.9 in VHK (2007) provided bills of materials for several electric water heaters; the heater with $200 \mathrm{~L}$ ( $53 \mathrm{gal}$ ) storage tank was used, as its size is closest to the 189 l (50 gal) needed for BIRDS. Since the Material Groups listed in Table B.9 were fairly general, these data were supplemented by more detailed parts and materials provided by Table B.10 in VHK (2007) to develop the data shown in Table 4-35. Any assumptions made are noted.

\section{Table 4-35 Electric Water Heater Bill of Materials}

\begin{tabular}{|c|c|c|c|}
\hline \multirow[b]{2}{*}{ B.9 Material Group } & \multicolumn{2}{|c|}{ Mass } & \multirow[b]{2}{*}{ Parts, Materials \& Assumptions } \\
\hline & kg & $\mathbf{l b}$ & \\
\hline 3-Ferro & 40.5 & 89.2 & $\begin{array}{l}\text { Tank, mounting plate, screws. Tank assumed to be } \\
\text { stainless steel }\end{array}$ \\
\hline 2-TecPlastics & 1.5 & 3.3 & $\begin{array}{l}\text { Rubber gasket (assume } 25 \% \text { ), PVC pipe protection and } \\
\text { pipe collar, PVC thermal control (assume } 75 \% \text { ) }\end{array}$ \\
\hline 1-BlkPlastics - & 1.2 & 2.7 & Assume EPS insulation \\
\hline 7-Misc & 1.2 & 2.7 & $\begin{array}{l}\text { Portion of the Misc. category; part unknown. Assuming } \\
\text { packaging, based on Table B.10. Not included in this } \\
\text { analysis. }\end{array}$ \\
\hline 7-Misc & 0.3 & 0.7 & Portion of the Misc. category; Assume resistance heater \\
\hline 5-Coating & 3.1 & 6.7 & Assume enamel \\
\hline 4-Non-ferro & 0.2 & 0.5 & Assume copper \\
\hline 6-Electronics & 0.06 & 0.1 & Assume wiring, thermal control \\
\hline TOTAL & 48.1 & 106.0 & \\
\hline
\end{tabular}

Bill of materials for the gas water heater and its storage tank shown in Table 4-36 are based on Table B. 8 in VHK (2007), which contains materials for a generic water storage tank and the natural gas component of a water heater. Since a 1891 ( 50 gal) storage tank was not offered by VHK (2007), the data for the 1501 (39.6 gal) tank was normalized on a mass basis. The data for the gas heating component was left the same. 
Table 4-36 Gas Water Heater Bill of Materials

\begin{tabular}{|c|c|c|c|}
\hline \multirow{2}{*}{$\begin{array}{l}\text { Parts } \\
\text { Generic tank }\end{array}$} & \multicolumn{2}{|c|}{ Mass } & \multirow[t]{2}{*}{ Materials } \\
\hline & kg & lb & \\
\hline Tank & 26.0 & 57.3 & Galvanized steel \\
\hline Enamel & 4.7 & 10.3 & Enamel \\
\hline Insulation & 9.1 & 20.0 & Rigid PUR foam \\
\hline Mantle & 11.7 & 25.9 & Galvanized steel \\
\hline Top/bottom & 0.3 & 0.6 & Polypropylene \\
\hline Diptube & 2.1 & 4.7 & Galvanized steel \\
\hline Fitting & 1.3 & 2.8 & Brass \\
\hline Mounting & 0.6 & 1.4 & Galvanized steel \\
\hline Subtotal & 55.8 & 122.9 & \\
\hline \multicolumn{4}{|c|}{ Gas storage component } \\
\hline Burner & 1.5 & 3.3 & Galvanized steel \\
\hline H Ex & 3.5 & 7.7 & Galvanized steel \\
\hline Flue parts & 2.7 & 6.0 & Galvanized steel \\
\hline Gas valve & 1.4 & 3.1 & Aluminum diecast \\
\hline Brass parts & 1.0 & 2.2 & Brass \\
\hline Various steel parts & 41.0 & 90.4 & Galvanized steel \\
\hline Subtotal & 51.1 & 112.7 & \\
\hline Total & 106.9 & 235.6 & \\
\hline
\end{tabular}

All steel and galvanized steel data come from World Steel Association (2011). Aluminum is modeled as a 50/50 mix of primary and secondary extruded aluminum which come from the U.S. LCI Database. Data for copper sheet and wire come from ICA (2012). U.S. LCI Database provided the production data for PVC and PP. Ecoinvent provided the data for the stainless steel, brass, rubber (as synthetic rubber), EPS, PUR foam, and enamel.

Raw materials are modeled as transported to the manufacturing plant via diesel truck an assumed average distance of $805 \mathrm{~km}$ (500 mi). 
No manufacturing data were available for residential water heaters, so as proxy, the ecoinvent data set for a $10 \mathrm{~kW}(34 \mathrm{MBH})$ oil boiler was used. Since manufacturing the smaller units is assumed to require less energy and resources than the $150 \mathrm{~kg}(331 \mathrm{lb})$ boiler, these data were normalized based on the total weights of the water heaters.

\section{Transportation to the Building Site through End-of-Life}

Transportation of the equipment to the building site is modeled an assumed average of $644 \mathrm{~km}$ (400 mi) by heavy-duty diesel fuel-powered truck.

It is assumed that a qualified service technician comes to the building site to check and service the unit every three years to ensure optimal performance and lifetime. It is assumed that the qualified technician is within a $24 \mathrm{~km}(15 \mathrm{mi})$ service radius. This distance, driven in a gasolinepowered van, is shared amongst other service visits for that technician, assuming that the same technician is making more than one service call during that trip. Assuming the technician makes 5 service calls in one day, one-fifth of the impacts from driving $24 \mathrm{~km}(15 \mathrm{mi})$ are allocated to the product, or $4.8 \mathrm{~km}$ (3 mi). Data for a van come from ecoinvent. Unplanned service visits (i.e., unanticipated issues that require a service technician) are not included in the modeling assuming that the home owner adequately follows the maintenance and care guidelines.

Lifetimes of 11 and 10 years have been assumed for the electric and gas-fired water heaters, respectively. (NAHB, 2007 Table 1, Section 1) At the end-of-life, it is assumed that the water heaters are sent for recycling to recover valuable metal (see Section 4.5.3.7 for the recycling methodology used). What cannot be recovered, i.e., the non-metal parts, are modeled as landfilled. A distance of $48 \mathrm{~km}$ (30 mi) to the landfill in a heavy-duty diesel truck has been modeled. The landfill is based on ecoinvent waste management process data.

\subsubsection{Lighting}

Three lighting alternatives were included in BIRDS: incandescent, compact fluorescent lamp (CFL), and light-emitting diode (LED). These were calculated on a per one $\mathrm{W} / \mathrm{h}$ basis so that BIRDS could calculate the energy needed for lighting based on time used. Figure 4-9 presents the lighting system boundaries for a CFL example. 


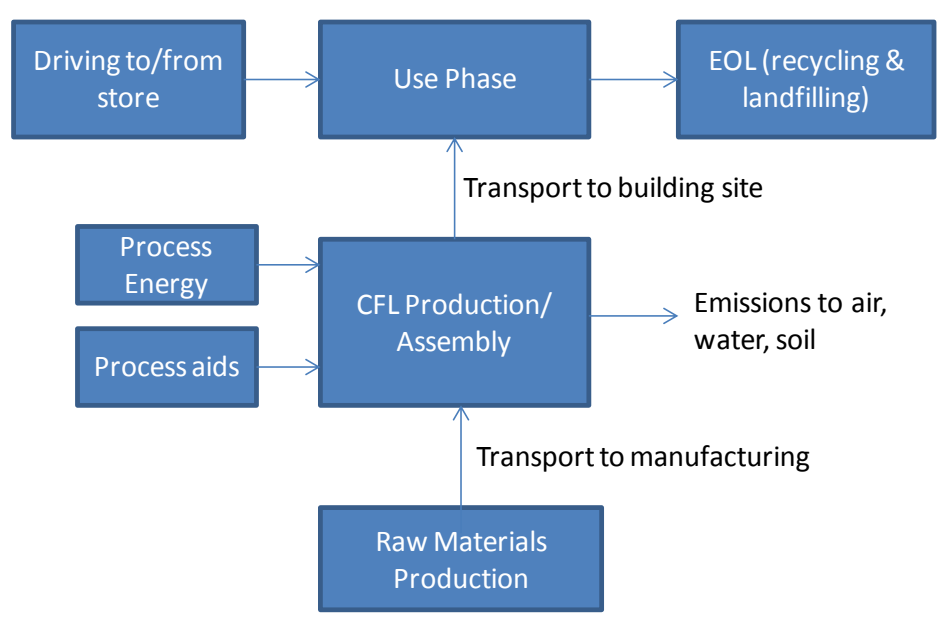

\section{Figure 4-9 Lighting System Boundaries - CFL Example}

In order to model the lighting alternatives on the basis of functional equivalency, the model must account for an equivalent or comparable lumen output, i.e., measure of brightness. The lighting characteristics from EERE (2012) were used to define the BIRDS' lighting systems' functional equivalency. Table 4.1 in EERE (2012), reproduced in part in Table 4-37, summarizes the average characteristics of the lamps analyzed within existing lighting LCA literature (at the time) in terms of lumen output, wattage, and lifetime. For the continuously-improving LED technology, they used a lumen output available in 2011, which was higher than lumens from earlier studies.

Table 4-37 Performance of Lighting Technologies in BIRDS

\begin{tabular}{lcccc} 
Lamp Type & Watts & Lumens & $\begin{array}{c}\text { Operating } \\
\text { Lifetime (hr) }\end{array}$ & $\begin{array}{c}\text { Number of Equiv. } \\
\text { Systems }\end{array}$ \\
Incandescent & 60 & 900 & 1000 & 25 \\
CFL & 15 & 900 & 8500 & 2.9 \\
LED (2011) & 12.5 & 800 & 25000 & 1 \\
\hline
\end{tabular}

\section{Upstream Materials Production through Manufacturing}

The bills of materials for all three alternatives come from Defra (2009); these bills of materials are based on Ramroth (2008), with more detail/aggregation.

Incandescent

The bill of materials shown in Table 4-38 was based on a $100 \mathrm{~W}$ (soft white) incandescent manufactured by General Electric. Other sources provided data available for $60 \mathrm{~W}$ 
incandescents, ${ }^{23}$ but Table B-12 of Defra (2009) was used since its data are based on a detailed tear-down for a widely available product. Furthermore, when factoring in use phase energy, the BOM differences between $60 \mathrm{~W}$ and $100 \mathrm{~W}$ are negligible.

\section{Table 4-38 Incandescent Light Bulb Bill of Materials}

\begin{tabular}{lccl} 
Parts and Materials & \multicolumn{2}{c}{ Mass } & Notes \\
Ballast & $\mathbf{g}$ & $\mathbf{l b}$ & \\
Black glass insulation & 2.0 & $4.4 \mathrm{E}-3$ & Modeled as foam glass \\
Internal filler & 1.0 & $2.2 \mathrm{E}-3$ & Modeled as foam glass \\
\hline Lamp & & & \\
Tin plate base & 2.0 & $4.4 \mathrm{E}-3$ & \\
Tungsten filament & $2.0 \mathrm{E}-2$ & $4.4 \mathrm{E}-5$ & Modeled as chromium \\
Internal glass & 2.0 & $4.4 \mathrm{E}-3$ & Modeled as borosilicate glass tube \\
\hline Lens & & & \\
Globe (glass) & 20.0 & $4.4 \mathrm{E}-2$ & Modeled as borosilicate glass tube \\
\hline Packaging & & & \\
\hline Corrugated board & 4.0 & $8.8 \mathrm{E}-3$ & \\
Total & $\mathbf{3 1 . 0}$ & $\mathbf{6 . 8}$ E-2 & \\
\hline
\end{tabular}

The data sets used to model the incandescent system's parts and materials come from ecoinvent. Defra (2009) used proxy data for materials not available in ecoinvent or other publicly-available data or databases. These proxies were also used for BIRDS, and are indicated in the table notes. Raw materials are modeled as transported to the manufacturing plant via diesel truck an assumed average distance of $805 \mathrm{~km}$ (500 mi).

No manufacturing data were available, but the parts forming (wire drawing, injection molding, extrusion, etc.) have been included with the upstream raw materials, accounting for at least some of the production energy.

\section{Compact Fluorescent Lamp (CFL)}

The bill of materials in Table 4-39 was based on a 23 W Philips Marathon Mini CFL. Other data were available for an $18 \mathrm{~W} \mathrm{CFL}^{24}$ which might have been preferable in terms of wattage

${ }^{23}$ See, for example, Parsons (2006).

24 Ibid. 
identified in Table 4-39, but Tables B.10-B.11 of Defra (2009) were used since the tear-down was quite detailed and for a widely available product. Furthermore, the difference in mass between the two sources was $3 \%$ to $5 \%$, with a similar bill of materials. Factoring in use phase energy, this difference becomes negligible. 
Table 4-39 CFL Bill of Materials

\begin{tabular}{|c|c|c|c|}
\hline Parts and Materials & & ass & Notes \\
\hline Ballast & g & lb & \\
\hline PUR foam (rigid) & 3.0 & $6.6 \mathrm{E}-3$ & \\
\hline Plastic base (Polyvinyl chloride, PVC) & 17.0 & $3.7 \mathrm{E}-2$ & \\
\hline Printed wiring board & 4.0 & $8.8 \mathrm{E}-3$ & \\
\hline Printed board assembly (PBA) - & & & \\
\hline Polypropylene (PP) caps & 4.0 & $8.8 \mathrm{E}-3$ & \\
\hline PBA- inductor (cast iron) & 7.0 & $1.5 \mathrm{E}-2$ & \\
\hline PBA- inductor (copper) & 4.5 & $9.9 \mathrm{E}-3$ & \\
\hline PBA - transistor (ABS copolymer) & 1.0 & $2.2 \mathrm{E}-3$ & \\
\hline PBA - transistor (Aluminum) & 3.5 & $7.7 \mathrm{E}-3$ & \\
\hline PBA - resistors, diodes, HV capacitor & 1.0 & $2.2 \mathrm{E}-3$ & $\begin{array}{l}\text { Modeled as a logic type } \\
\text { integrated circuit }\end{array}$ \\
\hline PBA - torus magnet (cast iron) & 1.0 & $2.2 \mathrm{E}-3$ & \\
\hline Lamp & & & \\
\hline Electrode assembly - mercury gas & $4.0 \mathrm{E}-3$ & $8.8 \mathrm{E}-6$ & \\
\hline Electrode assembly - chromium & 2.0 & 4.4 E-3 & \\
\hline Copper pins & 2.0 & $4.4 \mathrm{E}-3$ & \\
\hline Tin base plate & 5.0 & $1.1 \mathrm{E}-2$ & \\
\hline Black glass insulation & 5.0 & $1.1 \mathrm{E}-2$ & Modeled as foam glass \\
\hline Lens & & & \\
\hline Glass tube & 34.0 & $7.5 \mathrm{E}-2$ & $\begin{array}{l}\text { Modeled as borosilicate } \\
\text { glass tube }\end{array}$ \\
\hline Packaging & & & \\
\hline Corrugated board & 4.0 & $8.8 \mathrm{E}-3$ & \\
\hline Total & 98.0 & 2.2 E-1 & \\
\hline
\end{tabular}

The U.S. LCI Database provided data for the polyvinyl chloride base, polypropylene caps, acrylontrile-butadiene-styrene (ABS) copolymer transistor, and aluminum (as an average mix of 
primary and secondary aluminum). Data for copper sheet and wire come from ICA (2012). The remaining data sets come from ecoinvent. Defra (2009) used proxy data for materials and/or parts not available in ecoinvent or other publicly-available data or databases. These proxies were also used for BIRDS, and are indicated in the table notes. Raw materials are modeled as transported to the manufacturing plant via diesel truck an assumed average distance of $805 \mathrm{~km}$ (500 mi).

No manufacturing data were available, but the parts forming (wire drawing, injection molding, extrusion, etc.) and manufacture of the individual electronics components have been included with the upstream raw materials, accounting for at least some of the production energy. For assembly, Defra (2009) used data provided by ecoinvent - assembly of an LCD screen - which the authors determined to be a suitable proxy for CFL manufacturing. According to Defra (2009), this surrogate was selected because an LCD screen is also a complex electrical product, involving circuits and components that are assembled, and the impacts were expressed on a per $\mathrm{kg}$ basis so the assembly of the lighting systems could be modeled based on their respective weights. This was a conservative assumption on the part of Defra. Four Elements tested this assumption with sensitivity analysis, which showed that it did not make a significant difference to the overall results. BIRDS used this same assumption, applying the assembly data to a $98.0 \mathrm{~g}$ $(0.22 \mathrm{lb})$ system.

\section{Light-Emitting Diode (LED)}

The integrated LED system from Table B.2 and Table B.3 in Defra (2009) was modeled, giving the LED system the opportunity to be retrofitted into existing lighting infrastructure. The LED inventory shown in Table 4-40 factored in 10 LED die. 
Table 4-40 LED Bill of Materials

\begin{tabular}{|c|c|c|c|}
\hline \multirow{2}{*}{$\begin{array}{l}\text { Parts and Material } \\
\text { Ballast }\end{array}$} & \multicolumn{2}{|c|}{ Mass } & \multirow[t]{2}{*}{ Notes } \\
\hline & g & lb & \\
\hline PUR foam (rigid) & 3.0 & $6.6 \mathrm{E}-3$ & \\
\hline Inductor (cast iron) & 6.0 & $1.3 \mathrm{E}-2$ & \\
\hline Inductor $(\mathrm{Cu})$ & 4.0 & $8.8 \mathrm{E}-3$ & \\
\hline Zener Diodes & 0.1 & $2.2 \mathrm{E}-4$ & Modeled as an unspecified diode \\
\hline Capacitors (aluminum) & 5.0 & $1.1 \mathrm{E}-2$ & \\
\hline Resistor & 10.0 & $2.2 \mathrm{E}-2$ & \\
\hline Transistor & 3.0 & $6.6 \mathrm{E}-3$ & \\
\hline PCB (aluminum machined tooled block) & 100.0 & $2.2 \mathrm{E}-1$ & Modeled as aluminum \\
\hline Wiring $(\mathrm{Cu})$ & 2.0 & 4.4 E-3 & \\
\hline Solder paste (used for electronics) & 1.0 & $2.2 \mathrm{E}-3$ & \\
\hline Polypropylene (PP) housing & 35.0 & $7.7 \mathrm{E}-2$ & \\
\hline Integrated circuit & 1.0 & $2.2 \mathrm{E}-3$ & \\
\hline Polyethylene terephthalate (PET) film & 2.0 & 4.4 E-3 & \\
\hline \multicolumn{4}{|l|}{ Lamp } \\
\hline Black glass insulation & 6.0 & $1.3 \mathrm{E}-2$ & Modeled as foam glass \\
\hline Tinplate base & 3.0 & $6.6 \mathrm{E}-3$ & Modeled as a low-alloyed steel \\
\hline Copper pins & 0.1 & $2.2 \mathrm{E}-4$ & \\
\hline Base contacts $(\mathrm{Cu})$ & 0.4 & $8.8 \mathrm{E}-4$ & \\
\hline Base contacts (solder paste for electronics) & 0.2 & 4.4 E-4 & \\
\hline Plastic base (PVC) & 16.0 & $3.5 \mathrm{E}-2$ & \\
\hline Light emitting diodes (LED, 10 total) & 19.0 & 4.2 E-2 & \\
\hline \multicolumn{4}{|l|}{ Lens } \\
\hline Glass & 20.0 & 4.4 E-2 & Modeled as borosilicate glass tube \\
\hline Coating (aluminum) & 1.0 & $2.2 \mathrm{E}-3$ & \\
\hline \multicolumn{4}{|l|}{ Packaging } \\
\hline Corrugated board & 3.0 & $6.6 \mathrm{E}-3$ & \\
\hline Total & 240.8 & $5.3 \mathrm{E}-1$ & \\
\hline
\end{tabular}

The U.S. LCI Database provided data for the PVC base, PP housing, PET film, and aluminum (as average production mix). Data for copper sheet and wire come from ICA (2012). The remaining data sets, including the production of the LEDs, come from ecoinvent. Defra (2009) used proxy data for materials not available in ecoinvent or other publicly-available data or 
databases. These proxies were also used for BIRDS, and are indicated in the table notes. Raw materials are modeled as transported to the manufacturing plant via diesel truck an assumed average distance of $805 \mathrm{~km}$ (500 mi).

Data for LED die manufacturing comes from OSRAM (2009). Primary data were collected on the two main process stages to produce OSRAM's Golden Dragon Plus: the front end, where the $1 \mathrm{~mm}^{2}$ (1.6 E-3 $\mathrm{in}^{2}$ ) semiconductor chip is fabricated, and back end, where the chip is contacted and packaged. See OSRAM (2009), pp.9-11, for more qualitative detail and schematics on the manufacture of the LED. Figure 6 in OSRAM (2009) presents the primary energy to produce one LED: approximately $0.41 \mathrm{kWh}$. Given that the other categories of data in the figure include materials production, an assumption was made that "common consumption" is energy at manufacturing, amounting to approximately $0.27 \mathrm{kWh}$ per LED, or $2.7 \mathrm{kWh}$ for $10 \mathrm{LEDs}$. No other manufacturing data could be gleaned from this study, but the ecoinvent data set on assembly of an LCD screen was used for assembly (see above discussion), and parts forming data were applied to other parts and materials listed in the table.

\section{Transportation to the Building Site through End-of-Life}

A number of the LCA studies mentioned China or Asia in general as being the main manufacturing location for incandescents. For their study, EERE (2012), p.32, assumed that an incandescent lamp is either manufactured in the northeastern U.S. or Shanghai, China, while also acknowledging that production occurs all over the world. BIRDS assumed $25 \%$ of production of incandescents to be produced in the northeast U.S., and $75 \%$ in Shanghai, China.

BIRDS modeled CFLs as manufactured in China. (EERE 2012, p.33; Defra 2009; Parsons 2006; RMI 2008)

EERE (2012) stated that LED lighting market is highly fragmented, with several firms focusing on a specific part within the LED supply chain (this was seen with OSRAM (2009)). BIRDS adopted EERE's approach to simplifying the sourcing logistics as follows: "the complete LED package is produced in Taiwan and then is assembled into the finished LED lamp product in Taiwan or the United States. In the second scenario, LED packages are produced in Taiwan and then shipped to the southeast region of the U.S. where they are assembled into complete LED lamp products." (EERE 2012, p.33)

For Asia manufacturing, transportation includes the ocean freighter transport to a port in California, plus heavy duty diesel truck an assumed $2414 \mathrm{~km}$ (1 $500 \mathrm{mi}$ ), an average distance traveled from California to other parts of the United States. For U.S. manufacturing, transport is modeled an assumed average of $2414 \mathrm{~km}$ (1 $500 \mathrm{mi}$ ) by heavy-duty diesel fuel-powered truck. Intermediate transportation (i.e., from LED production to lamp assembly) is also included.

For every light bulb purchased and needing to be replaced, customer driving from the retail store has been included. 
How these lighting systems affect operating energy during the home's use phase is addressed in other sections of this report.

At end-of-life, each of the lighting alternatives was modeled as $20 \%$ recycling (and material recovery), $80 \%$ landfill. A distance of $48 \mathrm{~km}$ (30 mi) in a heavy-duty diesel truck to the landfill or recycler has been assumed.

\subsubsection{Sealants}

LCAs of an interior and exterior sealant have been included in BIRDS. The interior sealant is modeled as an aluminum foil-backed multi-purpose tape designed for taping joints and seams against moisture and vapor on ductwork. The exterior sealant, an acrylic latex caulk with silicone, is used to minimize air infiltration around windows, door frames, and other areas on the building envelope. The LCAs are based on one linear foot of each type of sealant (boundaries shown in Figure 4-10).

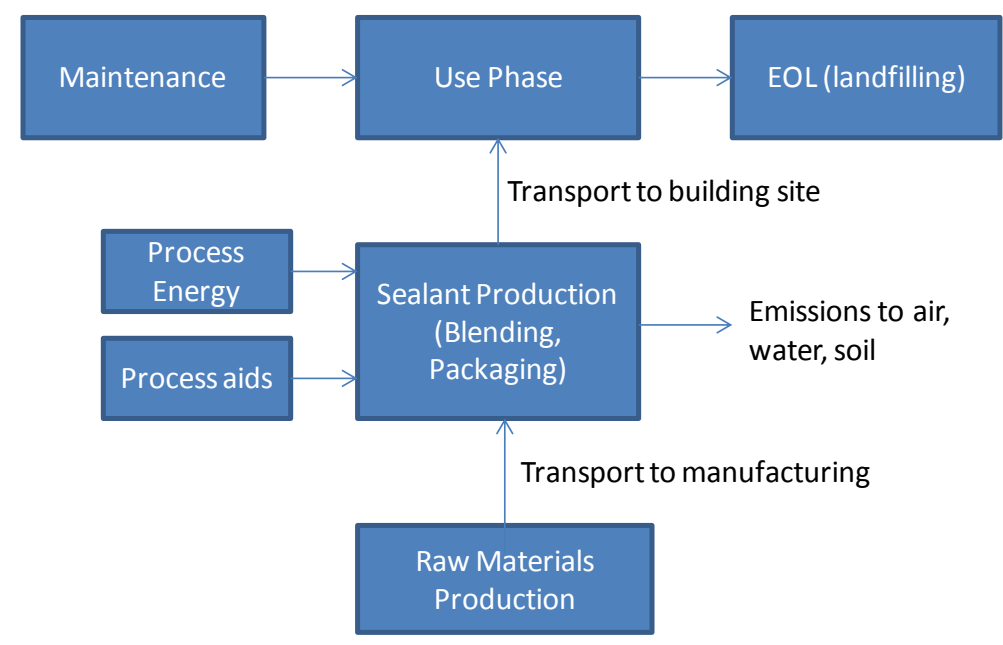

Figure 4-10 Sealants System Boundaries - Exterior Sealant Example

Both types of sealants have been modeled based on products that are readily available and whose published product literature provided sufficient data to model their production without the need to make too many assumptions. It should be reminded that there are many products on the market that can perform the same sealing functions, and that the products described herein are not considered endorsements.

\section{Upstream Materials Production through Manufacturing}

\section{$\underline{\text { Ductwork Sealant }}$}

The ductwork sealant modeled for BIRDS is modeled as a multi-purpose foil-backed tape. The 0.13-mm (5.0-mil) thick tape contains three distinct layers: 0.05-mm (2.0-mil) thick aluminum foil, synthetic rubber for the adhesive, and unbleached natural Kraft paper for the liner (Nashua, 2013). One roll of $46 \mathrm{~m}$ (151 ft) long by $48 \mathrm{~mm}(0.16 \mathrm{ft})$ wide tape, or $2.2 \mathrm{~m}^{2}\left(23.8 \mathrm{ft}^{2}\right)$ of tape, 
weighed $0.55 \mathrm{~kg}(1.2 \mathrm{lb})$, or $3.64 \mathrm{~g}(0.13 \mathrm{oz})$ per linear foot. ${ }^{25}$ Based on this weight, the material components were broken down as shown in Table 4-41, with assumptions noted.

Table 4-41 Foil Tape Bill of Materials

\begin{tabular}{lccl} 
Tape material & \multicolumn{2}{c}{ Mass } & \multicolumn{2}{l}{ Notes } \\
& g & $\mathbf{~ o z}$ & \\
Aluminum & 2.01 & 0.071 & Based on $0.05 \mathrm{~mm}(2.0 \mathrm{mil}) \&$ density of $2.7 \mathrm{~g} / \mathrm{cm}^{3}$ \\
Unbleached Kraft & 0.16 & $5.8 \mathrm{E}-3$ & Assumed $10 \%$ of remaining weight \\
Synthetic rubber & 1.39 & 0.049 & Assumed $85 \%$ of remaining weight \\
Cardboard core & 0.08 & $2.9 \mathrm{E}-3$ & Assumed $5 \%$ of remaining weight \\
LDPE film (packaging) & negl. & negl. & \\
Total & 3.64 & 0.13 & \\
\hline
\end{tabular}

Production data for the foil is modeled as 50/50 primary and secondary aluminum from the U.S. LCI Database, plus sheet rolling (ecoinvent). Data for the remaining materials were supplied by ecoinvent. Assembly of the tape was assumed to consist of layering and laminating the materials, rolling, and cutting. The electricity-only portion of the ecoinvent data set for "laminating foil (with an acrylic binder)" was used, which was reported as $0.0183 \mathrm{kWh} / \mathrm{m}^{2}\left(0.0017 \mathrm{kWh} / \mathrm{ft}^{2}\right)$ laminated. This value is likely underestimated since cutting and rolling are not included in this dataset.

\section{$\underline{\text { Exterior Sealant }}$}

The exterior sealant was modeled based on composition information for an MSDS of a commonly used acrylic latex sealant with silicone (DAP 2005). The amount modeled for one linear foot was calculated to be $28.9 \mathrm{~g} / \mathrm{m}(0.31 \mathrm{oz} / \mathrm{ft})$, based on a specific gravity of 1.65 ,

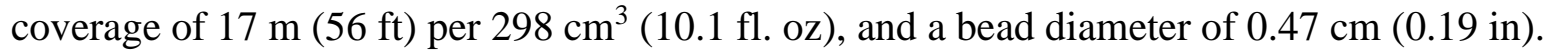
(DAP 2011) Since composition was provided in the customary percentage ranges, the quantities of each ingredient modeled were estimated based on best-guess assumptions (see Table 4-42).

\footnotetext{
${ }^{25}$ Weight taken by Four Elements.
} 
Table 4-42 Exterior Sealant Bill of Materials

\begin{tabular}{lcccl} 
& \multicolumn{4}{c}{ Wt Percentage } \\
Components & Low \% & High \% & \% Modeled & Notes \\
Non-hazardous polymer & 10 & 30 & 30 & Acrylic polymer assumed \\
Water & 10 & 30 & 18 & "82\% solids" (DAP, 2011) \\
Calcium carbonate & 40 & 70 & 46 & \\
Phthalate ester & 1 & 5 & 3 & \\
Titanium dioxide & 0.1 & 1 & 0.55 \\
Ethylene glycol & 0.1 & 1 & 0.55 & \\
Crystalline silica & 0.1 & 1 & 1 & \\
Carbon black & 0 & 1.5 & 0.75 \\
Ammonia & & 0.01 & 0.01 \\
Formaldehyde & & 0.02 & 0.02 \\
Ethyl acrylate & & 0.009 & 0.009 \\
Acetaldehyde & & 0.002 & 0.002 \\
Acrylonitrile & & 0.0003 & 0.0003 \\
Total & & & $\mathbf{1 0 0}$ \\
\hline & & & &
\end{tabular}

The mass of the high density polyethylene (HDPE) squeeze tube packaging was calculated by subtracting the quantity of $10.1 \mathrm{fl}$ oz sealant $(493 \mathrm{~g}(17.3 \mathrm{oz})$ ) from the weighed product $(539 \mathrm{~g}$ (19.0 oz)). Thus, HDPE amounted to $46 \mathrm{~g}(1.6 \mathrm{oz})$, or $2.7 \mathrm{~g} / \mathrm{m}(0.029 \mathrm{oz} / \mathrm{ft})$.

The U.S. LCI Database provided production data for HDPE, calcium carbonate, and ethylene glycol. Ecobilan (2001) provided the inventory data on the phthalate ester, and ecoinvent provided the remaining data. Manufacturing data were limited; the electricity-only portion of an ecoinvent data set for acrylic filler production - likely mixing energy - were used, which amounted to $1.8 \mathrm{E}-3 \mathrm{kWh} / \mathrm{kg}(1.6 \mathrm{E}-5 \mathrm{kWh} / \mathrm{ft})$.

Raw materials for both products are modeled as transported to the manufacturing plant via diesel truck an assumed average distance of $805 \mathrm{~km}$ (500 mi). 


\section{Transportation to the Building Site through End-of-Life}

Transportation of the equipment to the building site is modeled an assumed average of $483 \mathrm{~km}$ (300 mi) by heavy-duty diesel fuel-powered truck.

The tape is assumed to be replaced every 10 years. The exterior sealant is modeled as being replaced every 15 years (Vigener 2012). At the end of each of their respective lives, it is assumed that they are landfilled. Data on the landfill is based on ecoinvent end-of-life waste management process data. A distance of $48 \mathrm{~km}$ (30 mi) to the landfill in a heavy-duty diesel truck has been assumed. 


\section{Economic Performance Measurement}

When a decision maker wants a dollar measure of cost effectiveness and cash flows are primarily costs, the most appropriate method for measuring the economic performance of a building is the life-cycle cost (LCC) method (ASTM 2012; Fuller and Petersen 1996). BIRDS follows the ASTM International standard method for life-cycle costing of building-related investments (ASTM 2010), which involves calculating a cost's present value (PV) by discounting its future value into 2011 dollars based on the year the cost occurs and the assumed discount rate. The formulas and discount factors used to calculate the present values will vary depending on the type of cost. The different cost types and related formulas, discount factors, and data sources are described below.

\subsection{First Cost}

The first costs of a building are the total costs of constructing a building in a particular city. First costs include costs for labor, materials, equipment, overhead, and profit.

\subsubsection{Approach}

The construction costs for a prototype building are estimated by summing the costs of the baseline building ( $C_{\text {NatAvg }}$ ) and the changes in costs required to meet the prototype building design $\left(\Delta C_{x}\right)$, adjusted for location-related cost variation as well as contractor and architectural profits. Both the baseline building costs and component cost estimates are based on national average construction cost data, and must be adjusted with the city level cost indexes to control for local material and labor price variations in the 228 locations for which energy simulations are run. A city construction cost index $\left(I_{F G}\right)$ (Faithful + Gould 2011) is used to adjust the sum of the costs for both the incremental building component costs and the baseline prototypical building. The formula below shows the indexed construction cost $\left(C_{\text {Index }}\right)$ calculation.

$$
\begin{aligned}
& C_{\text {Index }}=\left[\left(C_{\text {NatAvg }}\right)+\left(\Delta C_{H V A C}\right)+\left(\Delta C_{\text {Wall }}\right)+\left(\Delta C_{\text {Ceiling }}\right)+\left(\Delta C_{\text {Foundation }}\right)+\left(\Delta C_{\text {Lighting }}\right)\right. \\
& \left.+\left(\Delta C_{\text {Sealant }}\right)+\left(\Delta C_{\text {Window }}\right)\right] * I_{F G} \\
& \text { Where } C_{\text {Index }} \quad=\text { Indexed construction costs } \\
& C_{\text {NatAvg }} \quad=\text { National average construction costs } \\
& \Delta C_{H V A C} \quad=\text { Change in HVAC costs } \\
& \Delta C_{\text {Wall }} \quad=\text { Change in wall insulation costs } \\
& \Delta C_{\text {Ceiling }} \quad=\text { Change in ceiling insulation costs } \\
& \Delta C_{\text {Foundation }}=\text { Change in foundation costs } \\
& \Delta C_{\text {Lighting }} \quad=\text { Change in lighting costs } \\
& \Delta C_{\text {Sealant }} \quad=\text { Change in air sealing costs } \\
& \Delta C_{\text {Window }}=\text { Change in window costs } \\
& I_{F G} \quad=\text { "Faithful + Gould" residential construction cost index }
\end{aligned}
$$


Once the indexed construction costs of the building are calculated, it is necessary to adjust for the contractor and architect profits by multiplying the costs by the contractor "mark-up" rate $\left(I_{M}\right)$, assumed to be $25 \%$, and then the architectural fees rate $\left(I_{A}\right)$, assumed to be $7 \%$, as shown in the following equation.

$$
C_{\text {First }}=\left(C_{\text {Indexed }} *\left(1+I_{M}\right)\right) *\left(1+I_{A}\right)
$$

These mark-up rates are based on the default values used by the RS Means Square Foot Cost Estimator (SFCE). The marked-up, indexed construction costs are the first costs of constructing the prototype building in the particular city $\left(C_{\text {First }}\right)$.

\subsubsection{Data}

Building construction costs are obtained from two sources: RSMeans (2011) and Faithful + Gould (2012). The baseline costs of each prototypical building is estimated based on the average cost per unit of floor area for "average" construction quality in RSMeans (2011) for one-story and two-story single-family dwellings, which is a function of total floor area.

Figure 5-1 shows that the average cost per unit of floor area decreases as the total floor area increases for both one- and two-story single family dwellings. A power curve is fit to the available data points (base index of the cost per unit of floor area for the 1-story, $148.6 \mathrm{~m}^{2}\left(1000 \mathrm{ft}^{2}\right)$ house $){ }^{26}$

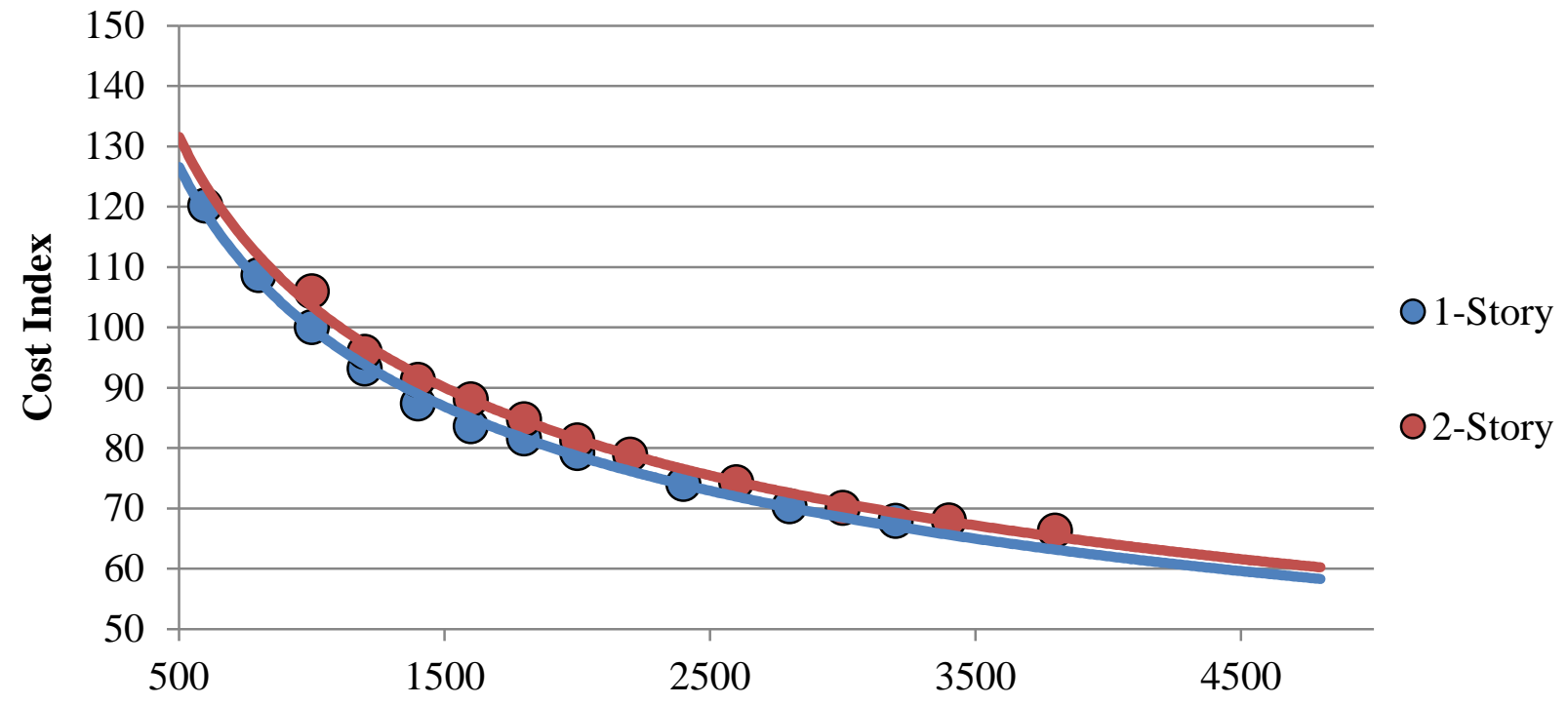

Floor Area $\left(\mathbf{f t}^{2}\right)$

Figure 5-1 Baseline Construction Costs ${ }^{27}$

\footnotetext{
${ }^{26}$ Indexed to protect proprietary RSMeans data.

$271 \mathrm{~m}^{2}=10.764 \mathrm{ft}^{2}$
} 
Incremental cost data from Faithful + Gould (2012) for each required energy efficiency measure are added to the baseline costs used to estimate the total first costs of a building that is compliant with each of the four energy efficiency design alternatives: 2003 IECC, 2006 IECC, 2009 IECC, and 2012 IECC. Six components - roof insulation, wall insulation, foundation insulation, air sealant, windows, and lighting - are changed to make the prototypical designs compliant with 2003, 2006, 2009, and 2012 IECC. A summary of the requirement ranges (varying climate zone) for each building design are shown in Table 5-1.

The cost data for windows is based on the cost per unit of area for "average casement window across sizes" in the $\mathrm{F}+\mathrm{G}$ database (Faithful and Gould 2012). The lowest cost window that meets the maximum window characteristics (U-factor and solar heat gain coefficient (SHGC)) required by the building design is selected.

There are three different insulation values required for the BIRDS new residential prototypes: wall, ceiling, and foundation. The foundation insulation requirements include two values, the Rvalue of the insulation and the depth of the insulation. Based on these two values, a cost per linear unit is estimated and multiplied by the total perimeter of the prototype. The cost of ceiling insulation is estimated based on the cost per unit of area for a given R-value multiplied by the area of the top story ceiling. The wall insulation requirements are met using wall cavity insulation or a combination of wall cavity insulation and rigid exterior insulation. Costs per unit of floor area for installed insulation are treated as additive, and are multiplied by the net exterior wall area (gross wall area minus window area) to estimate the total installed cost of the insulation.

Infiltration rates defined in IECC are maximum requirements based on a blower door test at $50 \mathrm{~Pa}$. However, the cost data in Faithful+Gould (2011) are based on natural infiltration rates, which required conversion of $\mathrm{ACH}_{50}$ requirements to $\mathrm{ACH}_{\mathrm{NAT}}$ (see Section 3.3.3 for details). The cost data is mapped to the IECC requirements in the following manner:

$$
\begin{gathered}
A C H_{N A T}=0.35 \rightarrow A C H_{50}=7.0 \\
A C H_{N A T}=0.16 \text { to } 0.25 \rightarrow A C H_{50}=5.0 \\
A C H_{N A T} \leq 0.15 \rightarrow A C H_{50}=3.0
\end{gathered}
$$

The fraction of hard-wired lighting that is high efficiency is adjusted to meet each edition's requirements. The BA Protocol baseline lighting is assumed for IECC editions with no lighting requirement (see Section 3.3.5 for details). The cost of lighting is estimated using the cost data for comparable incandescent and spiral CFL bulbs, which is converted into a normalized cost per watt using incandescent wattage as the basis for the normalization to allow for simple cost change estimates based on wattage values. 
The capacity of the HVAC equipment varies based on the thermal load for a given building prototype, with all equipment meeting minimum federal requirements (SEER 13 for $\mathrm{AC}$ unit and $80 \%$ AFUE for gas furnace). Installed costs for $\mathrm{AC}$ units (2.0, 2.5, 3.0, 4.0, or 5.0 ton) and furnaces (40 MBH to $50 \mathrm{MBH}, 60 \mathrm{MBH}$ to $64 \mathrm{MBH}, 78 \mathrm{MBH}$ to $80 \mathrm{MBH}$, and $96 \mathrm{MBH}$ to 100 $\mathrm{MBH})$ are selected based on the closest match to the "autosized" system in the $E+$ simulation.

\section{Table 5-1 Energy Efficiency Component Requirements for Alternative Building Designs}

\begin{tabular}{|c|c|c|c|c|c|c|}
\hline $\begin{array}{l}\text { Design } \\
\text { Comp. }\end{array}$ & Parameter & Units & 2003 IECC & 2006 IECC & 2009 IECC & 2012 IECC \\
\hline $\begin{array}{l}\text { Ceiling } \\
\text { Insulation }\end{array}$ & R-Value & $\begin{array}{l}\mathrm{m}^{2} \cdot \mathrm{K} / \mathrm{W} \\
\left(\mathrm{ft}^{2 \cdot}{ }^{\circ} \mathrm{F} \cdot \mathrm{h} / \mathrm{Btu}\right)\end{array}$ & $\begin{array}{c}2.3 \text { to } 8.6 \\
(13.0 \text { to } 49.0)\end{array}$ & $\begin{array}{c}5.3 \text { to } 8.6 \\
\text { (30.0 to } 49.0 \text { ) }\end{array}$ & $\begin{array}{c}5.3 \text { to } 8.6 \\
\text { (30.0 to } 49.0 \text { ) }\end{array}$ & $\begin{array}{c}5.3 \text { to } 8.6 \\
(30.0 \text { to } 49.0)\end{array}$ \\
\hline $\begin{array}{l}\text { Wall } \\
\text { Insulation }\end{array}$ & R-Value & $\begin{array}{l}\mathrm{m}^{2} \cdot \mathrm{K} / \mathrm{W} \\
\left(\mathrm{ft}^{2 \cdot}{ }^{\circ} \mathrm{F} \cdot \mathrm{h} / \mathrm{Btu}\right)\end{array}$ & $\begin{array}{c}1.9 \text { to } 3.7 \\
\text { (11.0 to } 21.0)\end{array}$ & $\begin{array}{c}2.3 \text { to } 3.7 \\
\text { (13.0 to } 21.0)\end{array}$ & $\begin{array}{c}2.3 \text { to } 3.7 \\
\text { (13.0 to } 21.0)\end{array}$ & $\begin{array}{l}2.3 \text { to } 3.5+0.9 / 3.7+1.8 \\
(13.0 \text { to } 20+5 / 13+10)\end{array}$ \\
\hline \multirow[t]{2}{*}{$\begin{array}{l}\text { Foundation } \\
\text { Insulation }\end{array}$} & $\mathrm{R}$-value & $\begin{array}{l}\mathrm{m}^{2} \cdot \mathrm{K} / \mathrm{W} \\
\left(\mathrm{ft}^{2 \cdot}{ }^{\circ} \mathrm{F} \cdot \mathrm{h} / \mathrm{Btu}\right)\end{array}$ & $\begin{array}{c}0.0 \text { to } 3.2 \\
(0 \text { to } 18.0)\end{array}$ & $\begin{array}{c}0 \text { to } 1.7 \\
(0 \text { to } 10.0)\end{array}$ & $\begin{array}{c}0 \text { to } 1.7 \\
(0 \text { to } 10.0)\end{array}$ & $\begin{array}{c}0 \text { to } 1.7 \\
(0 \text { to } 10.0)\end{array}$ \\
\hline & Depth & $\mathrm{m}(\mathrm{ft})$ & $\begin{array}{c}0 \text { to } 1.2 \\
(0 \text { to } 4.0)\end{array}$ & $\begin{array}{c}0 \text { to } 1.2 \\
(0 \text { to } 4.0)\end{array}$ & $\begin{array}{c}0 \text { to } 1.2 \\
(0 \text { to } 4.0)\end{array}$ & $\begin{array}{c}0 \text { to } 1.2 \\
(0 \text { to } 4.0)\end{array}$ \\
\hline Infiltration & $\begin{array}{l}\text { Air } \\
\text { Changes } \\
\text { Per Hour }\end{array}$ & ACH50 & NR & 7.0 & 7.0 & 3.0 to 5.0 \\
\hline \multirow[t]{2}{*}{ Windows } & U-Factor & $\begin{array}{l}\mathrm{W} /\left(\mathrm{m}^{2} \cdot \mathrm{K}\right) \\
\left(\mathrm{Btu} /\left(\mathrm{h} \cdot \mathrm{ft}^{2 \cdot} \cdot{ }^{\circ} \mathrm{F}\right)\right)\end{array}$ & $\begin{array}{c}1.99 \text { to } \mathrm{NR} \\
(0.35 \text { to } \mathrm{NR})\end{array}$ & $\begin{array}{l}1.99 \text { to } 6.81 \\
(0.35 \text { to } 1.2)\end{array}$ & $\begin{array}{l}1.99 \text { to } 6.81 \\
(0.35 \text { to } 1.2)\end{array}$ & $\begin{array}{c}1.82 \text { to } \mathrm{NR} \\
\text { (0.32 to NR) }\end{array}$ \\
\hline & SHGC & Fraction & NR & 0.30 to $\mathrm{NR} \dagger$ & 0.30 to $\mathrm{NR} \uparrow$ & 0.25 to $\mathrm{NR}$ \\
\hline Lighting & $\begin{array}{l}\text { Fraction } \\
\text { High } \\
\text { Efficiency }\end{array}$ & Fraction & NR & NR & $50 \%$ & $75 \%$ \\
\hline
\end{tabular}

\subsection{Future Costs}

Future costs of a building include maintenance, repair, and replacement (MRR) costs as well as operational energy-related costs from electricity and natural gas consumption. Each of these is discussed below.

\subsubsection{Approach}

Building MRR costs are discounted to equivalent present values using the Single Present Value (SPV) factors for future non-fuel costs reported in Rushing, Kneifel, and Lippiatt (2011). These factors are calculated using the DOE Federal Energy Management Program (FEMP) 2011 real 
discount rate for federal energy conservation projects (3\%). Table 5-2 reports the SPV factors used to develop the BIRDS new residential database. The MRR costs for each year $\left(C_{M R R, i}\right)$ are multiplied by the SPV for that year and then summed and indexed to determine the total present value MRR costs $\left(C_{M R R}\right)$.

Table 5-2 2009 SPV Discount Factors for Future Non-Fuel Costs, 3 \% Real Discount Rate

\begin{tabular}{cc} 
Yrs & SPV Factor \\
1 & 0.971 \\
\hline 2 & 0.943 \\
\hline 3 & 0.915 \\
\hline 4 & 0.888 \\
\hline 5 & 0.863 \\
\hline 6 & 0.837 \\
\hline 7 & 0.813 \\
\hline 8 & 0.789 \\
\hline 9 & 0.766 \\
\hline 10 & 0.744 \\
\hline
\end{tabular}

\begin{tabular}{cc} 
Yrs & SPV Factor \\
\hline 11 & 0.722 \\
\hline 12 & 0.701 \\
\hline 13 & 0.681 \\
\hline 14 & 0.661 \\
\hline 15 & 0.642 \\
\hline 16 & 0.623 \\
\hline 17 & 0.605 \\
\hline 18 & 0.587 \\
\hline 19 & 0.570 \\
\hline 20 & 0.554 \\
\hline
\end{tabular}

\begin{tabular}{cc} 
Yrs & SPV Factor \\
21 & 0.538 \\
\hline 22 & 0.522 \\
\hline 23 & 0.507 \\
\hline 24 & 0.492 \\
\hline 25 & 0.478 \\
\hline 26 & 0.464 \\
\hline 27 & 0.450 \\
\hline 28 & 0.437 \\
\hline 29 & 0.424 \\
\hline 30 & 0.412 \\
\hline
\end{tabular}

\begin{tabular}{cc} 
Yrs & SPV Factor \\
31 & 0.400 \\
\hline 32 & 0.388 \\
\hline 33 & 0.377 \\
\hline 34 & 0.366 \\
\hline 35 & 0.355 \\
\hline 36 & 0.345 \\
\hline 37 & 0.335 \\
\hline 38 & 0.325 \\
\hline 39 & 0.316 \\
\hline 40 & 0.307 \\
\hline
\end{tabular}

The electricity and natural gas use predicted by the building's energy simulation is used as the annual energy use of the building for each year of the selected study period. Electricity and natural gas prices are assumed to change over time according to U.S. Energy Information Administration forecasts from 2011 to 2041 (EIA 2013a, 2013b). These forecasts are embodied in the FEMP Modified Uniform Present Value Discount Factors for energy price estimates (UPV*) reported in Rushing, Kneifel, and Lippiatt (2011). ${ }^{28}$ Multiplying the annual electricity costs and natural gas costs by the associated UPV* value for the study period of interest estimates the present value total electricity costs $\left(C_{\text {Elect }}\right)$ and natural gas costs $\left(C_{\text {Gas }}\right)$. The discount factors vary by census region, end use, and fuel type.

Total present value future costs $\left(C_{\text {Future }}\right)$ is the sum of present value location-indexed MRR costs and present value energy costs, as shown in the following equation:

$$
C_{\text {Future }}=C_{M R R}+C_{\text {Elect }}+C_{\text {Gas }}
$$

\subsubsection{Data}

Residential building component and building lifetimes are based on three data sources: NAHB (2007) for building components excluding lighting, Energy Star (2011) for light bulbs, and U.S. Census (2011) for building lifetime. A residential building's service lifetime is assumed constant across climate zones at 65 years because, when well maintained, a building can remain in use for up to or beyond 65 years. This assumption is supported by the data in Table C-010AH of the 2011 AHS, which shows that about half of all owner-occupied housing units are 40 years of age or older and $6 \%$ are 96 years of age or older (U.S. Census 2011). Additionally, NAHB (2007)

\footnotetext{
${ }^{28}$ Since the U.S. Energy Information Administration forecasts end at year 30, the escalation rates for years 31 through 40 are assumed to be the same as for year 30 .
} 
estimates the lifetime of a number of house components (e.g. foundations, chimneys) to be greater than 65 years, which implies that the house structure lasts over 65 years. Insulation and air barriers are assumed to have a lifespan greater than 40 years and have no maintenance or repair requirements. Windows have an assumed lifespan of 20 years with costs that vary depending on the required window specifications. Windows are assumed to have no maintenance costs or repair costs. The heating and air conditioning units have assumed lifespans of 15 years while the hot water heater is assumed to have a lifespan of 10 years. Incandescent and fluorescent light bulbs are assumed to have lifespans of 1 year and 7 years, respectively (Energy Star 2011).

MRR cost data are collected from two sources: U.S. Census (2011) and Faithful + Gould (2011). The total maintenance and repair costs per square foot of conditioned floor area represent the baseline (non-energy related) MRR costs per unit of floor area, which occur for a building type regardless of the energy efficiency measures incorporated into the design. These data are collected from Table C-12-OO and Table C-15-OO in U.S. Census (2011), which reports median floor area and average maintenance and repair costs per unit of floor area for "Total OwnerOccupied Units" Housing Units and "New Construction the Past 4 Years" Housing Units, respectively. These two data points are used to interpolate and extrapolate for all years considered (1 through 40) as shown in Figure 5-2. Costs are assumed to remain constant after 10 years. These costs are assumed to include all maintenance and repair costs associated with a single-family dwelling.

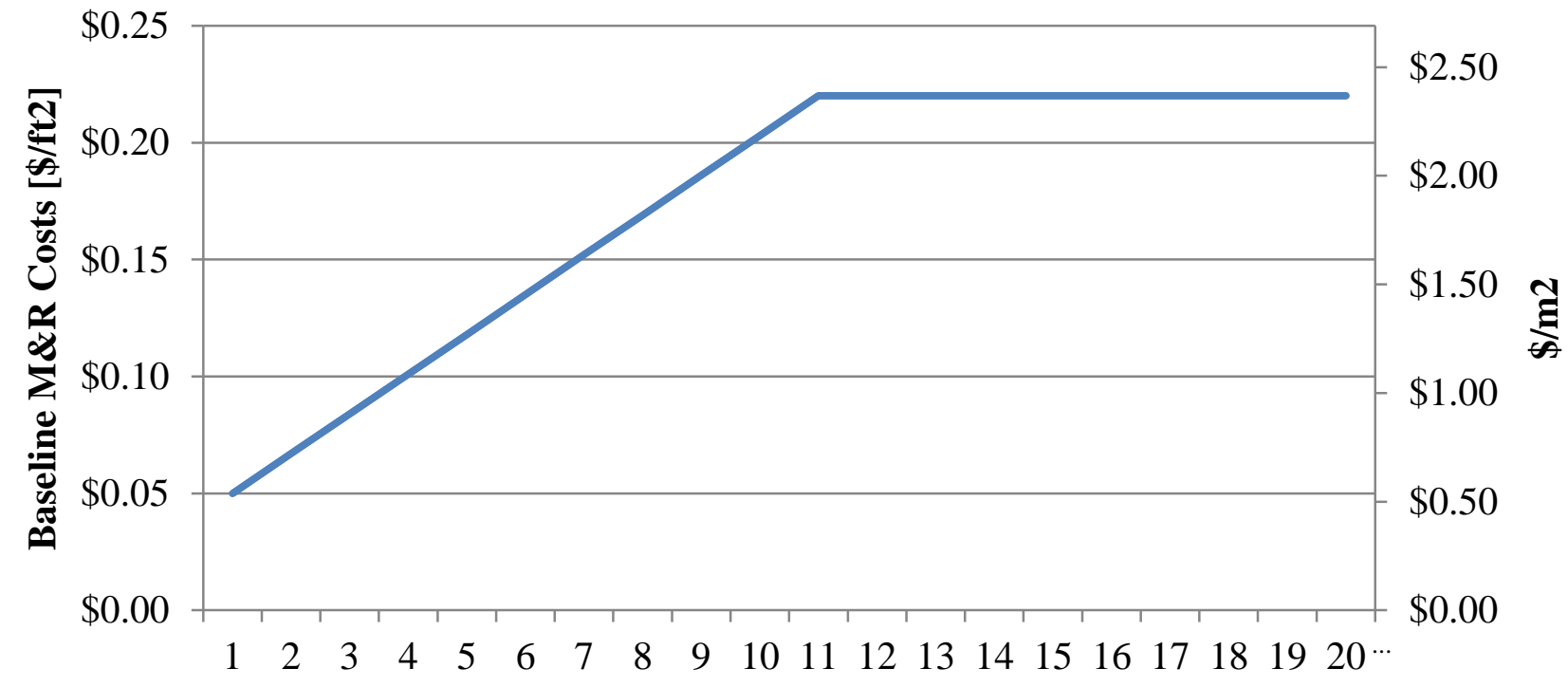

Figure 5-2 Baseline Maintenance and Repair Costs by Year

Faithful + Gould (2011) is the source of replacement costs for the individual components for which costs change across alternative building designs, which in this analysis are the HVAC system, lighting, and windows. The replacement cost of windows is assumed to be equal to the 
initial installation costs of the same window. The cost of replacing CFL light bulbs is greater than the cost of replacing incandescent light bulbs. However, CFLs last at least 7 times longer than incandescents, which may lead to the replacements costs of light bulbs to be lower for the more efficient CFLs (EPA 2012). The HVAC system capacity size varies based on the thermal performance of the building design, which results in varying replacement costs (based on first cost estimates) because smaller capacity systems are relatively cheaper.

Future MRR costs are discounted to equivalent present values using the Single Present Value (SPV) factors for future non-fuel costs reported in Rushing, Kneifel, and Lippiatt (2011), which are calculated using the U.S. Department of Energy's 2011 real discount rate for energy conservation projects (3\%).

Annual energy costs are estimated by multiplying annual electricity and natural gas use predicted by the building's energy simulation by the average state retail residential electricity and natural gas prices, respectively. Average state residential electricity and natural gas prices for 2011 are collected from the Energy Information Administration (EIA) Electric Power Annual State Data Tables (EIA 2013a) and Natural Gas Navigator (EIA 2013b), respectively.

\subsection{Residual Value}

A building's residual value is its value remaining at the end of the study period. In life-cycle costing it is treated as a negative cost item. In BIRDS, it is estimated in four parts based on the approach defined in Fuller and Petersen (1996): the building (excluding HVAC, windows, and lighting), HVAC system, windows, and lighting. The building's residual value is calculated as the building's location-indexed first cost multiplied by one minus the ratio of the study period to the service life of the building, discounted from the end of the study period. For example, if a building has first costs (excluding HVAC, windows, and lighting) of $\$ 500$ 000, a 65 year service life, and the study period length is 10 years, the residual value of the building at the end of the study period (excluding HVAC, window, and lighting) is $\$ 500000 \cdot\left(1-\frac{10}{65}\right)=\$ 423077$.

Because they may be replaced during the study period, residual values for the HVAC, windows, and lighting are computed separately. The remaining "life" of the HVAC equipment is determined by taking its service life minus the number of years since its last installation (as of the end of the study period), whether it occurred during building construction or replacement. The ratio of remaining life to service life is multiplied by the location-indexed installed cost of the system and discounted from the end of the study period. For example, assume an HVAC system's installed costs are $\$ 12000$ with a service life of 15 years, and a 20-year study period. After one replacement, the system is 5 years old at the end of the study period, leaving 10 years

remaining in its service life. The residual value in year 20 is $\$ 12000 \cdot \frac{10}{15}=\$ 8000$. The residual value for the light bulbs and windows is computed in a similar manner. 
The total residual value of the building and its HVAC, windows, and lighting, multiplied by the SPV factor for the number of years in the study period, estimates the present value of the residual value $\left(C_{\text {Residual }}\right)$.

\subsection{Life-Cycle Cost Analysis}

The total life-cycle cost of a prototype building $\left(C_{L C C}\right)$ is the sum of the present values of first cost and future costs minus the residual value as shown in the following equation:

$$
C_{\text {LCC }}=C_{\text {First }}+C_{\text {Future }}-C_{\text {Residual }}
$$

LCC analysis of buildings typically compares the LCC for a "base case" building design to the costs for alternative, more energy efficient building design(s) to determine if future operational savings justify higher initial investments. For BIRDS, total life-cycle costs are calculated as described above for all building design options for all study periods. The user of the tool has the option to select any of the building designs as the "base case," and compare it to any of the alternative designs. For an investor comparing mutually exclusive design alternatives, the same study period must be used for all alternatives. For those interested in the sensitivity of LCC results to the assumed study period length, BIRDS permits the study period length for a given building design to vary.

Two metrics are used to analyze changes in life-cycle costs: net LCC savings (ASTM 2009) and net LCC savings as a percentage of base case LCC. Net LCC savings (NS) is the difference between the base case LCC $\left(C_{\text {Base }}\right)$ and alternative design LCC $\left(C_{A l t}\right)$ as shown in the following equation:

$$
N S=C_{\text {Base }}-C_{A l t}
$$

Net LCC savings as a percentage of base case LCC (PNS) is the net LCC savings divided by the base case LCC. This metric, shown in the equation below, allows for comparisons across building types that vary significantly in terms of floor area.

$$
P N S=\frac{N S}{C_{\text {Base }}} \cdot 100
$$




\section{$6 \quad$ Limitations and Future Research}

BIRDS is limited in scope and would be strengthened by including uncertainty analysis, expanding the database and metrics, and adding design flexibility to the tool.

Uncertainty analysis is needed for at least three elements of the analysis. First, consider the assumed discount rate. Although $3 \%$ is a reasonable discount rate, in real terms, for federal government investment decisions, it may be too low of a value for an expected real return on an alternative investment in the private sector. Sensitivity analysis on the assumed discount rate is needed to determine the robustness of the cost results. Second, the current analysis assumes that building cooling loads are met by equipment running on electricity while heating loads are met by equipment running on natural gas, which is not the typical fuel mix for some areas of the nation. The database should be expanded to include alternative fuel source options, such as electricity in the South. Third, the BIRDS environmental impact scores do not incorporate uncertainty analysis as required by international standards (ISO 2006). While incorporating uncertainty analysis is problematic due to a lack of underlying uncertainty data, this omission should be brought into the interpretation of the BIRDS results in the future.

Additional data are needed to refine and expand the BIRDS database. The 10 prototypical singlefamily dwellings analyzed in this study may not be representative of the entire building stock because of the assumed simplicity of the building geometry. For this reason, the results should be considered as general magnitudes for making reasonable comparisons instead of precise quantitative analysis. Future research should include additional prototypes in the database. The state average energy cost rates do not control for local variation in energy tariffs. By using utility-level energy cost data, the accuracy of the estimates in BIRDS could be improved.

The analysis in this study ignores the impacts that variations in occupancy and behavior patterns, in terms of plug and process load use, thermostat setpoints, and number of occupants, and HVAC equipment efficiency have on the reductions in energy use. Homes with greater plug and process loads will realize smaller percentage changes in energy use because the energy efficiency measures considered in this study focus on the IECC requirements (building envelope and lighting) holding constant the efficiency of other equipment (HVAC equipment and appliances) used in the building and the number of occupants living in the building. Future research should consider the impact that improved equipment efficiency and occupant activity may have on the overall energy savings realized by energy efficiency improvements to buildings.

Properly interpreting the BIRDS environmental performance results requires placing them in perspective. The environmental impact scores assess the life-cycle impacts of operating energy use based on inventories of localized energy simulation results and regional electricity grids. All other elements of the scores - including a building's use of materials and its water consumption over the study period - are based on U.S. average life-cycle inventory data for prototypical buildings. The baseline data for these buildings represent status quo building technologies as of 
2002, the year of the latest available input-output data from the U.S. Bureau of Economic Analysis at the time of the database development. To account for evolution in status quo technologies over time, future versions of BIRDS should incorporate newer releases of these data as they become available.

The BIRDS results do not apply to buildings constructed in other countries where industry practices, fuel mixes, environmental regulations, transportation distances, and labor and material markets may differ. Furthermore, all buildings of a given type are not created equal. Building designs, sizes, useful lives, materials compositions, and costs will all vary for an individual building. The BIRDS results for a building prototype do not necessarily represent the performance of an individual building of that type. Future versions of the tool should permit flexibility in building design and use of materials.

The BIRDS LCAs use selected inventory flows converted to selected local, regional, and global environmental impacts to assess environmental performance. Those inventory flows which currently do not have scientifically proven or quantifiable impacts on the environment are excluded, such as mineral extraction and wood harvesting, which are qualitatively thought to lead to loss of habitat and an accompanying loss of biodiversity. Any new or improved data and/or modeling approaches should be brought into the interpretation of the BIRDS results.

The Environmental Problems approach that BIRDS uses for impact assessment does not offer the same degree of relevance for all environmental impacts. For global and regional effects (e.g., global warming and acidification) the method may result in an accurate description of the potential impact. For impacts dependent upon local conditions (e.g., smog, ecological toxicity, and human health impacts) it may result in an oversimplification of the actual impacts because the indices are not tailored to localities.

Life-cycle impact assessment is a rapidly evolving science. Assessment methods unheard of a decade ago have since been developed and are now being used routinely in LCAs. While BIRDS incorporates state-of-the-art impact assessment methods, the science will continue to evolve and methods in use today — particularly those for land and water use - are likely to change and improve over time. Future versions of BIRDS should incorporate these improved methods as they become available.

During the interpretation step of the BIRDS LCAs, environmental impact results are optionally combined into a single environmental performance score using relative importance weights. These weights necessarily incorporate values and subjectivity. BIRDS users should routinely test the effects on the environmental impact scores of changes in the set of importance weights by completing their analysis with more than one weighting approach.

Analysis based on the energy performance is susceptible to the limitations of current whole building energy simulation models. As the underlying simulation software improves in accuracy and uncertainty, the sustainability analysis related to the modeling will improve as well. 
Energy, environmental, and economic performance are but three attributes of building performance. The BIRDS model assumes that its building prototypes all meet minimum technical performance requirements. However, there may be significant differences in technical performance not evaluated in BIRDS, such as acoustic, fire, or indoor environmental quality performance, which may affect energy, environmental, and economic considerations. 


\section{References}

2003 International Energy Conservation Code (IECC), 2003, International Code Council, Inc. 2006 International Energy Conservation Code (IECC), 2006, International Code Council, Inc. 2009 International Energy Conservation Code (IECC), 2009, International Code Council, Inc. 2012 International Energy Conservation Code (IECC), 2012, International Code Council, Inc.

Air Conditioning, Heating and Refrigeration Institute (AHRI), 2008, ANSI/AHRI 210/240-2008: 2008 Standard for Performance Rating of Unitary Air-Conditioning \& Air-Source Heat Pump Equipment".

Air-Conditioning, Heating, and Refrigeration Technology Institute (AHRTI), 2011, Life-cycle Climate Performance Model for Residential Heat Pump Systems, AHRTI Report No. 09003-01, Prepared by Optimized Thermal Systems, LLC.

American Society of Heating Refrigerating and Air-Conditioning Engineers (ASHRAE), Inc., 2010, ANSI/ASHRAE Standard 62.2-2010, Ventilation and acceptable indoor air quality in low-rise residential buildings.

American Society of Heating Refrigerating and Air-Conditioning Engineers (ASHRAE), Inc., 2007, ANI/ASHRAE Standard 90.2-2007, Energy-efficient design of low-rise residential buildings.

American Society of Heating Refrigerating and Air-Conditioning Engineers (ASHRAE), Inc., 2009, ASHRAE handbook - fundamentals.

Aroul, R. and Hansz A., 2012, The Value of "Green:” Evidence from the First Mandatory Residential Green Building Program, Journal of Real Estate Research, Vol. 34 No. 1.

ASTM International, 2010, Standard Practice for Measuring Life-Cycle Costs of Buildings and Building Systems, ASTM Designation E917-05, West Conshohocken, PA.

ASTM International, 2011, Standard Practice for Applying the Analytic Hierarchy Process to Multiattribute Decision Analysis of Investments Related to Buildings and Building Systems, ASTM Designation E1765-11, West Conshohocken, PA.

ASTM International, 2012, Standard Guide for Selecting Economic Methods for Evaluating Investments in Buildings and Building Systems, ASTM Designation E1185-12, West Conshohocken, PA.

Athena Sustainable Materials Institute, 2003, Exploratory Life-cycle Analysis of Residential Operating Energy Systems, performed for Natural Resources Canada. 
Atherton, J., 2007, International Council on Mining \& Metals (ICMM) (2006), Declaration by the Metals Industry on Recycling Principles, International Journal of Life-cycle Assessment, January 2007, Volume 12, Issue 1, pp 59-60.

Atlas Roofing Corporation, 2012, Energy Shield/Energy Shield Plus/Cavity Wall Material Safety Data Sheet, dated 4/2/2012.

Bare, J. et al., 2006, "Development of the Method and U.S. Normalization Database for Lifecycle Impact Assessment and Sustainability Metrics," Environmental Science and Technology, 40: 16, 5108-5115.

Bare, J., 2011, "TRACI 2.0: The Tool for the Reduction and Assessment of Chemical and Other Environmental Impacts 2.0," Clean Technologies and Environmental Policy, published online January 2011.

Bayer MaterialScience, 2008, Phelan J. and G. Pavlovich, "Energy and Environmental Benefits of Insulating Commercial Buildings with Polyiso."

Bayer MaterialScience, 2011, Phelan J. and G. Pavlovich (Bayer MaterialScience), and J. Jewell (PE Americas) (2011) Life-cycle Assessment of Polyiso Insulation - Final Report, prepared for Polyisocyanurate Insulation Manufacturers Association (PIMA).

Biswas, W. and M. Rosano, Curtin University (Perth), 2011, “A life-cycle greenhouse gas assessment of remanufactured refrigeration and air conditioning compressors", Int. J. Sustainable Manufacturing, Vol. 2, Nos. 2/3.

Brundtland Commision, 1987, Our Common Future: Report of the UN Commission on Environment and Development, Oxford University Press.

Building for Environmental and Economic Sustainability (BEES) Online, 2010, web interface, http://ws680.nist.gov/Bees/, Applied Economics Office, Engineering Laboratory, National Institute of Standards and Technology.

Cohen, Sacha, 2006, Green Buildings, Washington Post, 8/6/06, pp. M3. Accessible at http://www.washingtonpost.com/wpdyn/content/article/2006/08/03/AR2006080301410.html

Database of State Incentives for Renewables and Efficiency (DSIRE), Local jurisdiction building energy code requirements, http://dsireusa.org/, accessed 2014.

DAP, 2005, Alex Plus Acrylic Latex Caulk Plus Silicone Material Safety Data Sheet, dated 4/21/2005.

DAP, 2011, Technical Bulletin for ALEX PLUS Acrylic Latex Caulk Plus Silicone, dated 9/8/2011. 
De Kleine, R., 2009, Life-cycle Optimization of Residential Air Conditioner Replacement, Report No. CSS09-12, A thesis submitted in partial fulfillment of requirements for the degree of Master of Science (Natural Resources and Environment), University of Michigan, Ann Arbor.

Earthsure, 2013, Window Product Category Rule [Draft for Review]. Earthsure PCR No. 30171600, dated December 3, 2013.

Ecobilan, 2001, Eco-profile of high-volume commodity phthalate esters (DEHP/DINP/DIDP), commissioned by European Council for Plasticisers and Intermediates (ECPI), a Sector Group of CEFIC.

Ecoinvent, 2007, Life-Cycle Inventory database, http://www.ecoinvent.org/database/.

Efficient Windows Collaborative tool, accessed 2013, http://www.efficientwindows.org/selection.cfm,

Energy Independence and Security Act (EISA) of 2007, P.L. 110-140, Sec 441.

Extruded Polystyrene Foam Association (XPSA) website. http://www.xpsa.com/.

Faithful+Gould, June 2012, Residential Energy Efficiency Measures: Prototype Estimate and Cost Data Revision 6.0, prepared for National Renewable Energy Laboratory.

Faithful+Gould, December 2011, Residential Energy Efficiency Measures: Location Factors, prepared for National Renewable Energy Laboratory.

Fuller, S. and Petersen, S., 1996, Life-Cycle Costing Manual for the Federal Energy Management Program, NIST Handbook 135, 1995 Edition.

Gloria, T. P., Lippiatt, B. C., and Cooper J., 2007, "Life-cycle Impact Assessment Weights to Support Environmentally Preferable Purchasing in the United States," Environmental Science and Technology, 41, 7551-7557.

Goedkoop, M.J. et al., 2008, A Life-cycle Impact Assessment Method which comprises Harmonized Category Indicators at the Midpoint and the Endpoint Level; First edition Report I: Characterisation; http://www.lcia-recipe.net/, 2009.

Guinee, J.B, et al., 2002, Handbook on Life-cycle Assessment: Operational Guide to the ISO Standards, Kluwer Academic Publisher.

Hendrickson, C. T., Lave, L. B., and Matthews, H. S., 2006, Environmental Life-cycle Assessment of Goods and Services: An Input-Output Approach, Resources for the Future Press.

Hendron, R., Engebrecht, C., September 2010, Building America house simulation protocols, National Renewable Energy Laboratory, Building Technologies Program. 
Intergovernmental Panel on Climate Change (IPCC) and the Montreal Protocol's Technology and Economic Assessment Panel, 2005, IPCC/TEAP Special Report: "Safeguarding the Ozone Layer and the Global Climate System."

International Copper Association (ICA), 2012, Life-cycle Assessment of Primary Copper Cathode, supplied by ICA.

International Organization for Standardization (ISO), 2006a, Environmental Management--LifeCycle Assessment--Principles and Framework, International Standard 14040.

International Organization for Standardization (ISO), 2006b, Environmental Management - Lifecycle Assessment - Requirements and Guidelines, International Standard 14044.

Kneifel, J., 2010, "Life-cycle Carbon and Cost Analysis of Energy Efficiency Measures in New Commercial Buildings," Energy and Buildings 42: 3, 333340.

Kneifel, J., 2011a, "Beyond the Code: Energy, Carbon, and Cost Savings using Conventional Technologies," Energy and Buildings, 43: 951-959.

Kneifel, J., 2011b, Prototype Commercial Buildings for Energy and Sustainability Assessment: Whole Building Energy Simulation Design, NIST Technical Note 1716.

Kneifel, J., 2012, Prototype Residential Building Designs for Energy and Sustainability Assessment, NIST Technical Note 1765.

Kneifel, J., 2012, Prototype Commercial Buildings for Energy and Sustainability Assessment: Design Specification, Life-Cycle Costing and Carbon Assessment, NIST Technical Note 1732.

Kok, N. and Kahn, M., July 2012, The Value of Green Labels in the California Housing Market: An Economic Analysis of the Impact of Green Labeling on the Sales Price of a Home, Funded by San Francisco Department of the Environment and StopWaste.Org.

Lawrence Berkeley National Laboratory, accessed 2012, Useful conversion equations, http://epb.lbl.gov/blowerdoor/docs/conversions.pdf.

Levin, L., November 1996, “Best Sustainable Indoor Air Quality Practices in Commercial Buildings," Third International Green Building Conference and Exposition--1996, NIST Special Publication 908, Gaithersburg, MD, p. 148.

Lippiatt, B., Kneifel, J., Lavappa, P., Suh, S., and Greig, A., September 2013, Building Industry Reporting and Design for Sustainability (BIRDS) Technical Manual and User Guide, NIST Technical Note 1814.

McCulloch, Archie, 2010, "Life-cycle Inventory Analysis of the Production of a Highperformance Foam Blowing Agent HFC-245fa (1,1,1,3,3-pentafluoropropane),” Journal of Cellular Plastics, Volume 46. 
National Association of Home Builders, February 2007, Study of Life Expectancy of Home Components, prepared by Economic Group of National Association of Home Builders for Bank of America Home Equity.

Nashua Tape Products, 2013, 322 Multi-Purpose Foil Tape specification sheet prepared by Berry Plastics Corporation, dated 12/16/13.

National Renewable Energy Laboratory (NREL), 2005-present, U.S. Life-Cycle Inventory Database, Golden, CO, found at: http://www.nrel.gov/lci/database.

Office of Energy Efficiency \& Renewable Energy (EERE) of the U.S. Department of Energy, 2012, Life-Cycle Assessment of Energy and Environmental Impacts of LED Lighting Products Part 1: Review of the Life-Cycle Energy Consumption of Incandescent, Compact Fluorescent, and LED Lamps. Prepared by Navigant Consulting, Inc.

OSRAM Opto Semiconductors GmbH., 2009, Life-cycle Assessment of Illuminants - A Comparison of Light Bulbs, Compact Fluorescent Lamps and LED Lamps (Executive Summary), prepared by Siemens AG, Corporate Technology.

Pacific Northwest National Laboratory (PNNL), September 2009, Impacts of the 2009 IECC for residential buildings at state level, Department of Energy Building Energy Codes Program.

Parsons, David, 2006, "The Environmental Impact of Compact Fluorescent Lamps and Incandescent Lamps for Australian Conditions," The Environmental Engineer, Vol. 7, No. 2, pp.8-14.

PE International (2010) Eco-Profile of Aromatic Polyester Polyols (APP), performed for PU Europe, Federation of European rigid Polyurethane Foam Associations.

PE International, GaBi database (2011).

PE International, 2012, Life-cycle Assessment of Spray Polyurethane Foam Insulation Products, prepared for the Spray Polyurethane Foam Alliance (SPFA).

Persily, A., Musser, A., Leber, D., August 2006, A collection of homes to represent the U.S. housing stock, National Institute of Standards and Technology, NISTIR 7330.

Ramroth, L., 2008, Comparison of Life-Cycle Analyses of Compact Fluorescent and Incandescent Lamps Based on Rated Life of Compact Fluorescent Lamp. Rocky Mountain Institute (RMI).

Rheem, 2012, Rheem Classic Series, Upflow Gas Furnaces, Physical Data and Specifications, Form No. G11-527. 
Roxul, 2013, ComfortBatt Technical Product Information sheet dated 26 June 2013, retrieved from: http://www.roxul.com/files/RX-NA_EN/pdf/Technical\%20Data\%20Sheets\%20updated/COMFORTBATT-USAwithSS.pdf

RSMeans, 2012, Square Foot Costs - 32nd annual edition, Reed construction data.

Rushing, A., Kneifel, J., and Lippiatt, B., 2011, Energy Price Indices and Discount Factors for Life-Cycle Cost Analysis 2011, NISTIR 85327326.

Salazar, James, 2007, Life-cycle Assessment Case Study of North American Residential Windows, A Thesis Submitted in Partial Fulfillment of the Requirements for the Degree of Master of Science in the Faculty of Graduate Studies, University of British Columbia.

Spray Polyurethane Foam Alliance (SPFA), 2012, Life-cycle Assessment of Spray Polyurethane Foam Insulation for Residential and Commercial Building Applications. Found at: http://www.sprayfoam.org/files/docs/SPFA\%20LCA\%20Long\%20Summary\%20New.pd f.

Suh S, et al., 2004, "System boundary selection in life-cycle inventories using hybrid approaches," Environmental Science \& Technology, 38: 657-664.

Suh S. and Huppes G., 2005, "Methods for Life-cycle Inventory of a Product," Journal of Cleaner Production, 13:687-697.

Suh, S., 2005, "Developing a Sectoral Environmental Database for Input-Output Analysis: The Comprehensive Environmental Data Archive of the U.S.," Economic Systems Research, 17: 4, 449-469.

Suh, S., 2010, “Comprehensive Environmental Data Archive (CEDA),” In: Murray J, Wood R (Eds.) The Sustainability Practitioner's Guide to Input-Output Analysis, Common Ground Publishing.

Suh, S. and Lippiatt, B., 2012, "Framework for Hybrid Life-cycle Inventory Databases: A Case Study on the Building for Environmental and Economic Sustainability (BEES) Database," International Journal of Life-cycle Assessment, 17: 604-612.

Swiss Centre for Life-cycle Inventories, 2007, ecoinvent Data v.2.2, Dubendorf. Found at: http://www.ecoinvent.org.

Swiss Centre for Life-cycle Inventories, 2007, ecoinvent Data v.2.2. "Oil boiler 10kW/CH/I U", LCI for Furnaces (English version of the ecoinvent Report 6-IV, "Erdol”), Chapter 11 (ecoinvent Report No. 6-IV, 2007).

U.K. Department for Environment, Food and Rural Affairs (Defra), 2008, Life-cycle Assessments of Natural Fibre Insulation Materials, Final Report, prepared for the National Non-Food Crops Centre (NNFCC). 
U.K. Department for Environment, Food and Rural Affairs (Defra), 2009, Life-cycle Assessment of Ultra-Efficient Lamps, performed by Navigant Consulting Europe, Ltd.

UL Environment, 2011, Product Category Rule (PCR) for Building Envelope Thermal Insulation, Product Category Rule Number UL 110116.

UL Environment, 2013, "Spray Polyurethane Foam Insulation and Roofing Systems," Declaration \#13CA29310.101.1.

U.S. Census Bureau, 2011, American Housing Survey (AHS) for the United States, Series H150, Complete Set of Tables and Standard Errors, Department of Commerce. http://www.census.gov/housing/ahs/data/national.html.

U.S. Census Bureau, 2012, Survey of Construction, Annual 2010 characteristics of new housing, http://www.census.gov/const/www/charindex.html, Manufacturing, Mining, and Construction Statistics Division.

U.S. Department of Energy (DOE), 2012a, Building Energy Codes Program, Residential Prototype Building Models, http://www.energycodes.gov/development/residential/iecc_models/.

U.S. Department of Energy (DOE), 2012b, Building Technologies Program, EnergyPlus energy simulation software, http://apps1.eere.energy.gov/buildings/energyplus/.

U.S. Department of Energy (DOE), 2014, Building Technologies Program, Building Energy Code Program, Status of State Energy Code Adoption, http://www.energycodes.gov/adoption/states, accessed November 2014.

U.S. Energy Information Administration (EIA), 2013a, Electric Power Annual State Data Tables, accessed 2013, http://www.eia.doe.gov/fuelelectric.html.

U.S. Energy Information Administration (EIA), 2013b, Natural Gas Navigator, accessed 2013, http://www.eia.doe.gov/oil_gas/natural_gas/info_glance/natural_gas.html.

U.S. EPA Science Advisory Board, August 2000, Toward Integrated Environmental DecisionMaking, EPA-SAB-EC-00-011, Washington, D.C.

U.S. EPA Science Advisory Board, September 1990, Reducing Risk: Setting Priorities and Strategies for Environmental Protection, SAB-EC-90-021, Washington, D.C.

U.S. Environmental Protection Agency, 2001, EPA Energy star home sealing specification.

U.S. Environmental Protection Agency, 2012, http://www.energystar.gov/products/certifiedproducts/detail/light-bulbs. 
United Nations Environment Programme (UNEP) Report of the Technology and Economic Assessment Panel (TEAP), 2005, Volume 3: Report of the Task Force on Foam End-ofLife Issues.

Van Holsteijn en Kemna, BV (VHK), 2007, Preparatory Study on Eco-Design of Water Heaters, Task 5 Report (Final), prepared for European Commission.

Vigener, N. \& M.A. Brown, 2012, Building Envelope Design Guide - Windows, written for the Whole Building Design Guide, a program of the National Institute of Building Sciences. http://www.wbdg.org/design/env_fenestration_winphp

World Steel Association, 2011, Methodology report - Life-cycle inventory study for steel products. Found at: http://www.worldsteel.org/

Yang, L., Zmeureanu, R. \& Rivard, H., 2008, "Comparison of Environmental Impacts of Two Residential Heating Systems", Building and Environment, 43, pp. 1072-1081. 


\section{A Appendix}

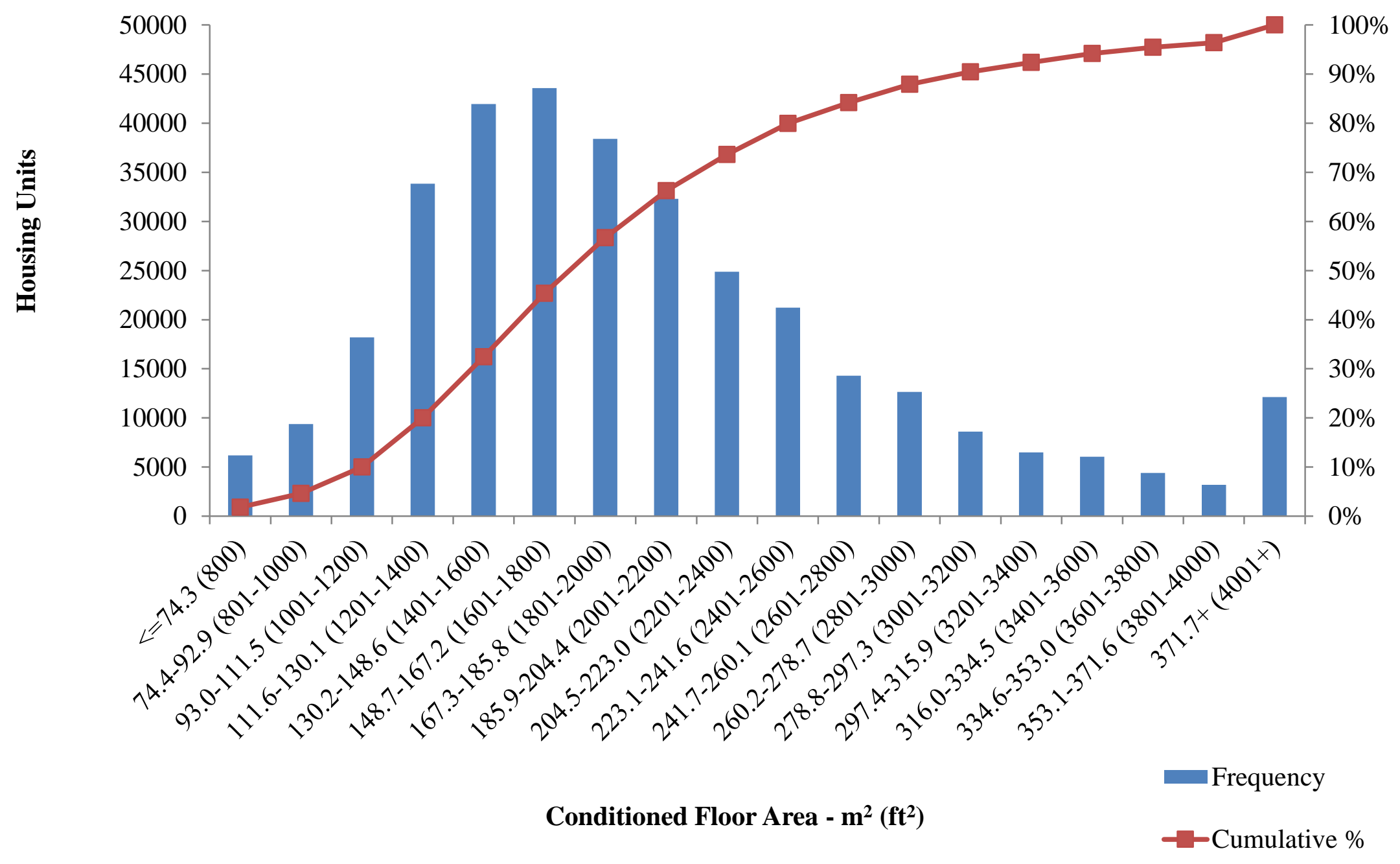

Figure A-1 Conditioned Floor Area of New 1-Story Single-Family Housing 


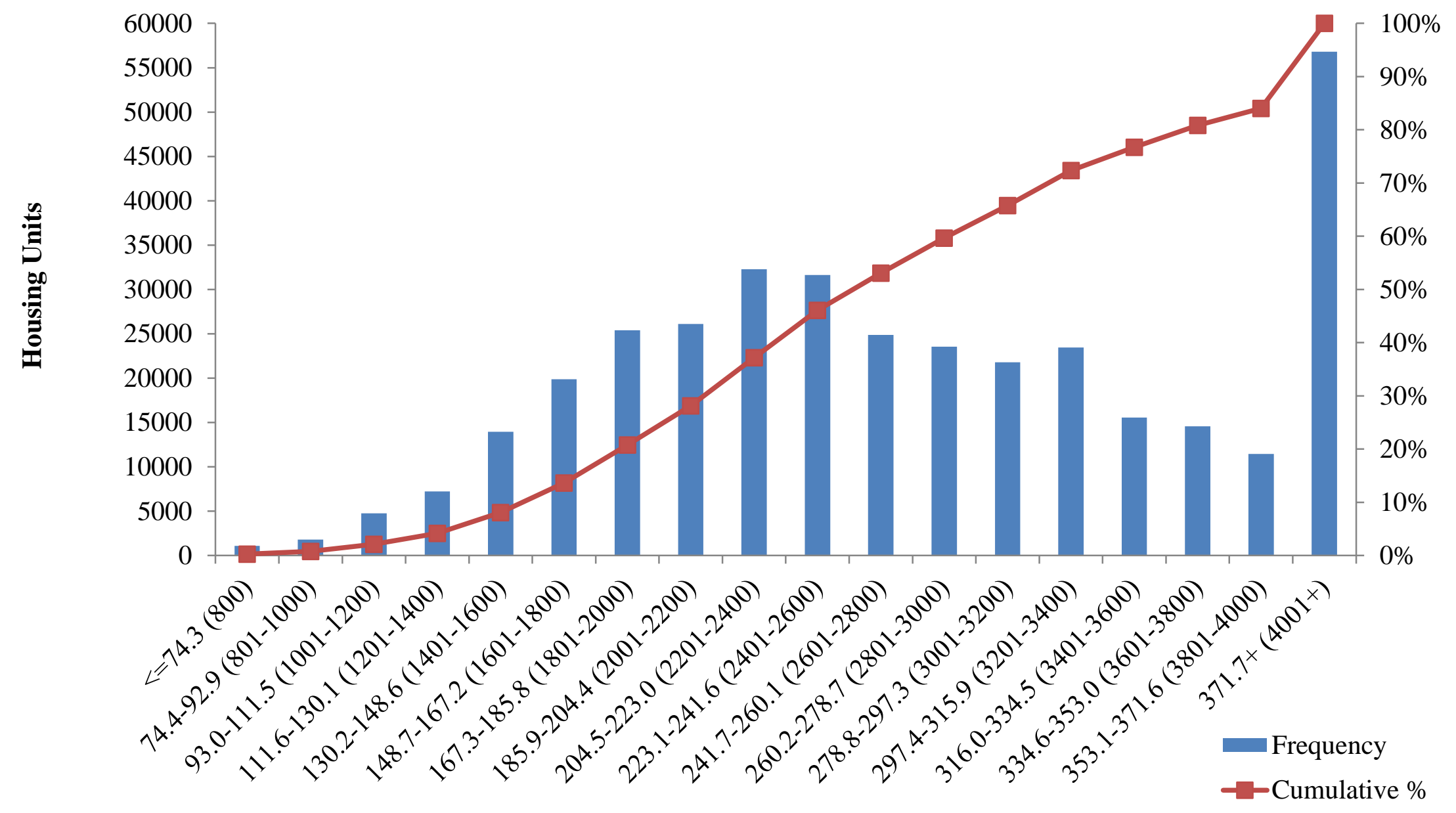

Conditioned Floor Area - $\mathbf{m}^{2}\left(\mathbf{f t}^{2}\right)$

Figure A-2 Conditioned Floor Area of New 2-Story Single-Family Housing 